\title{
LA-UR-14-27140
}

Approved for public release; distribution is unlimited.

Title: $\quad$ Proceedings of the Workshop on the Structural Cracking of the Cupola of Santa Maria del Fiore

Author(s): $\quad$ De Lorenzi-Venneri, Giulia; Lee, Richard Cacy; Luscher, Darby Jon; Bronkhorst, Curt Allan; Rougier, Esteban; Knight, Earl E.; Lei, Zhou; Milner, Edward Casteel; Bacon, Jeffrey Darnell; Guardincerri, Elena; Miyadera, Haruo; Salmon, Michael W.

Intended for: Report

Issued: $\quad$ 2014-09-23 (rev.1) 
Disclaimer:

Los Alamos National Laboratory, an affirmative action/equal opportunity employer,is operated by the Los Alamos National Security, LLC for the National NuclearSecurity Administration of the U.S. Department of Energy under contract DE-AC52-06NA25396. By approving this article, the publisher recognizes that the U.S. Government retains nonexclusive, royalty-free license to publish or reproduce the published form of this contribution, or to allow others to do so, for U.S. Government purposes. Los Alamos National Laboratory requests that the publisher identify this article as work performed under the auspices of the U.S. Departmentof Energy. Los Alamos National Laboratory strongly supports academic freedom and a researcher's right to publish; as an institution, however, the Laboratory does not endorse the viewpoint of a publication or guarantee its technical correctness. 


\section{The Structural Cracking of the Cupola of Santa Maria del Fiore}

\section{February 13-14, 2013}

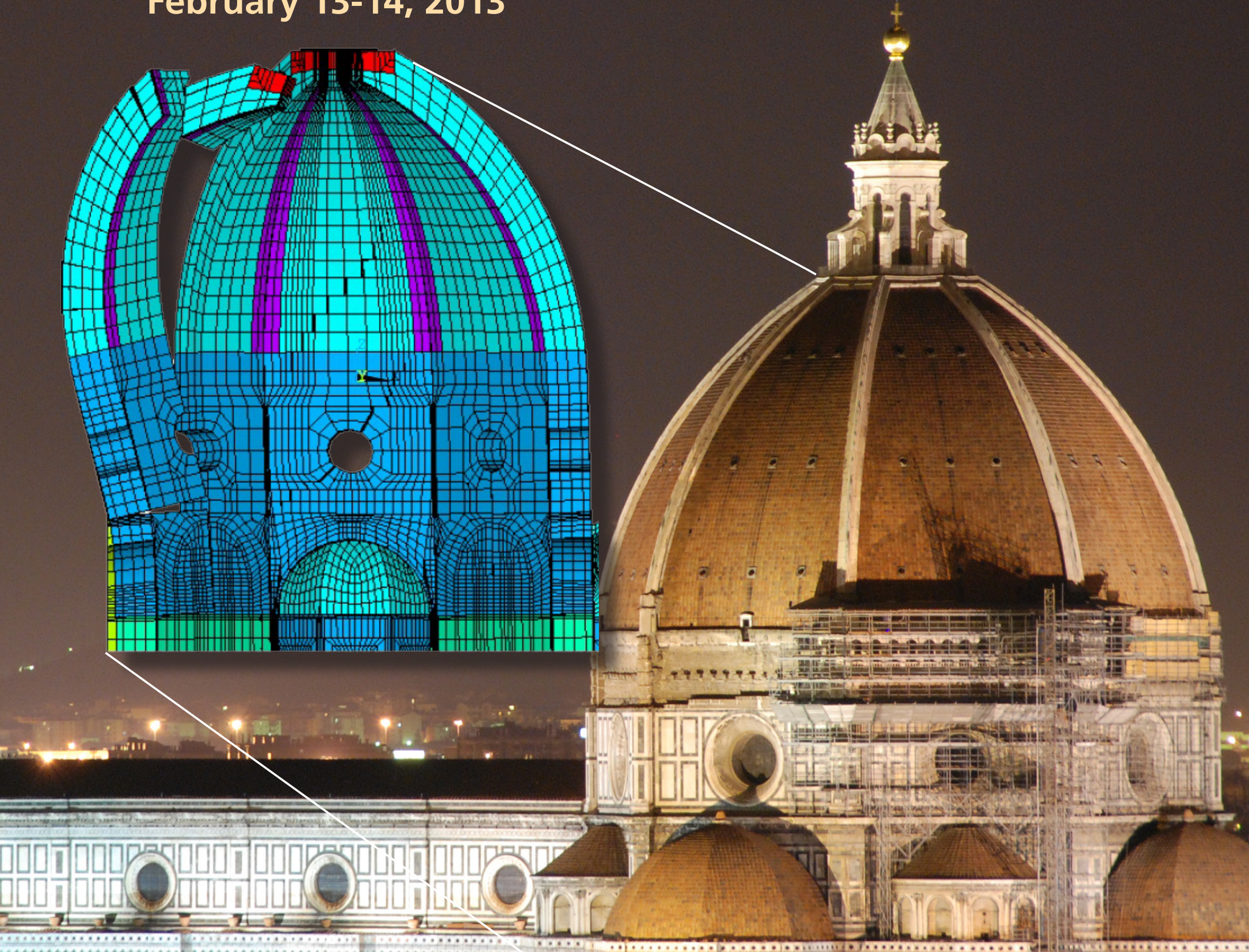

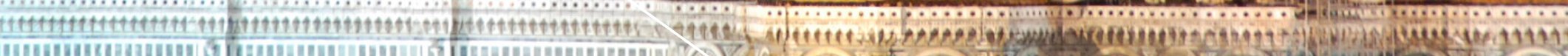
ing

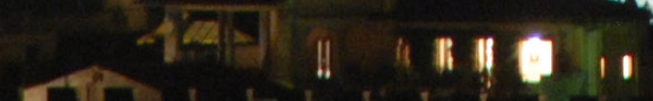


Proceedings of the Workshop on

\title{
The Structural Cracking of the Cupola of Santa Maria del Fiore
}

\author{
Los Alamos National Laboratory \\ Los Alamos, New Mexico
}

February 13-14, 2013

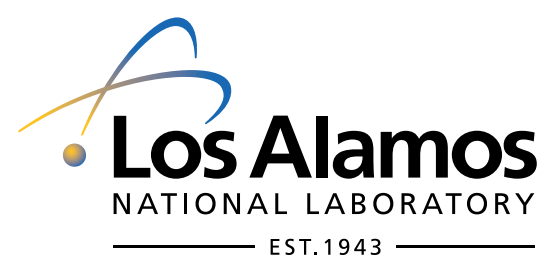



The Cupola of Santa Maria del Fiore cathedral in Florence was engineered by Filippo Brunelleschi in 1420 and is considered to be the widest masonry dome in the world. The building is part of the UNESCO world heritage site covering the historic center of Florence and is a major attraction to tourists visiting the region of Tuscany. The cupola is affected by a widespread crack pattern that appeared soon after its construction. In a high seismic region like Italy, where many historical buildings collapsed during past earthquakes, this historic building is likely to present a high degree of vulnerability. The cupola has been extensively studied over the centuries, structurally, analytically and with numerical models. Furthermore, monitoring systems of increasing extent and accuracy, up to the present system of 165 instruments operating since 1988, have been measuring all kinds of details of the evolution of the crack pattern over time, through daily and seasonal changes and during exceptional events like earthquakes and floods.

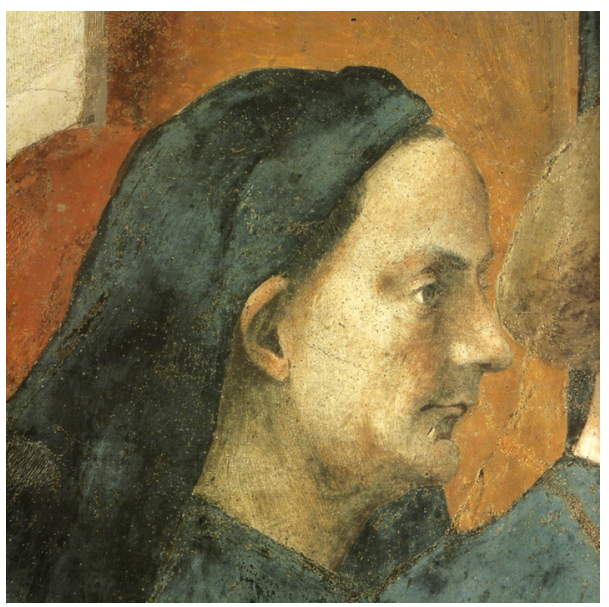

Filippo Brunelleschi

An acceptable solution to preserve Brunelleschi's cupola from possible destruction however has not yet been found. Los Alamos National Laboratory, with its expertise in advanced computer simulations, earthquake engineering, structural dynamics, soil-structure interaction and material properties, might be able to help in better understanding the problem and testing the comparative merits of several alternative options of structural strengthening. This particular building is not only extremely visible and important as a symbol of our own historical background, but also offers, thanks to all the available data, an extremely rich case to benchmark and test our present capabilities and develop new ones that could be used in other historical and modern buildings in the US and worldwide.

The results of a workshop are here summarized, gathering experts from Italy that have been directly involved in the best studies of the Cupola up to date, and experts from the Laboratory whose capabilities could help in this project. The goal of this workshop was to share knowledge and know-how in the attempt to put together a collaboration to study the Cupola and put forward new suggestions on how to preserve this historic building.

Giulia DeLorenzi-Venneri

Los Alamos National Laboratory

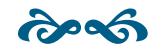




\section{Introduction}

The problem of the stability of the cupola of the Duomo has engaged many over the centuries. Earlier there were only experience with other similar structures and builders rules of thumb to go on. As the science of structures progressed, more powerful analytical methods have been used. In the last 20 years a novel development has offered unparalleled understanding of the behavior of this and other similar structures, not only in the current semi-static situation but also in the event of a strong earthquake. This development is powerful computer simulation.

As a modeler as Los Alamos National Laboratory I have been struck by how well we are now able to characterize things in motion, from our oceans and atmospheres to vehicular traffic on congested roadsfrom how the earth makes its magnetic field and moves its continents around to how communicable diseases propagate through a population. Thus I have always been interested in the possibility of studying some of the great buildings of the world. For me it was the great churches of Europe. One in particular intrigued me-the Duomo in Florence. How it was built without supports, held up during construction solely on its own compressive dead weight stresses seemed a mystery to be solved. I had read books on

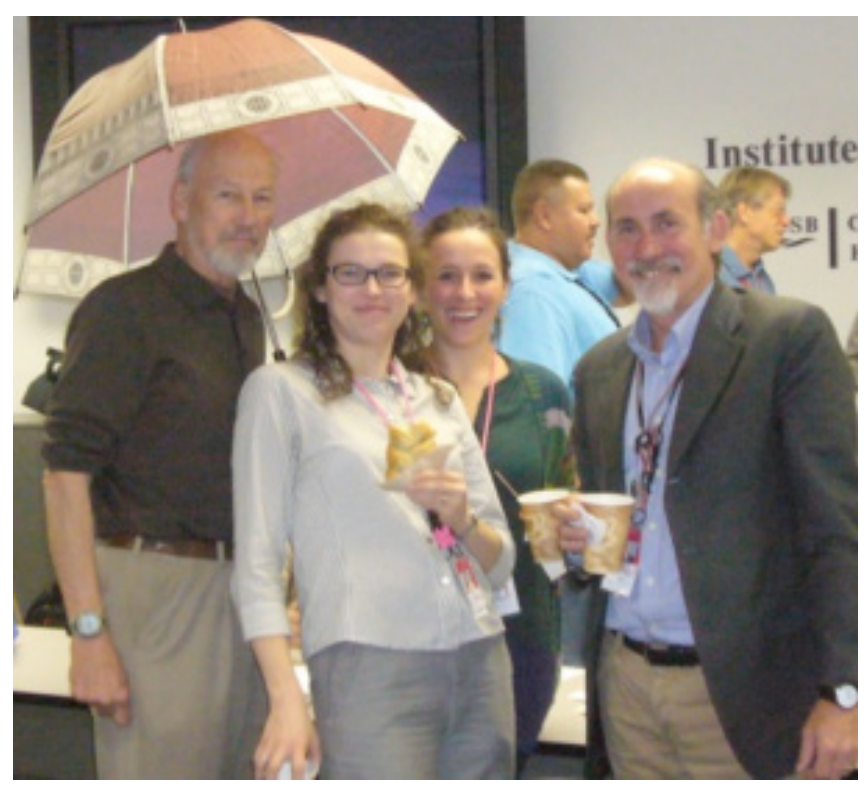

Figure 1. Duomo Umbrella under which are C. Keller, Drs. Eva Coïsson and Federica Ottoni, Univ. Parma, Dr.Gianni Bartoli, Univ. of Florence.

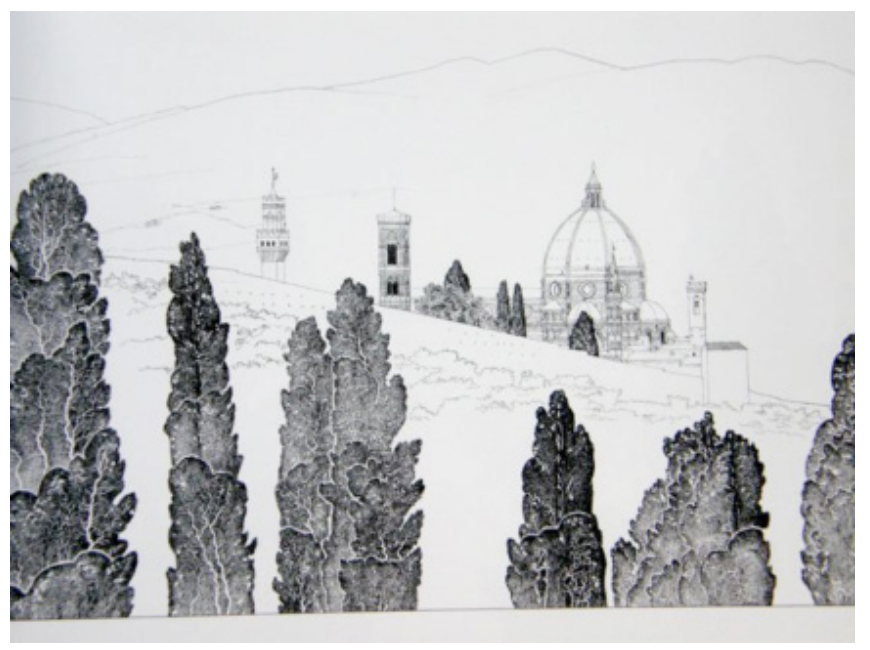

Figure 2.

this, like Ross King's Brunelleschi's Dome ${ }^{1}$. But none adequately dealt with the details of construction.

Then one day in 2006 I had the opportunity to climb up inside the dome. I was surprised to see the extent of its cracking - took lots of pictures and noticed the extensive monitoring that was being done. To my surprise below in the bookstore I found a new book that dealt with the very problems I was concerned about: Brunelleschi's Cupola by Giovanni and Michele Fanelli ${ }^{2}$.

The book was in two parts: the history and the scientific study. The history and art part was fascinating, but I went to the science and found to my surprise that people had actually subjected the cupola to computer simulation via a Finite Element stress code. And for the first time they had elucidated the reasons for the major cracks - compression and tension alternating on the 8 faces of the dome depending on whether they were above the four pediments or the four intervening arches. Other cracking was also studied with good results. However, I soon realized that the work was limited to rather coarse gridding (breaking the structure up into individual interacting cells). Also the Finite Element method, while excellent at defining stresses, could not propagate cracks.

It occurred to me that here was a singular opportunity - a possible collaboration between the Italian research teams and scientists at Los Alamos who had developed a structure code that coupled the 


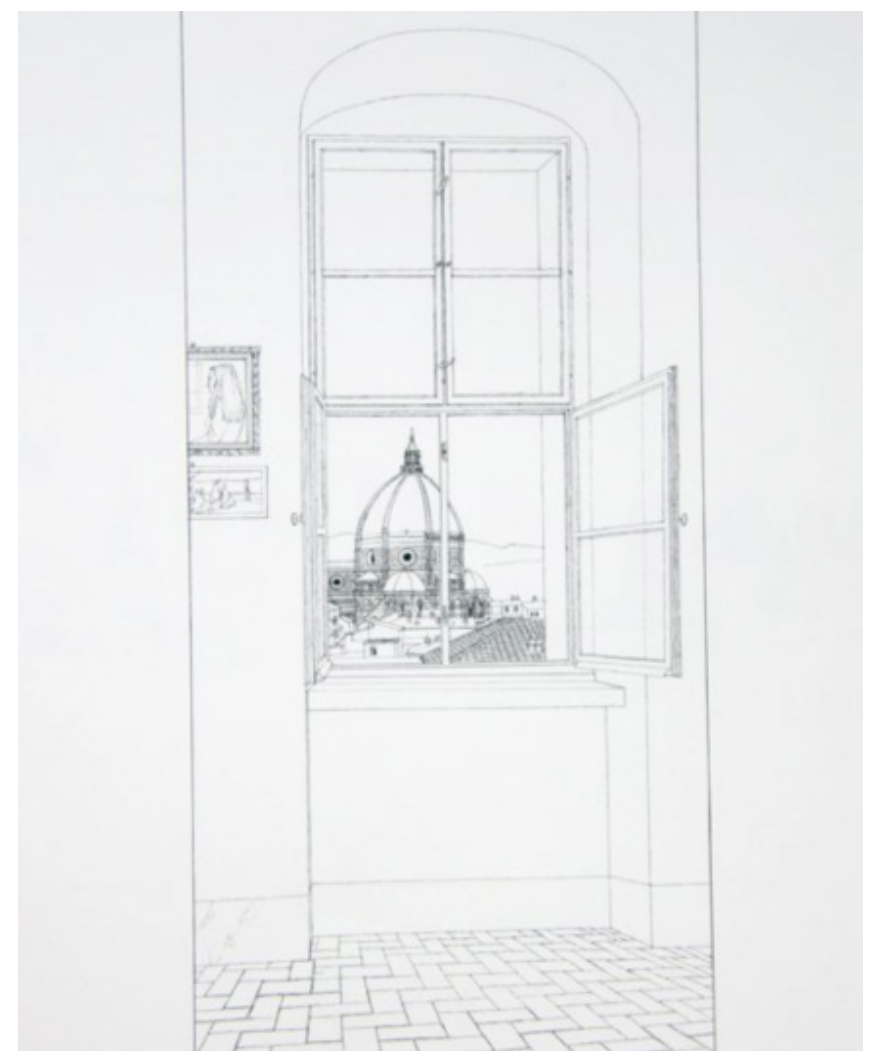

Figure 3.

finite element with what is called a discrete element approach which could propagate cracks based on the stresses given it by the finite element code. In addition Los Alamos was very experienced in doing such computer simulations in very high resolutionmany tens of thousands of grid cells or more. There were also experts in material properties and in how to incorporate them into the codes. With the extensive data about the dome there was a good opportunity to compare computer results with observed behavior.

For several years I attempted to get people at Los Alamos interested in this project with no success. Then about a year ago I found the right people. An informal working group was formed. We read the most recent scientific papers of our Italian colleagues and contacted them. Finally our group successfully proposed that one of the Italian scientists be invited to give a Director's Colloquium on this subject. And the rest is as they say history for we all decided to follow this colloquium with a joint workshop to compare in more detail what had already been done, and what could be accomplished I the future.
I finish with a more human side of the cupola's effect on people. It is truly iconic. It defines Florence. It is economic, witness my umbrella whose 8 sides are good representations of the dome (see Figure 1). And it is poetic as shown in these pen and ink sketches by Giovanni Fanelli taken from a book ${ }^{3}$ that shows the (Figures 2 and 3 ) dome viewed from many aspects as if it is truly part of people's every day life.

Our role in the centuries old story of this dome is perhaps a small one. But I believe it might be crucial to the dome's continued survival even in the event of a strong earthquake.

Chick Keller

Los Alamos National Laboratory

\section{References}

${ }^{1}$ Ross King, "Brunelleschi's Dome: How a Renaissance Genius Reinvented Architecture" Penguin Books (2001)

${ }^{2}$ G. Fanelli and M. Fanelli, "Brunelleschi's Cupola Past and Present of an Architectural Masterpiece", Mandragora (2004)

${ }^{3}$ G. Fanelli, "Twenty-two views of the Cupola", Mandragora (2006) 


\section{List of Participants}

Gianni Bartoli, Universita`di Firenze, Italy ........................gbartoli@dicea.unifi.it

Carlo Blasi, Universita`di Parma, Italy ...............................blasi.unipr@gmail.com

Michele Betti, Universita` di Firenze, Italy ..........................mbetti@dicea.unifi.it

Eva Coïsson, Universita`di Parma, Italy.............................coisson.eva@gmail.com

Giulia De Lorenzi-Venneri, LANL, T-1 ..............................gvenneri@lanl.gov

Michele Fanelli, retired from CRIS-ENEA .........................michele31fanelli@ gmail.com

Chick Keller, LANL (ret) ..................................................alfanso@cybermesa.com

Earl Knight, LANL, EES-17 ..........................................knighte@lanl.gov

Richard Lee, LANL, AET-2 ..............................................clee@lanl.gov

D.J. Luscher, LANL, T-3 .................................................dj1@lanl.gov

Cas Milner, LANL, P-25 ..................................................edward_cas_milner@lanl.gov

Federica Ottoni, Universita`di Parma, Italy ........................fede.ottoni@gmail.com

Esteban Rougier, LANL, EES-17 ....................................erougier@lanl.gov

Mike Salmon, LANL, AET-2 ...........................................salmon@lanl.gov

Kelsey Souza, LANL, ES-DE ..........................................kelsey@lanl.gov

Aleksander Zubelewicz, LANL, T-1 ..................................alek@1anl.gov 


\section{Table of Contents}

High Performance Computing and Masterpieces of Historical Architecture:

The Excellent Case of Santa Maria del Fiore Dome in Florence

(Carlo Blasi)

The Importance of Monitoring, Behaviour Analysis and Diagnostic Techniques in the Preservation of Great Historical Structures 17 (Michele Fanelli)

Santa Maria del Fiore Dome: Crack Pattern and Monitoring Systems 23

(Federica Ottoni)

Seismic Hazard Considerations for the Santa Maria del Fiore Dome ..... .26

(Richard Lee)

The Seismic Response of Historic Masonry Buildings: General Issues

(Eva Cö̈sson)

State-of-the-Art in Numerical Modeling of Masonry Structures

(Michele Betti, Gianni Bartoli)

The Numerical Analyses of Santa Maria del Fiore Dome: State of the Art

(Gianni Bartoli, Michele Betti)

Multiscale Homogenization for Masonry Mesostructure .38

(D. J. Luscher, David McDowell, Curt Bronkhorst)

Fracture Model for Masonry and other Frictional Materials

(Alek Zubelewicz)

Analyzing and Modeling the Response of Historical Monuments: Open Issues

(Gianni Bartoli, Michele Betti)

Application of the Combined Finite-Discrete Element Methodology (FDEM) to the Preservation of Significant Historical Structures ....

(Esteban Rougier, Earl Knight, Zhou Lei, Antonio Munjiza)

Evolution of Structural Design and Potential Design Changes

(Kelsey Souza)

Imaging Internal Structural Features of Santa Maria del Fiore with Cosmic Ray Muons

(Cas Milner, Jeff Bacon, Konstantin Borodzin, Elena Guardincerri, Haruo Miyadera,

Christopher Morris, John Perry)

Probabilistic Framework for Computational Modeling .57

(Michael Salmon)

Workshop Agenda .61 


\section{High Performance Computing and Masterpieces of Historical Architecture: The Excellent Case of Santa Maria del Fiore Dome in Florence}

\section{Can Los Alamos help save this and other world's architectural treasures?}

\section{Carlo Blasi}

Department of Civil Engineering and Architecture, University of Parma, Italy

\section{The preservation of the built cultural heritage}

The cultural heritage is a common richness and we must all work to preserve it. Humanity lives in the present, looks to the future, but has its own identity in the past. But the built cultural heritage has a terrible enemy: a real devil called earthquake. I believe that LANL scientists can really help against this devil thanks to their knowledge on computer simulations, earthquake engineering, structural dynamics, soil-structure interaction and material properties.

The seismic protection of historic buildings and cities is not easy because we cannot transform our historic buildings, built in masonry, into concrete or steel structures. It is not only a problem of appearance. We must respect the authenticity of the monuments, saving the original materials and the original conception of their structures.

The challenge is to protect historic buildings, not only the main monuments, making the most of the structural capacity of masonry, inserting the minimum number of new elements.

The same problems exists in many other seismic Nations and also in some parts of the U.S.A. To explain the seismic problems of masonry buildings I will present the most important example in the world of historic architecture: the dome built by Filippo Brunelleschi in the fifteenth century (XV) in Florence.

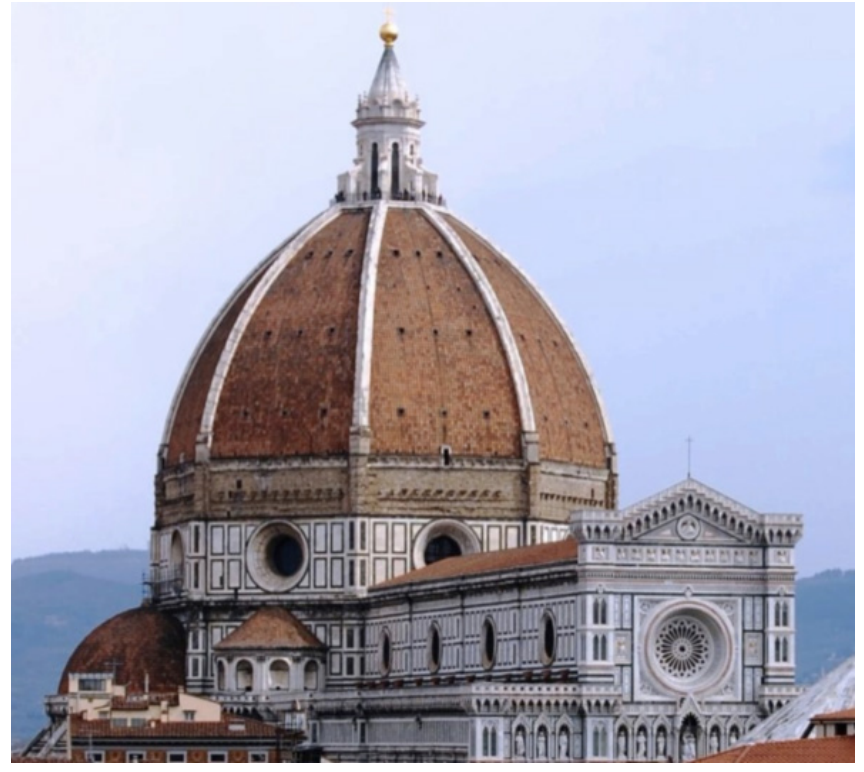

Figure 1. Florence, the dome of Santa Maria del Fiore built by Filippo Brunelleschi between 1420-1436. It has an internal diameter of about 43 meters.

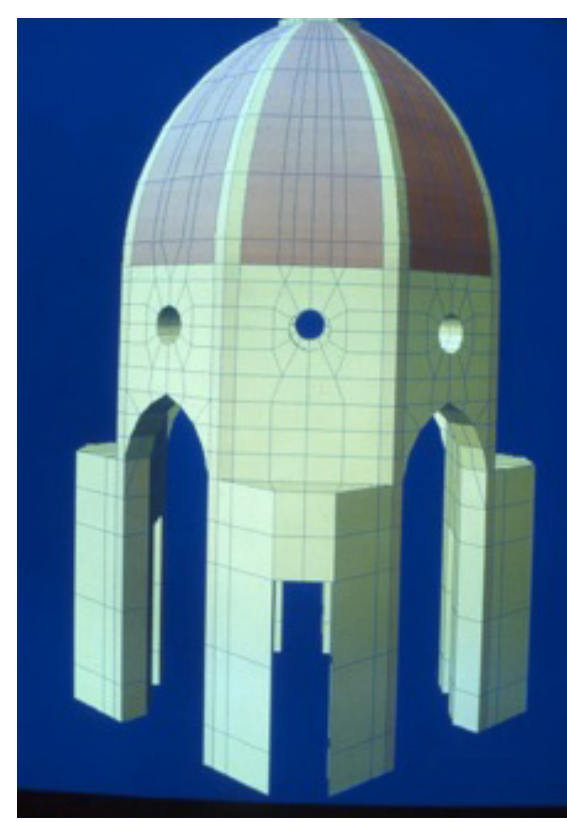

Figure 2. Bare structure of the dome and of the supporting piers: the base is a square but it becomes octagonal at the level of the drum. 


\section{The Brunelleschi's Dome}

The Florentine dome is the visible sign of the Renaissance of the city of Florence. To amaze the world, the new building had to be made with new inventions, with the most up-to-date technologies and with the most advanced sciences.

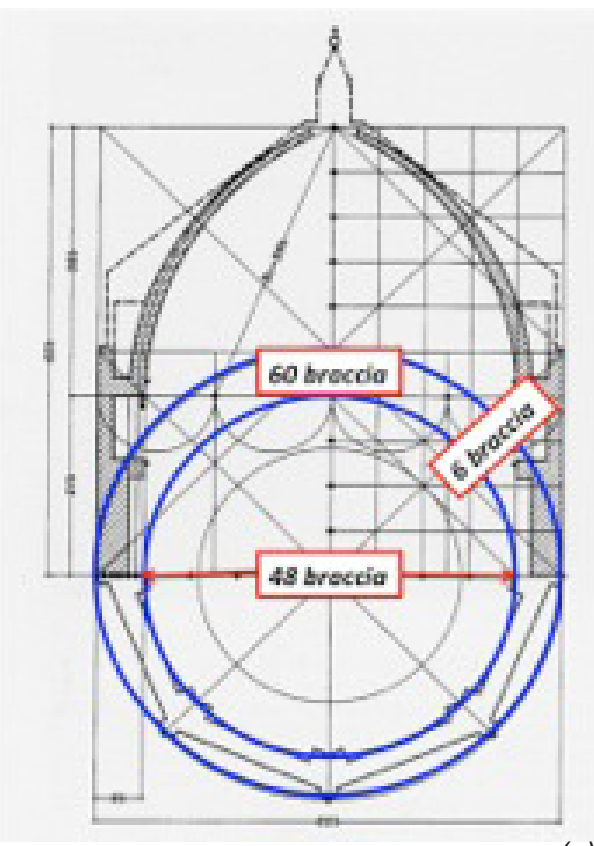

(a)

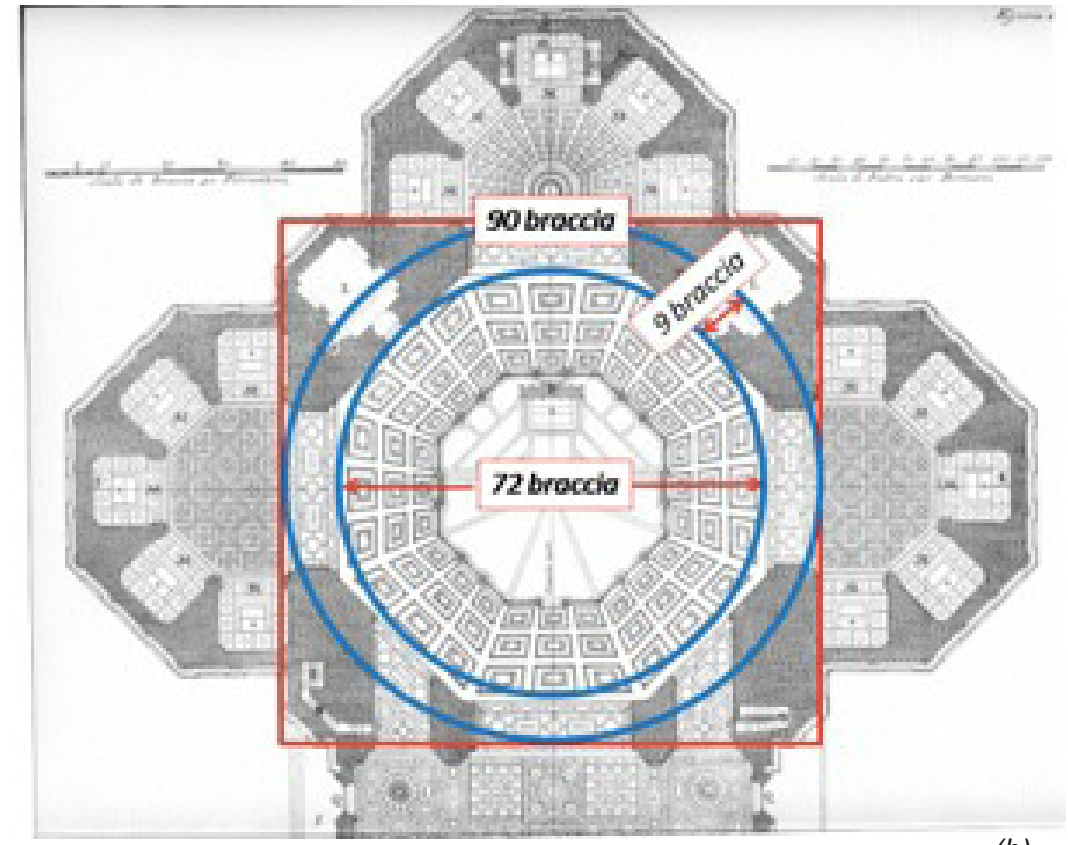

(b)

Figure 3a. Comparison between the geometry of (a) San Giovanni Baptistery and (b) Brunelleschi's dome: the ratio of the two structures is exactly 1:1.5.
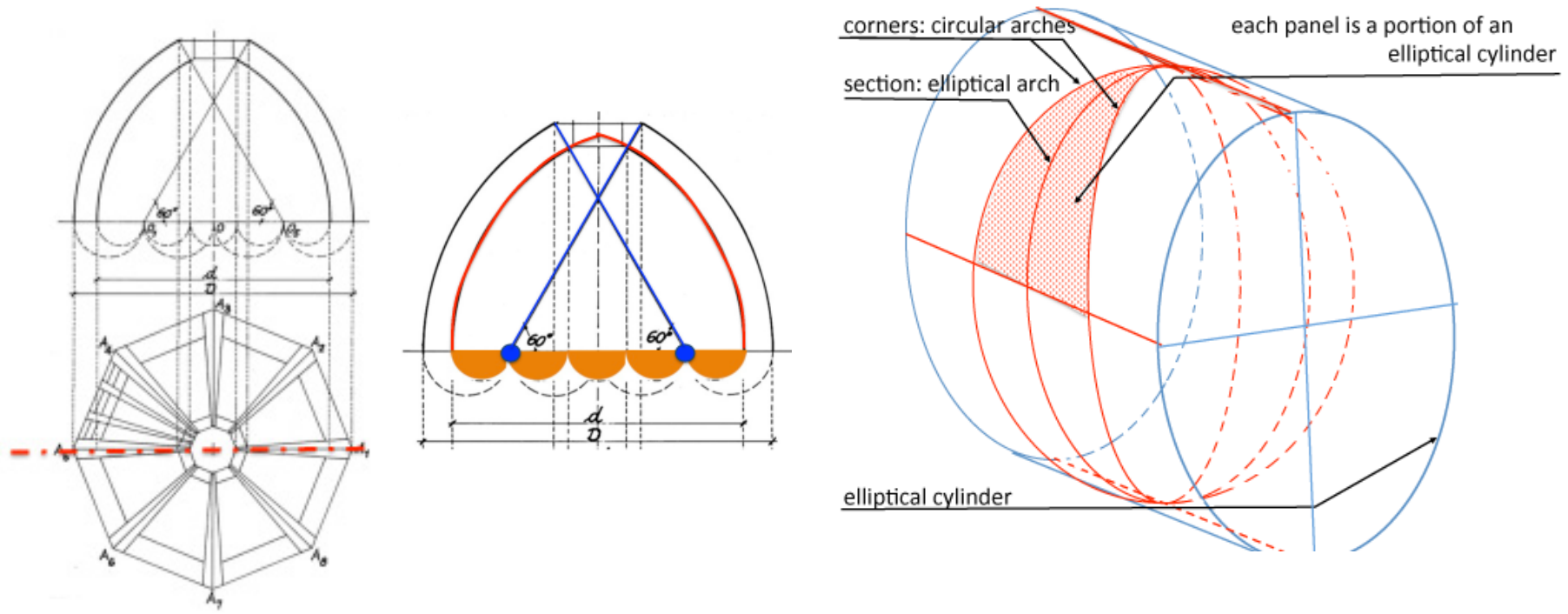

Figure 4. Geometry of the dome: the edges have a pointed shape "pointed fifth" (the center of curvature lies at one fifth of the diameter). The sails are sections of elliptical cylinders. 
The base of the dome is a perfect square. At about 100 feet of height, the horizontal section becomes a perfect octagon. The external diameter of the dome is exactly 90 arms (170 feet); the overall thickness of the dome is one/ tenth of the external diameter, the inner span is 72 arms (about 140 feet): the largest masonry dome in the world.

The section - from one corner to the other - is a pointed arch; it is a Gothic shape, but the pointed arch is more stable than the round arch. The corner section curve is a circular sector, with its center at one/fifth of the span. The panels therefore are portions of elliptical cylinders.

\section{The two caps}

The dome is made by two caps, separated by a corridor, connected by vertical and horizontal ribs. Therefore the structure is light but resistant.

Brunelleschi had two principal models: the Baptistery in Florence and the Pantheon in Rome. The octagonal Baptistery has an inner dome and a pyramidal masonry covering: nearly two domes. The Baptistery probably suggested to make a dome with two caps.

\section{The ribs}

The dome has vertical and horizontal ribs with a beautiful geometry. The ribs work as a reinforcement and as a connection between the two caps.

Also the Pantheon dome has vertical and horizontal ribs. Certainly the Pantheon gave him the idea to make the ribs. In the Pantheon the ribs are visible, in the Florentine dome they are hidden

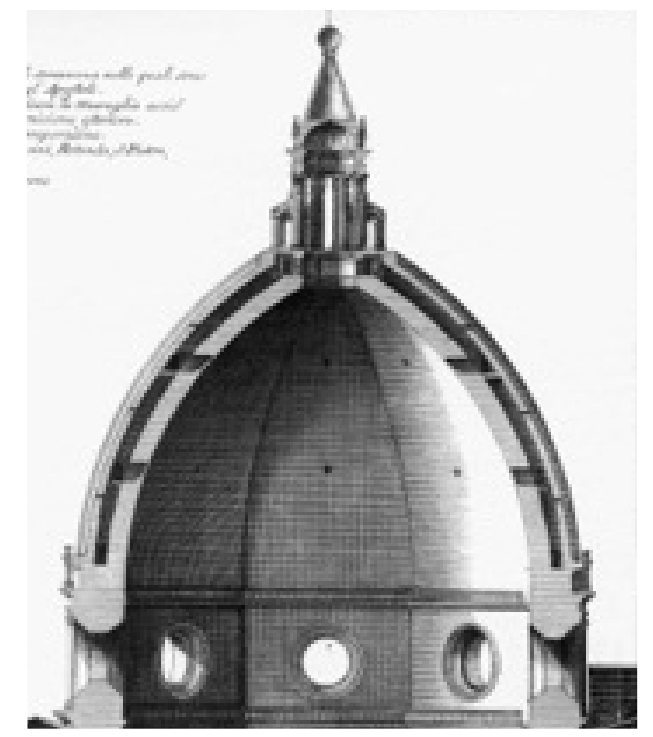

(a)

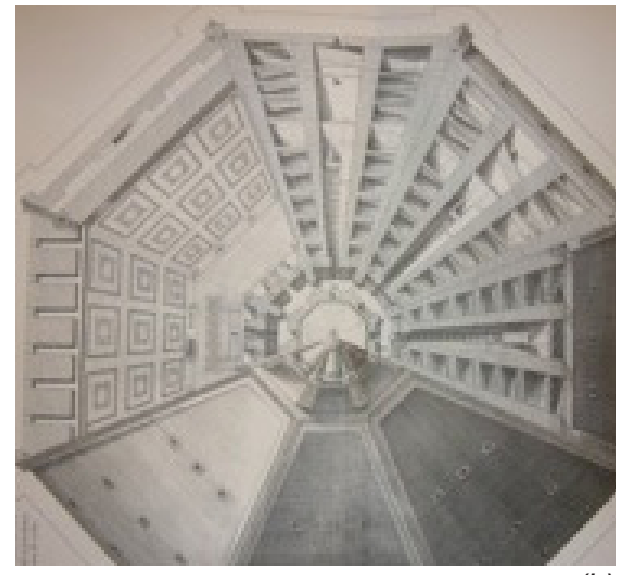

(b)

Figure 5. Vertical section (a) and horizontal section (b) of the dome: one can distinguish the two shells, the walkways and the vertical and horizontal ribs.

\section{The conical mortar beds—corda blanda}

To place the bricks in order to avoid discontinuities in the corners and to have only one center he invented the disposition of the bricks on conical mortar beds, as the point of a wooden pencil: the surface of the point of the pencil is smooth: it is a cone. The lines of mortar beds are the intersection between eight elliptical cylinders (the panels) with the surfaces of cones (always different). 
Figure 6.

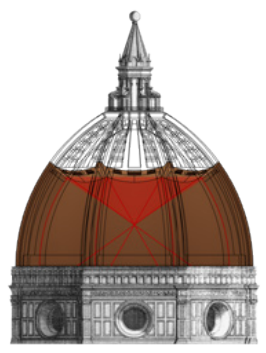

a. Bricklaying on conical beds (corda blanda, meaning 'slack line').
Figure 7.

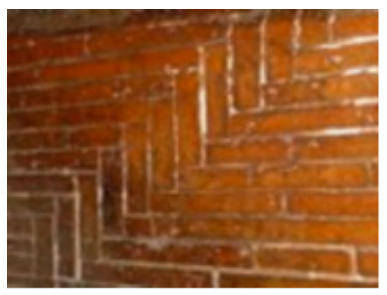

a. Spina-pesce (meaning 'herringbone') arrangement of the bricks. b. The curvature of the edges are circular sections with the centers at one fifth of the diameter. c. Comparison between bricklaying on pyramidal beds (not used amid the edges discontinuities) and the bricklaying on conical beds.

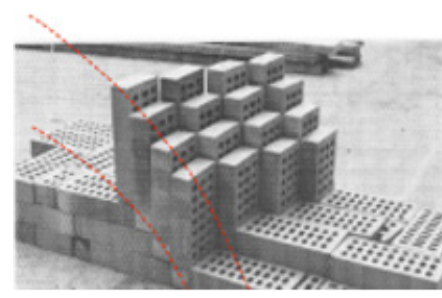

b. Spina-pesce brick arrangement, example.

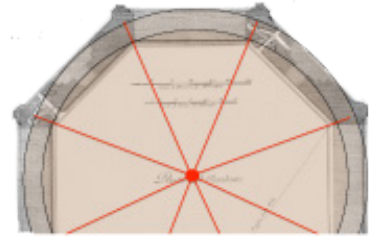

c. Vertical bricks are arranged radially
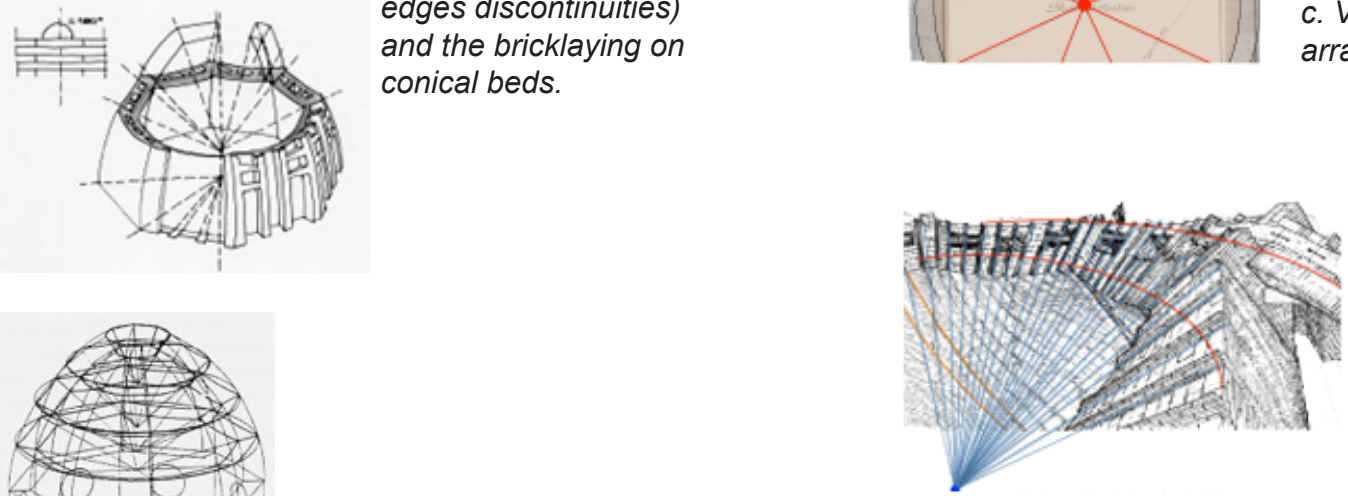

d. Vertical bricks converge

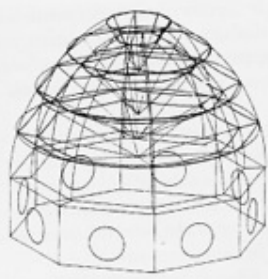

d. Salvatore di Pasquale: bricklaying cones.

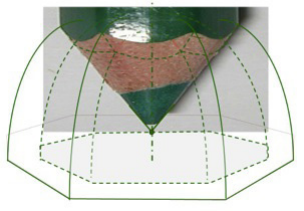

e. Comparison of the bricklaying surface with the point of a pencil.
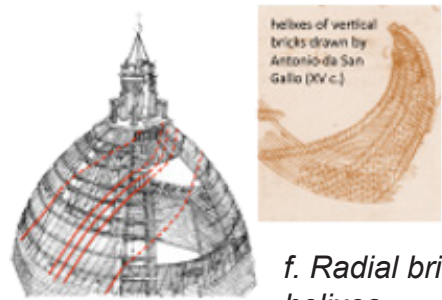

e.The spina-pesce brick arrangement has been used by many constructors.

f. Radial bricks form helixes.

\section{Circular helixes and herring-bone, spinapesce, bricks disposition}

Brunelleschi invented a new masonry texture for his dome, with vertical bricks arranged on circular helixes: the herring-bone. The vertical bricks are arranged on circular helixes and radially, referring only to the "median center". Starting from the base of the dome, the helixes come together at the top creating a perfectly connected masonry. 


\section{The climbing centering}

Brunelleschi built the dome without scaffoldings, but there is a lot of confusion between scaffoldings and centerings: we must distinguish between scaffoldings for the workers, centerings to support the masonry and centerings on the corners to trace the geometry. To build a scaffolding starting from the ground would have been very expensive and complicated. Brunelleschi used climbing cantilever scaffolds, like the ones used today for skyscrapers and climbing centering for tracing: only eight wooden circular arches sectors, about 16 feet long, correctly placed thanks to a star made of ropes, and moved step by step as the construction got higher.

\section{The wooden tie and the wooden machines}

Brunelleschi used even wood elements to build the dome: he built a wooden tie to hoop the dome, practically a circular tie but it is difficult to evaluate its structural effectiveness today. He also had to invent new machines to bring the materials up to about 300 feet from the ground.

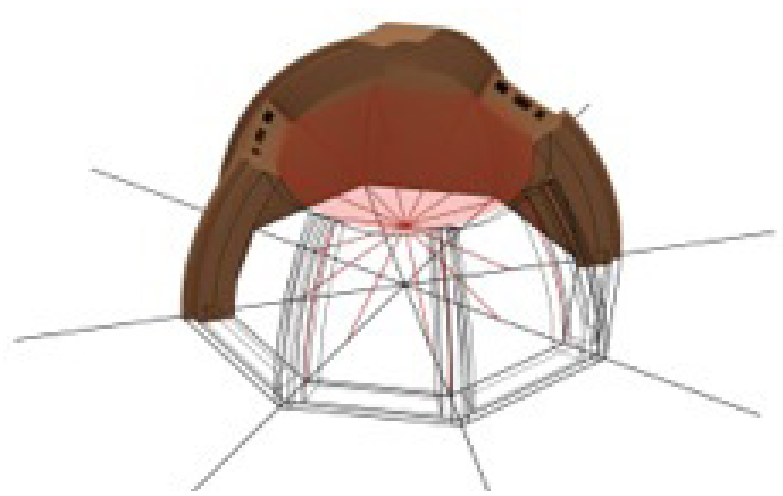

Figure 8a. Tracing of the geometry of the dome with plumb lines and climbing centering.

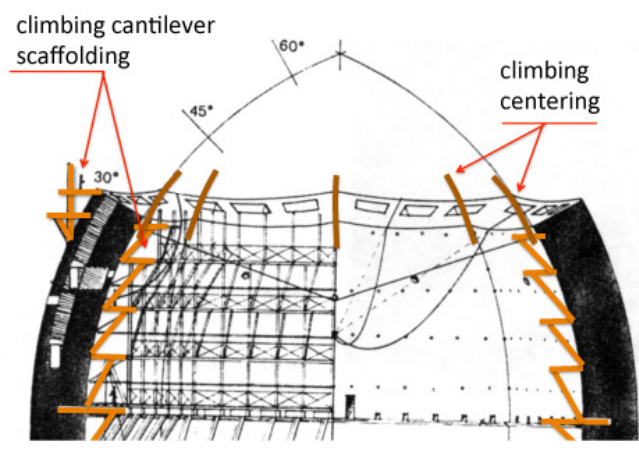

Figure 8b. Brunelleschi used climbing centering and climbing cantilever scaffolding in the construction of the dome.

\section{The cracks, the structural monitoring system and the numerical models}

All the large masonry domes have vertical cracks generated by the horizontal thrust. Even Brunelleschi's wonderful construction, despite all the technological inventions, has vertical cracks. Probably it first cracked in 1453, due to a strong earthquake. The main cracks are large over $6 \mathrm{~cm}$. Today the large cracks are four. For centuries experts have discussed on the cause of these cracks, but only in 1988, thanks to a first numerical model, the cause of the shape of the cracks was cleared. The horizontal thrusts tend to open the dome, but the arches settlements generate tensile stresses only over the four pillars. The cracks towards the apse are larger because on this side the dome has no constraints.

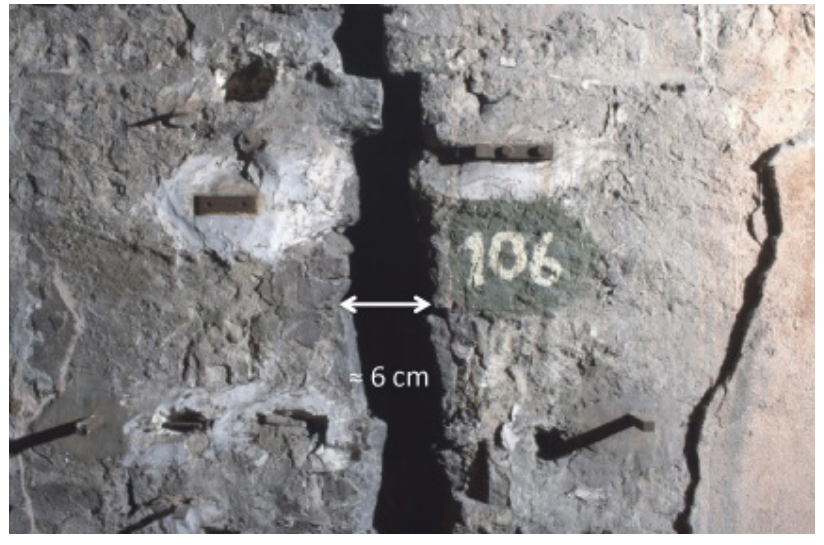

Figure 9. The main cracks are more than $6 \mathrm{~cm}$ wide and cut through 2 m-thick walls.

Thanks to many data taken from historical documents, I retraced the evolution of the cracks during centuries.

Today the trend is about $5.5 \mathrm{~mm}$ per century: not much, yet dangerous, as the dome is not a dome any more, but four arches, and this situation is much more unstable. 
In 1952, twenty-two mechanical instruments were placed on the cracks to measure their width variations. They were read four times a year until now.

Therefore the dome had a structural monitoring system for sixty years, about one tenth of its life. The graph confirms the present trend, but also shows the seasonal variations. In summer the masonry expands and the main cracks tend to close. In winter it is the opposite.

Since 1988 on the dome there is the largest structural monitoring system of the world applied to a monumental building: one hundred and sixty instruments to measure the variations in crack width, in inclination, in level, to measure the temperatures both of air and masonry and the level of the water table.

Today we know perfectly the normal behavior of the dome, even the important relation between temperature and deformations.

The things we do not know are: 1) the consequences in the future of the continuous opening of the cracks,

2) the possible consequences of a strong earthquake,

3) the real effectiveness of the wooden ties during an earthquake, 4) the consequences of the insertion of a new system of hooping ties.

Of course we need a good numerical model calibrated on the data of the monitoring system, but it is not easy. Ancient masonry has a very low tensile strength, especially when dynamic actions are present. In masonry there is no stress diffusion. We do not know the real reacting structure.

The structure changes as the forces change. During an earthquake the structure changes continuously. A masonry structure has no natural frequencies because it changes. In addition, the material is handmade, non-homogeneous, non-linear and non-isotropic. The building materials are not even homogeneous across the width of the walls. Historic buildings have also been subjected often to modifications and traumas in time (earthquakes, bombs, reconstructions, unknown soil settlements, etcetera). It is very difficult to model history with numbers. Due to the very low tensile strength, the masonry buildings do not have a global behavior, but they split into separate parts.

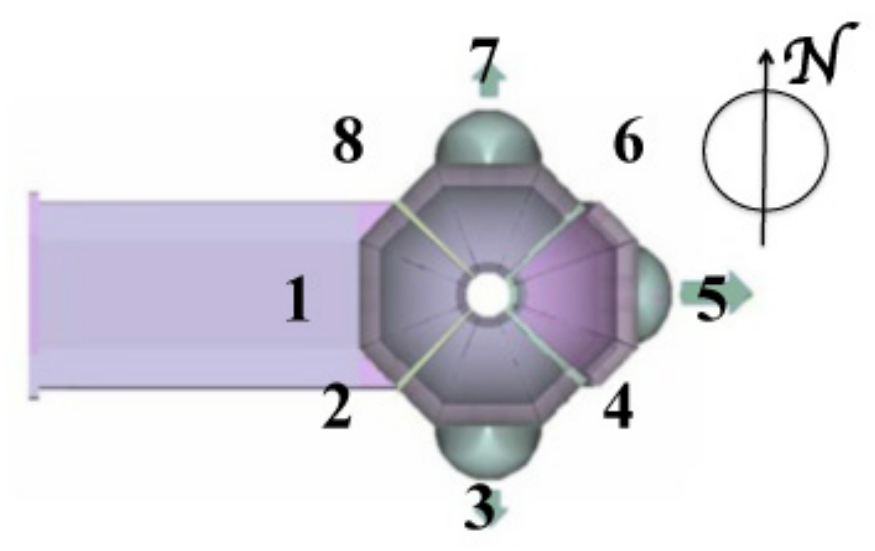

Figure 10. The major cracks today are four on the even sails; the cracks on sail 4 and 6 are more than $6 \mathrm{~cm}$ wide, while those on sail 2 and 8 are only about $2 \mathrm{~cm}$ wide.
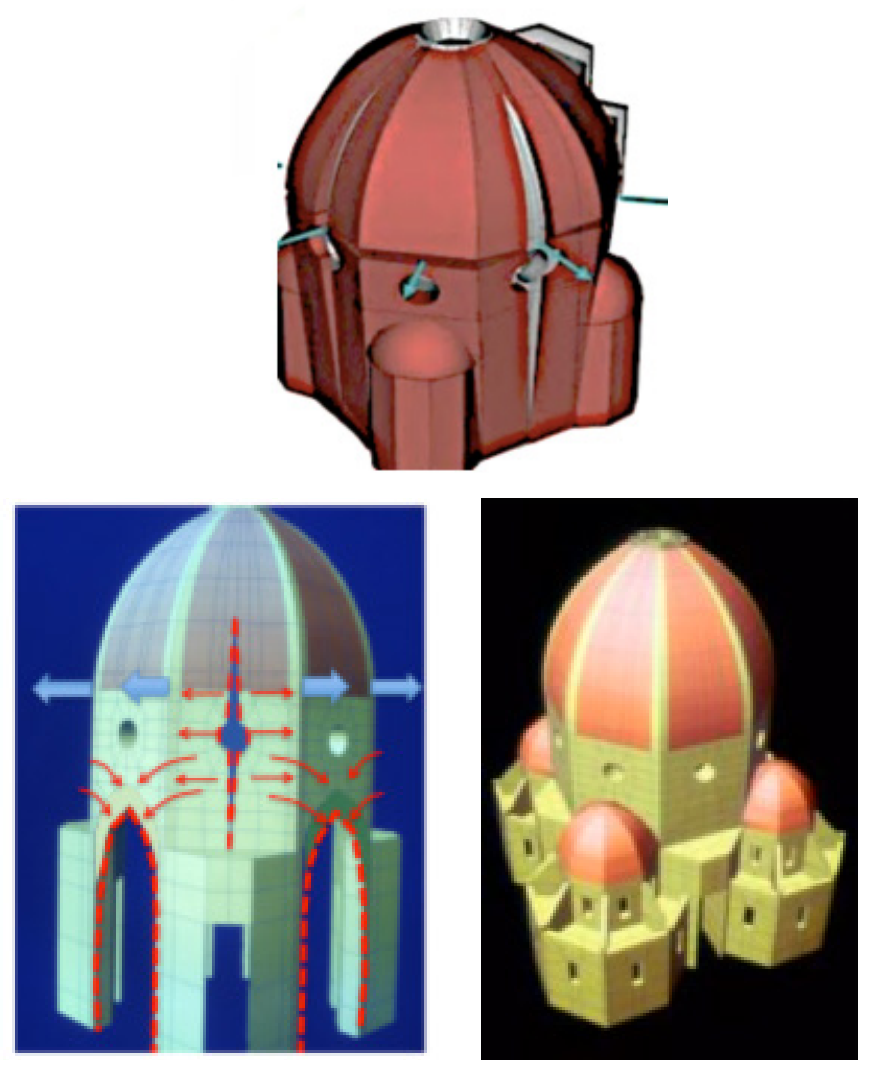

Figure 11. Model for the breaking mechanism that caused the cracks: the side chapels are not able to sufficiently counteract the thrust of the dome and the big arches.

The best method, I believe, is to follow the non-linear behavior in the time domain, considering a significant number of earthquakes. But this type of analysis require powerful calculators and many hard to find parameters. 


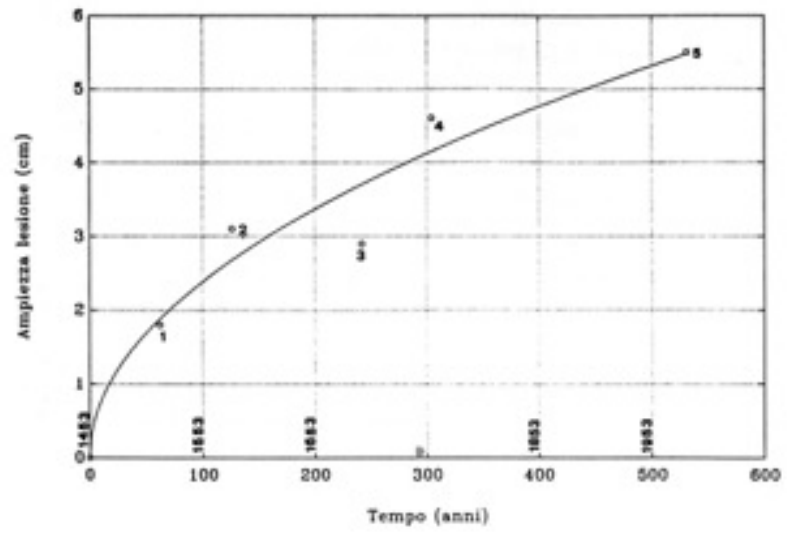

Figure 12. Hypothesis for crack evolution starting from the 1453 earthquake. The present average width increase is 5.5 $\mathrm{mm} /$ century.
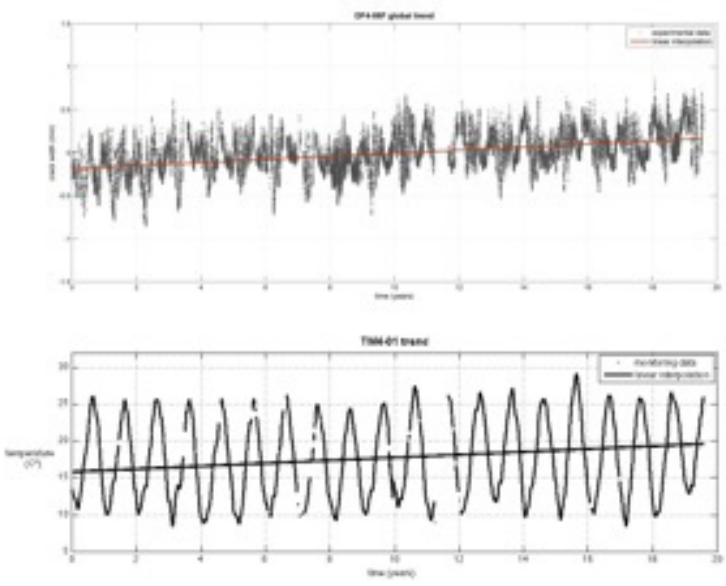

a.

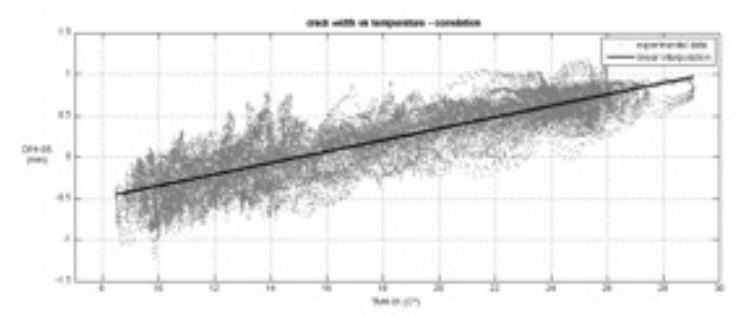

b.

Figure 13. Electronic monitoring system (160 instruments): a. evolution of cracks width (20 years); b. approximation of the same data as in a. showing the annual fluctuations; c. linear correlation between crack width and temperature.

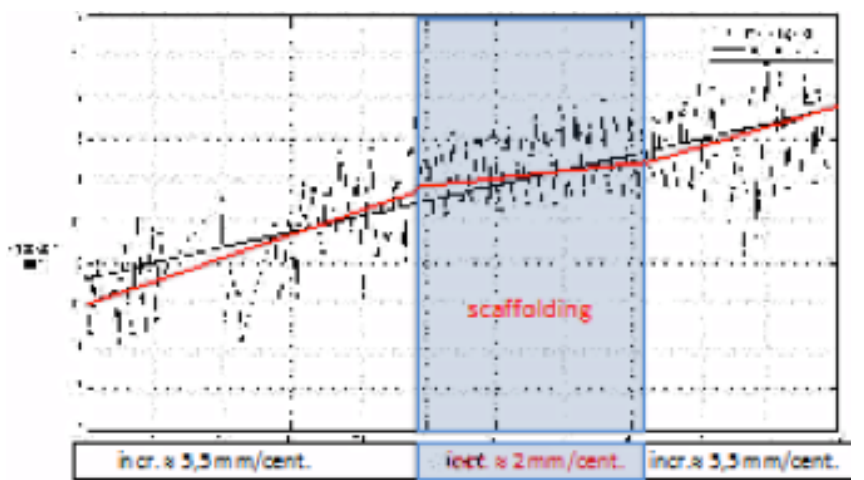

Figure 14. Crack width evolution in the last 60 years (mechanical monitoring): the metallic scaffolding built for the frescoes restoration had a positive encircling effect. Based on this observation, encircling of the dome appears as a possible action to counteract further widening of the cracks.

Certainly the Brunelleschi's Dome can be considered an excellent seminal case to define new procedures for the seismic protection of historic masonry buildings.

Recently we have developed non-linear models, considering also large displacements.The data from the structural monitoring system have been even analyzed with statistical procedures. 


\section{Conclusion}

Today the question can be: "How can the Los Alamos National Laboratory cooperate with Brunelleschi?" There are two different approaches to foresee the future seismic behavior of the dome. A statistical analysis of the past monitoring data and a non-linear structural modeling.

With the statistical analysis of the 60 years monitoring data, it is easy to find the mean increase, but if we examine well the data we can find out other hidden information, helpful even to foresee the future behavior: for example from 1978 to 1996 there was no significant opening of the cracks. During this period on the dome a scaffolding had been installed to restore the frescoes, well connected to the masonry at the base of the dome. Clearly the scaffolding had a positive role of hooping. This is an important piece of information to decide how to consolidate the dome.

Thanks to the electronic monitoring system we find out that after a small earthquake the cracks opened more quickly than usual, but not immediately: slowly in the two succeeding years. This slow phenomenon is well known: it is the creep phenomenon. For the structural analysis, the data from both the monitoring systems will be very useful also to calibrate a good mechanical model. An efficient numerical model must consider the slow trend of evolution of the cracks, the creep phenomenon, the non-linear behavior, the creation of new cracks during the seismic ground motion, in the time domain.

In conclusion, I believe that the problem of the seismic protection not only of the monuments, but also of all the masonry architectural heritage is still an open problem, which requires technical expertise and advanced tools in many sectors: computer simulations, earthquake engineering, structural dynamics, soilstructure interaction and material properties and also in historical technologies. Cooperation with the experts and the computers from the Los Alamos National Laboratory can help to develop new tools and capabilities to protect our heritage. A study to protect the Brunelleschi's dome can be a good publicity.

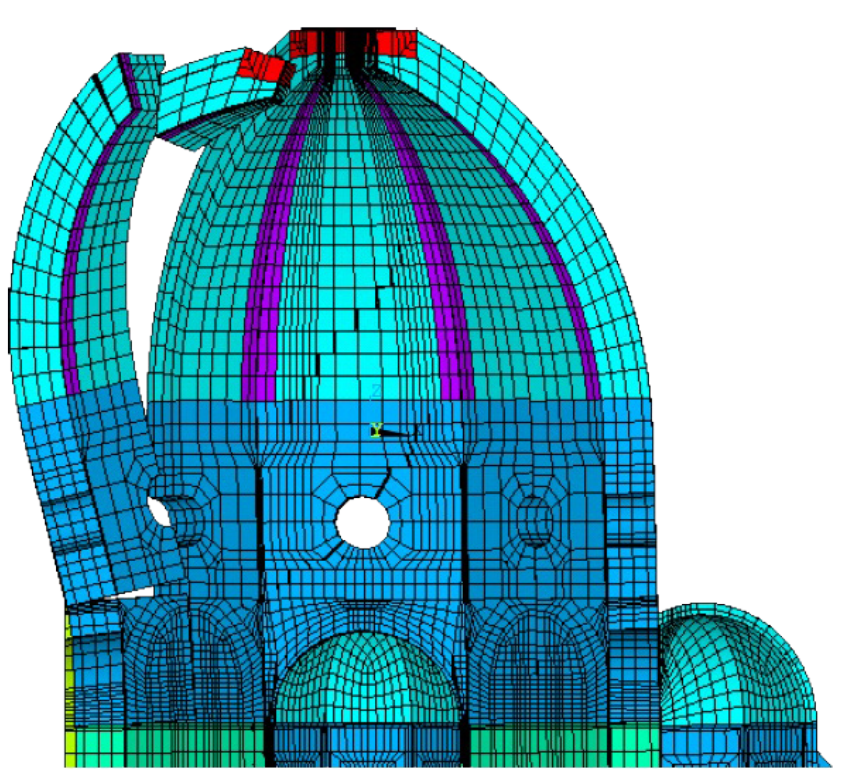

Figure 15. Non linear numerical model (G. Bartoli and M. Betti).

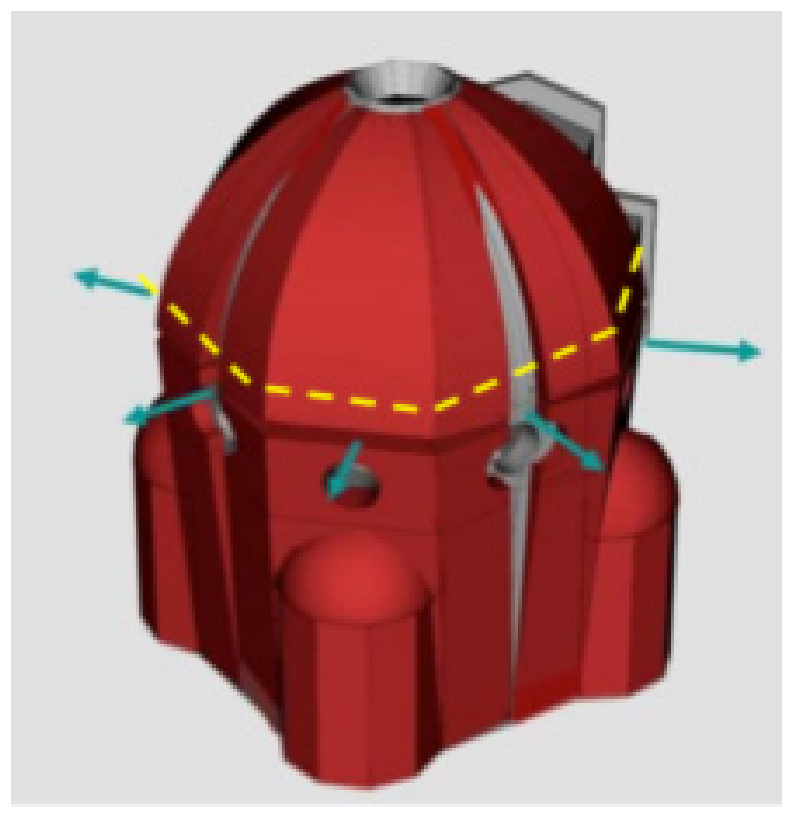

Figure 16. Sketch for a possible restraining hoop. 


\title{
The Importance of Monitoring, Behaviour Analysis and Diagnostic Techniques in the Preservation of Great Historical Structures
}

\author{
Michele Fanelli \\ CRIS-ENEL (retired), Milano, Italy
}

\section{Introduction}

Under the pressure of increasing industrial/residential development, in the last four decades of the past century great strides were made in the rational safety control of large civil and industrial structures. Awareness of Increasing hazard exposure (especially to seismic and hydro-geological hazards), as well as of the increasing vulnerability (and disastrous fallout of failures) of ever taller, slender structures led to the development and frequent application of sophisticated numerical analysis and to the detailed monitoring of actual behavior of the more imposing, or of the more exposed, structures.

A particularly important example is the safety control of dams, whose advancements were soon brought over to the safety analysis of other structures. Reference mathematical models, perfectly tailored to mimic and even forecast their "normal" reaction to the variable external inputs, were coupled to dissemination of automatic sensors and to mass data storage both of those external inputs and of the structure reactions to their variations in time. These installations can be coupled to practically instant data processing/interpretation so as to approach the ideal conception of a practically real-time safety surveillance. In the last years, the methods of rational risk analysis and control, borrowed from the reliability analysis of strategic structures or manufacts, have begun to be successfully applied to the safety analysis/risk analysis of dams and, doubtless, of other large civil buildings or infrastructures.

Key ingredients of the general progress achieved in the last 50 - 60 years were on one hand the perfecting of reference mathematical models, on the other hand the increasing availability (and decreasing unit costs) of effective, long-life, stable and sensitive sensors and of fast data storing/processing devices. The idea of a permanent monitoring installation coupled with off-line (or even, preferably, on-line, real-time) analysis and interpretation gradually gained ground in the dam engineering world.

In parallel, passive and active testing coupled with powerful diagnostic and identification numerical tools have become available. They are proving capable of yielding a vastly increased body of knowledge about the structure integrity, resistance and vulnerability (and maybe even its residual life expectation...). For their "once in a while" character, which puts them in a category apart from the permanent monitoring installations; these last methodologies (e.g. sonic tomography, artificial dynamic excitation etc.) are applied with removable set-ups and essentially off-line. In the field of the preservation of the integrity of ancient monumental structures the penetration and application of such methodologies suffered from a time lag of some years, but in the last three decades the consciousness of the remarkable potential of their application and diffusion began to penetrate also this traditional cultural environment, in the past largely dominated by a predominantly historical, humanitiesoriented approach.

In my opinion, a particularly important element of the whole concept is the availability of effective reference mathematical models. By this, we mean generally a mathematical model which can receive as input the sensor data monitoring the variations of the external factors, and can give as output an estimate, or forecast, of the structure response, to be compared (ideally in real time) to the actual response as monitored by other sensors. Any 'large' deviation between model forecasts and actual measurements are to be taken as symptoms of something that was not expected and therefore should be carefully investigated. Historically, the first type of such reference tools have been the statistical models based on a statistical analysis of the correlation between measured environmental actions and measured structural response. Though yielding acceptable results in normal practice, 


\section{DISTRIBUZIONE DI FREQUENZA DEGLI SCARTI}
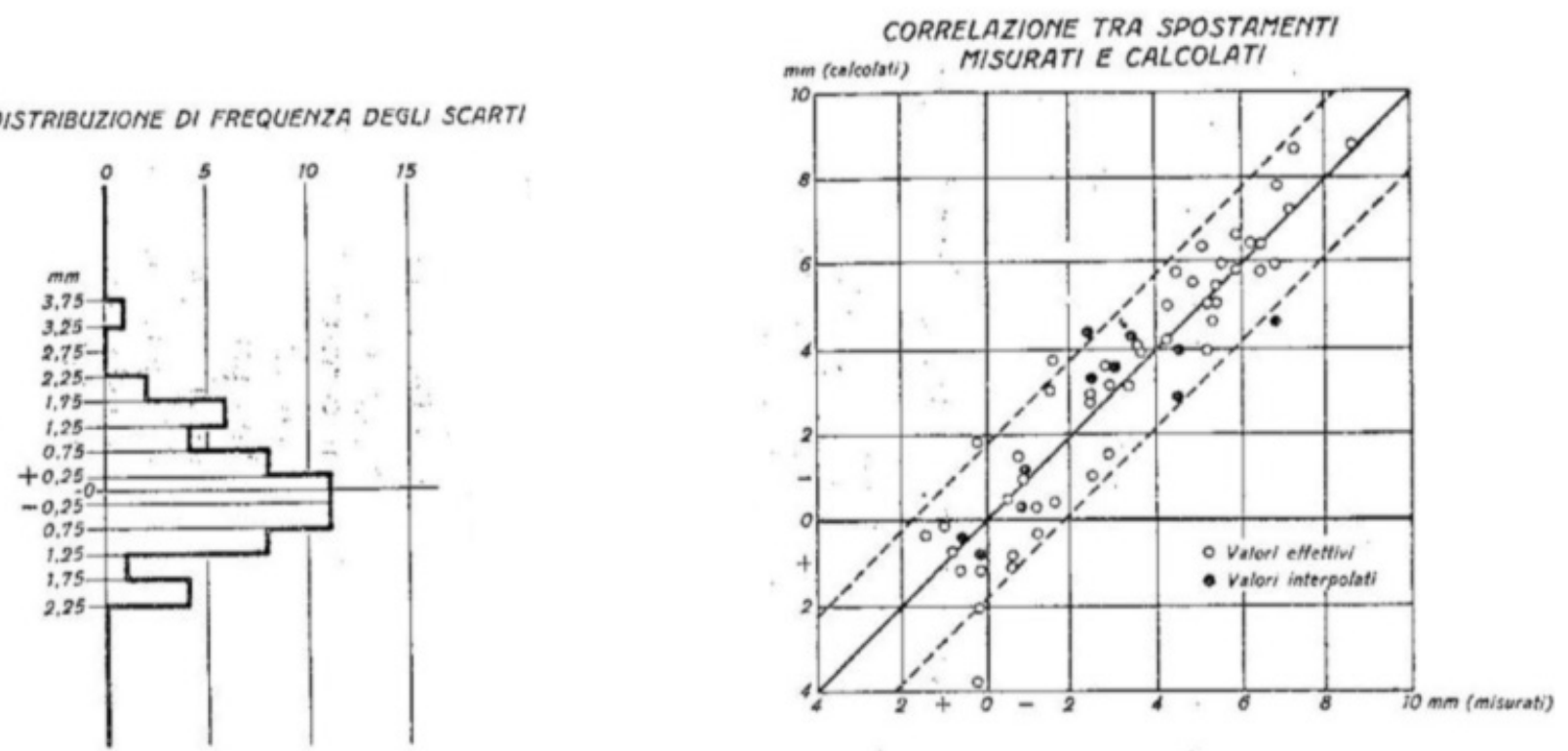

Figure 1. Poor accuracy of early deterministic models in the years 1960 : ISOLATO ARCH DAM. Left: frequency distribution of differences model forecasts-actual measurements Maximum deviation/maximum displacement of the order of $20 \%$.

these models embody an inherent flaw: the self-referentiality, i. e. the absence of an external judgment yardstick against which to measure, as objectively as the state of the art allows the quality of the structure performance. Also, sometimes it is difficult to achieve a satisfactory calibration of their mathematical components. As a result, in normal practice their sensitivity can be somewhat impaired in comparison with the deterministic models.

The development of more rational reference models, the deterministic ones, was achieved in the years spanning the mid-century decades, thanks to the availability of more and more advanced, general-purpose Finite Element methods of structural analysis. If the performance of the structure under the action of external inputs is accurately measured, it can then be compared to an 'expected response' given by an accurate, correctly calibrated F. E. model embodying essentially the same assumptions and knowledge of the designer and receiving from the readings of adequate sensors the numerical values representing the measured variations of the external agents having a significant influence on the measurable variations of the structure behavior (1).

For example, in the case of dams, the expected variations of the upstream-downstream displacements of some key points of the dam are synthesized by feeding the model input with the data coming from the water level gauge and from the thermometers; the expected displacements thus synthesized are then compared with those actually measured on the structure. The fidelity of representation of such models has become better and better through the years, to the point that the sensitivity of the whole system to potentially abnormal, persistent, systematic deviations ('drifts') of the difference between measure and model forecast is nowadays satisfactorily high.

Forecast, year 1998

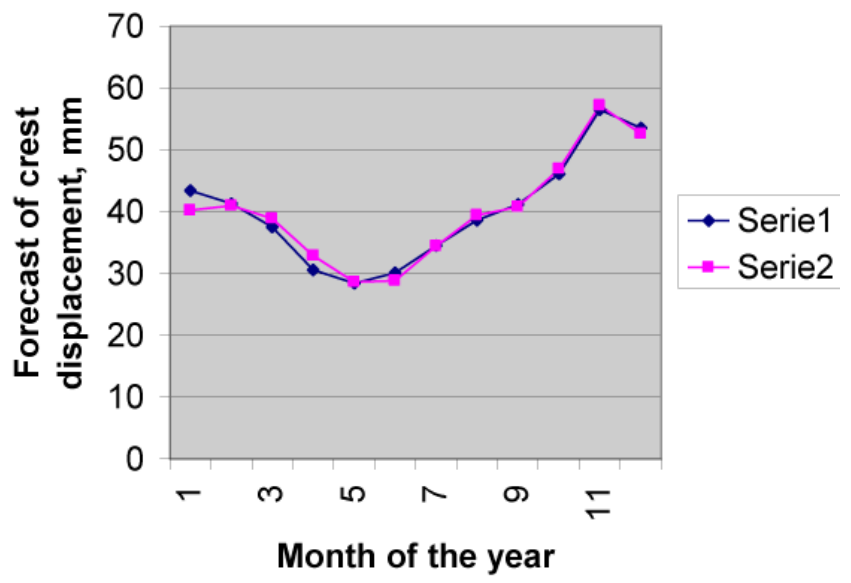

Figure 2. Improved accuracy of deterministic models, years 2000. Series 1: displacement forecasts of the SCHLEGEIS ARCH-GRAVITY DAM, deterministic model. Series 2: actual displacements measured on the dam by plumb-line. Accuracy of model forecasts of the order of $2 \%$. 
By this I mean, more precisely, that in the years from 1960 to 2010 the inevitable random discrepancies between the expected and the observed response in 'normal' conditions were brought down by at least an order of magnitude. Correspondingly, the sensitivity of the control loop to the onset of abnormal responses was more than proportionally improved (Figures 1 and 2).

At the same time, progress in sensor technology and experimental data processing was advancing as well. Problems that had plagued early attempts at providing the structures with permanent monitoring installations became a nightmare of the past (e. g., thermometers poor accuracy, stability and life expectancy were overcome; quality and noise protection of electrical connections underwent a decisive improvement; capability of data storage and data processing hardware and software increased beyond belief, while their cost plummeted; etc.). Thus the means of monitoring the actual behavior in a practically continuous modality, and the possibility of interpreting its meaning, practically in real time, in the light of the reference model, are now at hand. And this concept was actually implemented on a number of large dams. An early demonstrative project was successfully realized in 1966 on the double-curvature arch dam of Talvacchia in Central Italy: a dam that twenty years later became a real-size laboratory in an impressive three years of extensive and intensive monitoring and interpretation, teaching vital lessons about sides of the dam behaviour till then rather unclear.

The extension of these rational methods to large monumental structures of historical interest was from the start an obvious possibility, the only obstacle to its diffusion being the availability of the necessary financial sponsoring. A sporadic exception was the ENEL/CRIS-ISMES investigation and monitoring installation carried out in the years ' 80 s for the Brunelleschi Cupola, in close cooperation with the late Prof. Andrea Chiarugi and his team. In this ten-years investigation, a convincing interpretation of the cause and stability of the Cupola cracks was achieved and an imposing program of monitoring permanent installations, with 165 sensors and a robust data acquisition and storage system, was implemented. The conclusions of this extended study were incorporated in the official Report of the last Ministerial Commission (chaired by Prof. Angeli D'Ossat) charged with the task of re-appraising the state and safety of the Cupola. Several numerical, Finite Elements models of increasing size and complexity were built up and used to perform step by step accurate numerical simulations (FIG. 2). It was thus found that the main cause of the four big cracks affecting, from intrados to extrados, the NE, SE, SW and NW panels of inner shell is the deadweight of the Cupola with its skylight, through a subtle interplay with the stiffness of the underlying structures (the drum and the four massive pillars). Indeed, starting with a F. E. analysis of an uncracked Cupola subjected to its own deadweight, unacceptably high tensile stresses in a horizontal direction were obtained, along the affected panels vertical middle planes, at the junction between Cupola and drum, leading to the strong inference that this effect was at the root of the first inception of the four cracks. The F. E. model was then modified step by step, introducing artificially the four cracks over increasing intervals of elevation, starting from near the Cupola springing and going in the final step up to about $3 / 4$ of the whole Cupola height, at which level the tensile tress at the crack apex was reduced to a negligible value. Under these alterations of the geometry and stiffness of the structure, other secondary areas of excessive tensile stress in a horizontal direction were observed in the intrados of the inner shell, notably near the corners at the contact between adjacent panels and at mid-span of the until then unaffected panels. These lines of localized, superficial tensile states closely correspond, in location as well as in extension, to the secondary cracks actually observed on the intrados of the real Cupola. It was thus legitimate to conclude that:

a) the real cause of the main cracks had been undisputedly identified as a dead-weight effect (2);

b) that the F. E. model (Figure 3) was a reliable tool for numerical analyses of the Cupola behavior under different load distributions, and

c) that thermal effects, traffic vibration and low-level wind or moderate seismic excitation could act as a "secondary drive" of crack propagation, but were not their primary cause .

d) that strong-motion earthquakes could present a definite hazard for the Cupola. However, this point could not be studied in detail because of the termination of the financial sponsorship of ENEL. 
A limit of these analyses was their being carried out on a linear-elastic model, where the discontinuities were not an automatic output of non-linear computations, but were introduced step by step by hand. Indeed within the time span of ENEL's sponsorship, after the essential first phase of the analysis of the cracks origin and stability, the vital matter of the Cupola behavior under a severe earthquake, as well as the preliminary simulation of some hypothesis of structural reinforcing, could be explored only in a very cursory way, in the unrealistic context of the linear model. This limitation is particularly critical in the case of dynamic analyses, e. g. for the simulation of the effects of a strongmotion earthquake. Reliable models of the rheological behavior of the Cupola masonry in the non-linear field are therefore necessary for any realistic appraisal of the seismic safety of the Brunelleschi Cupola. However, the results gathered so far thanks to these studies define in a convincing way the present static conditions of the Cupola and constitute a necessary starting basis of any future refinement and extension.

These necessary extensions should also include the

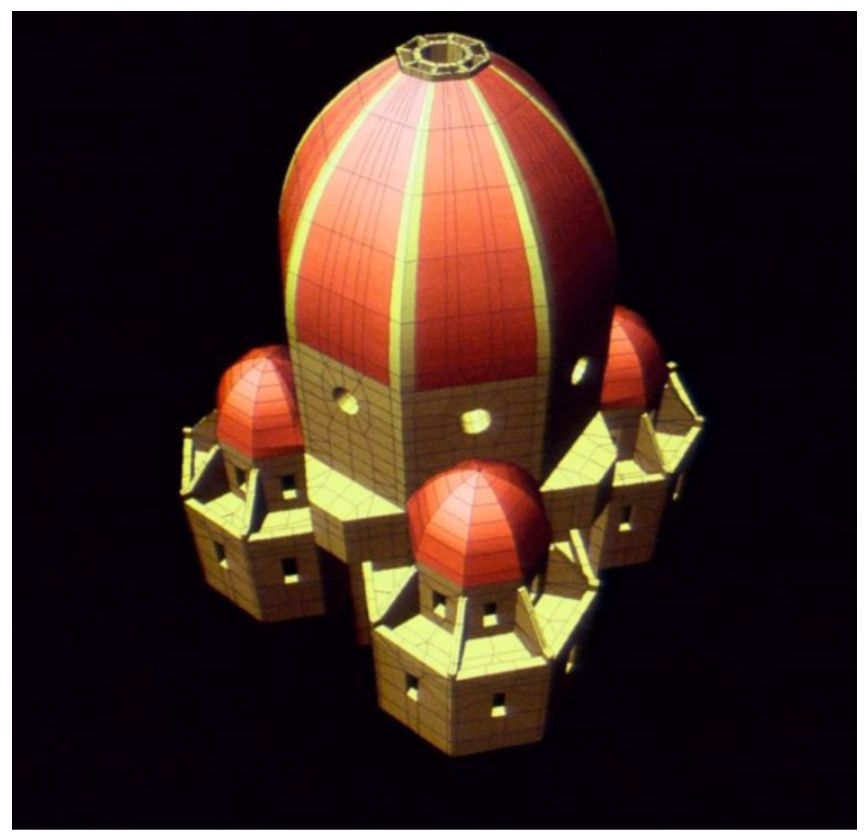

Figure 3. A perspective of the CRIS-ENEL F. E. model of the Brunelleschi Cupola. View from the East (apsidal) side. Note the absence of the main nave (with the two smaller lateral naves) on the opposite side. re-visitation of the size and complexity of the F. E. model as well as of the scope of the analyses to be carried out. In particular:

i) The new F. E. model should include the main nave and the two smaller lateral naves of the Cathedral, so far not represented;

ii) A suitably large volume of the underlying ground should also be modeled by a F. E. mesh;

iii) The geotechnical properties of the foundation ground should be investigated and an adequate rheological model be identified, in order to acceptably model the soil-structure static and dynamic interactions;

iv) The non-linear behavior of the Cupola masonry under static and dynamic inputs should be realistically characterized;

v) A range of spectral representation of possible moderate to extreme seismic inputs should be defined, consistently with the seismology of the Tuscan region;

vi) Non- linear analyses of the seismic behavior of the Cupola should then be carried out;

vii) Also thermal and wind inputs to the Cupola should be defined in accordance with local conditions, and their long-run effects on the Cupola integrity be assessed;

viii) A preliminary investigation on different, plausible schemes of strengthening of the Cupola should be modeled, and their degree of improvement of the Cupola resistance to external hazards should be assessed.

ix) An attempt at simulating the historical evolution of the cracks could be of some interest, notwithstanding the considerable difficulties (poor factual documentation, problematic definition of dynamic and other inputs.....) 
Other instances, dating back more or less to the past half-century, concerned the diagnostics and monitoring of tall, slender structures such as ancient towers or belfries. This activity, which saw the cooperation of CRIS/ ENEL, CISE and ISMES with Prof. Giorgio Macchi of the Pavia University, was spurred by the lamentable collapse of the Pavia tower in 1986.

Auscultation of the dynamic response of such slender structures, by means of artificial shaking or by recording of their behavior in response to seismic events, allows the identification of their first modal frequencies and eigenshapes. And this information already gives a rough criterion, especially on a comparative basis within a group of approximately homogeneous towers, to detect potentially worrisome situations.

The availability of a reliable, field-tested and calibrated mathematical model also allows to simulate the effects of various hypotheses of structural strengthening of a damaged structure, and if need be to follow its implementation step by step, respecting not only the necessary caution and graduality which are always a 'must' when dealing with artifacts of large historical/cultural interest, but also the necessary requisites of reversibility (and, wherever possible, of invisibility) of the structural reinforcements, requisites that are imposed by the obligation to respect the aesthetics of these monumental artifact. [To be noted that in the case of the Brunelleschi cupola the requisites of reversibility and invisibility could be rather easily met, thanks to the presence of the interspace between outer and inner shells].

\section{Conclusions}

Although impressive theoretical progress of the technical possibilities has been achieved in the past, the practical fallout of this progress on the monumental treasures of our cities has been sorely much slower. Only in part this state of things can be ascribed to funding difficulties; in my opinion, over and above such undeniable circumstances there is a fault of generalized cultural interest, which deprives the subject from political profitability and therefore generates a lack of 'political' will to act. Let us hope that this sorry state of mind does not lead us, in the future years, to lament the irreversible loss of some irreplaceable symbols of our most precious historical heritage.

\section{Appendices}

(1) It is correct to include in the picture a third category of reference models: the hybrid models, which partake of the statistical type for some components of the controlled behavioral variables (e. g. the thermal components) and of the deterministic models for other components (e. g. the effects of the variations of the hydrostatic load). In addition, it is only fair to admit that in the stage of model calibration also each deterministic model relies - as its statistical or hybrid counterpart- on the availability of a data base of past monitoring measurements, obtained under presumably "normal" conditions, from which to extract, by a suitable mathematical procedure, a maximum likelihood estimate of the model parameters. It is therefore evident that in this stage subjective judgments and personal preferences can affect the quality of calibration. On the other hand, the mathematical structure of the statistical models is not significantly different from the structure of the deterministic models; in fact, it is most of the times suggested by structural considerations. In definitive it is methodologically correct to say that all reference models are hybrid ones. Of course, deterministic, statistical and hybrid models can be periodically updated and/or recalibrated according to the intervened progresses in methodological or experimental knowledge (or to include structural modifications to the controlled manufact).

(2) The reduced-scale (about 1:8) model built by Brunelleschi prior to inception of the real Cupola erection, to demonstrate his method of erection without scaffolding, was presumably unaffected by cracks, thus probably inducing a misplaced confidence on the resistance of the real Cupola to cracking. It was not until two centuries later, indeed, that Galileo, formulating the first principles of the Strength of Materials science, stated clearly that in geometrically similar structures subjected to gravity the level of stress increases linearly with size. 


\section{References}

Fanelli, G. and Fanelli, M. 2004. Brunelleschi's Cupola: Past and Present of an Architectural Masterpiece. Florence: Mandragora (In this book there is an extensive bibliographic list). 


\section{Santa Maria del Fiore Dome: Crack Patten and Monitoring Systems}

\section{Federica Ottoni}

\section{Department of Civil Engineering and Architecture, University of Parma, Italy}

Despite the technical tricks put in work by its genial builder, Santa Maria del Fiore dome has shown, soon after its completion, a complex and widespread crack pattern which strongly increased in time, arousing alarm about dome stability during centuries, and which has been object of different studies, starting from G. Silvani in 1693 [1], up to the last scientific commissions (P.L. Nervi in 1936 [2]; P. Sanpaolesi and S. Di Pasquale in 1975 [3], and A. Chiarugi in 1988 [4]).
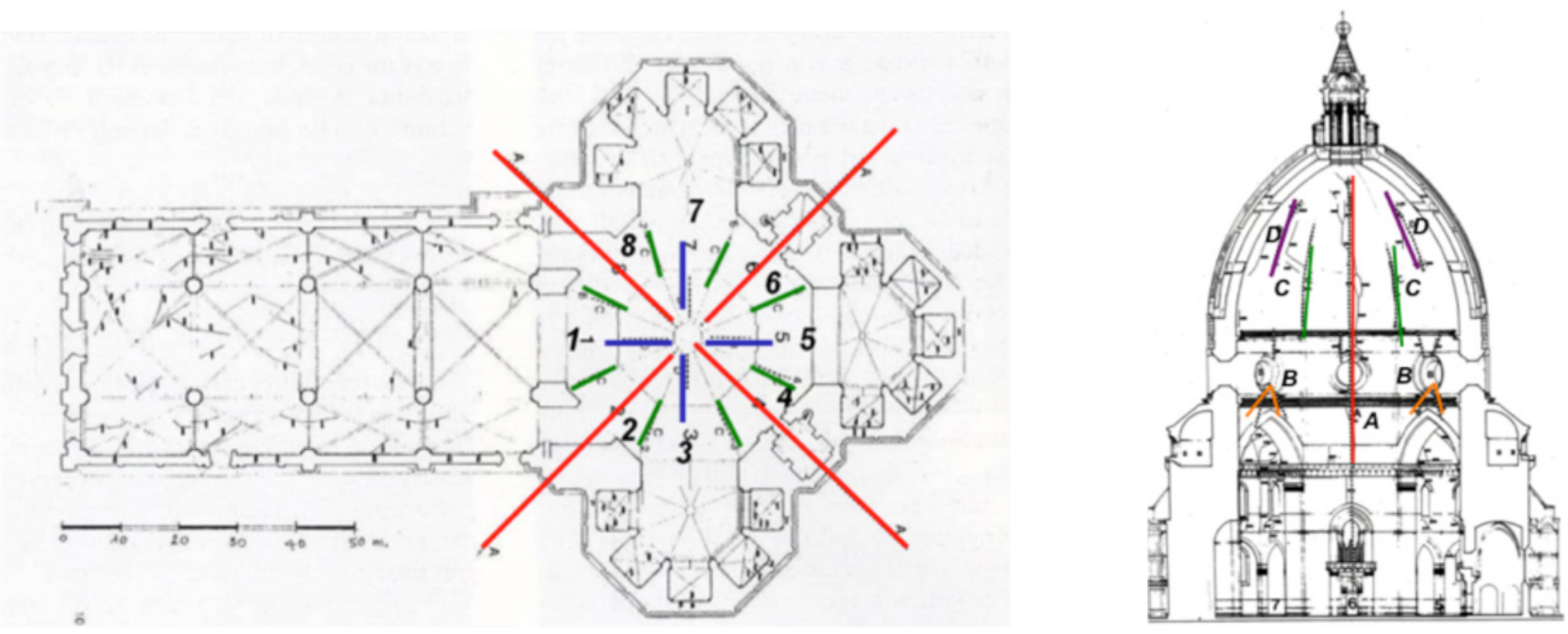

Figure 1. Scheme of the crack pattern of the dome: main cracks on the even webs (A, in red), angular cracks (C, in green) and minor cracks on the odd webs, under the oculi ( $B$, in blue).

This crack pattern is composed by almost symmetrical cracks [5], which, in step with the last commonly recognized classification, can be divided as follows (Fig.1):

A. major passing cracks (on both the domes) with vertical direction, lay at the centre of webs, on even sides (webs 2, 4, 6 and 8).

B. other major cracks on the tambour, in odd webs (1,3,5 and 7) starting from the central oculi, proceeding at $60^{\circ}$ to the horizontal, to the intrados of the arch below.

C. Vertical non passing cracks in the internal part of the dome, laying on the eight edges, starting from the base and reaching an intermediate level between the second and the third gallery.

Some minor cracks, 1 or $2 \mathrm{~mm}$ large, lay at the centre of the odd webs, at intrados of the inner dome, between the second and the third gallery level (D), while other minor lesions are visible on the semi-domes (E), the tribune (F) and the central nave $(\mathrm{G})$, representing a secondary crack system [6]. The even notable variations in the general symmetry of this crack outline (with a concentration on the peer slices) are explicable considering the different underlying bearing structures (the huge pillars instead of the wide arches). Howsoever, the current global crack pattern is consistent with the well known collapse mechanism typical of domed structures: a lowering of the top of the structure under its own weight with significant horizontal thrusts on the bearing elements [7]. 
The observation of dome damage, indeed, had begun soon after its completion, and it has evolved during centuries, with the application, time by time, of a better technology, up to the last modern monitoring systems installed on the dome during the last century.

At present, two are the main monitoring systems working on the dome:

1) the mechanical one installed by Opera del Duomo (O.D) in 1955;

2) and the digital one placed by ISMES (in cooperation with the Soprintendenza) in 1987.

The first system (from 1955 to 2009) has been installed by Opera del Duomo (O.D.) on the major cracks in the inner dome and it is constituted by 22 mechanical deformometers, which record crack width variations four times a year. The collected data have recorded the last 60 years cracks width evolution, together with dome internal and external temperatures.

The second and more articulated system was placed on the two domes by ISMES in 1987, and it is composed by 166 instruments. 72 displacements transistors inductive types (deformometers) are placed on the main cracks of the inner and outer domes, at five different levels, while 8 plumb-lines at the centre of each web (intercepted by telecoordinometers at three different levels: lower tambour, first galley level and ground) allow to measure horizontal relative displacements between pillars and tambour. Furthermore, the evolution in time of the pillars vertical subsidence phenomenon is measured by a hydraulic leveling system, placed in correspondence of the center of the oculi lower part, approximately at the second gallery level. Two piezometers, near the web n. 4 and below the nave, register the variation of the underground water level. Moreover, the ISMES system includes 60 thermometers, measuring masonry and air temperature in the two domes on each web, at the second corridor level $\left(+/-0.05^{\circ} \mathrm{C}\right.$ precision). The acquisition system registers data every six hours, starting at 6.00 a.m every day and 20 years data, recorded from 8th January 1987 to 31st July 2007 (about 31373 measures for each instrument, five million in total), and the recorded data have been analyzed.

The linear regression applied to the 22 instruments of O.D. system, has evidenced a global increasing trend of major crack width of about $3 \mathrm{~mm}$ per century, which can be better evaluated by slitting the data in two periods: before and during the presence of the really contested encircling scaffoldings put in work from 1980 to 1996 in the inner dome for the restoration of the frescoes. Considering these two periods, the analysis of data has shown a significant variation in the trend, from $6 \mathrm{~mm} / 100$ years to almost $2 \mathrm{~mm} / 100 y e a r s$. Moreover, the strict relation between crack width and temperature variation results clear by the analysis of the ISMES data, which - despite the clear periodicity observed, reliably due to thermal variations - show residual trend after the "purifying operation" [8].

Overall, the very limited observed displacements and their negligible evolution trends, joined to the lack of substantial differences between the 8 webs, lead to exclude, after centuries, the ancient hypothesis of differential settlement as the origin of Santa Maria del Fiore damage. Obviously, here are referred only the first results and a global model is needed in order to examine together all the experimental data, through a set of simultaneous equations model aimed at finding causal relationship between all the variables registered (currently in progress with the Florence Dept. of Statistics). This model could be really useful in order to establish the normal behaviour of the dome, and it could constitute a validation method for the necessary development of a reliable structural numerical model of the dome. 


\section{References}

[1] Nelli G.B. and Sgrilli B.S. 1733. Descrizione e studi dell'insigne fabbrica di S. Maria del Fiore, Florence: Metropolitana Fiorentina.

[2] Nobili, M., Sabatini, R., Alfani, G., Nervi, P.L. and G. Padelli. 1934. Rilievi e studi sulla Cupola del Brunelleschi, eseguiti dalla Commissione nominata il 12 gennaio 1934. Florence: Tipografia Ettore Rinaldi.

[3] Di Pasquale, S. 1977. Primo rapporto sulla Cupola di Santa Maria del Fiore, Florence: CLUSF.

[4] Chiarugi, A., Fanelli, M. and Giuseppetti G. 1983. Analysis of a Brunelleschi-Type dome including thermal loads. Proceedings of IABSE Symposium, Venice, 169-178.

[5] Blasi, C. and Ceccotti, A. 1984. La Cupola del Brunelleschi: indagine sullo stato di fessurazione, In: Proc. INARCOS Ingegneri Architetti Costruttori, Bologna. 228-236

[6] Petrini, G. (edited by) 1984. Catalogo dei plessi fessurativi della Cupola di Santa Maria del Fiore in Firenze, Florence: Italian Ministry of Cultural Heritage, 31-37.

[7] Chiarugi, A., Fanelli, M. and Giuseppetti, G. 1993. Diagnosis and Strengthening of the Brunelleschi Dome. In: Proc. IABSE Symposium, Rome, 441-448.

[8] Ottoni, F., Coisson, E. and Blasi, C. 2010. The crack pattern in Brunelleschi's dome in Florence. Damage evolution from historical to modern monitoring system analysis. In Advanced Materials Research, Trans Tech publications, Switzerland, 133-134: 53-64. 


\title{
Seismic Hazard Considerations for the Santa Maria del Fiore Dome
}

\section{Richard Lee}

\author{
Los Alamos National Laboratory, Los Alamos, New Mexico
}

\section{Summary}

This discussion summarizes the pertinent topics addressing uncertainty and site response for seismic hazard and engineering evaluation criteria relative to the Santa Maria del Fiore Dome in Florence, Italy (hereafter referred to as the Cupola). The Cupola, located in Florence, Italy is situated is a generally high seismic region and has experienced a number of historic earthquakes. Italy has nine seismotectonic domains giving rise to active compressional, extensional and transcurrent faulting as a result of converging seismotectonic plates. This dynamic results in a beautiful natural setting for Florence but also presents serious risks to the public and antiquities due to the nature of historic construction. Unlike New Mexico, Italy has a long historical record of earthquakes dating back $\sim 1000$ years. These records suggest that Italy experiences 10-15 magnitude 6-7 earthquakes in a given hundred year period. This historic earthquake rate demonstrates the high hazard Italy faces that together with the risk of a high population density and a high density of historic unreinforced masonry structures. More recently, the 1980 Irpinia and 2009 L'Aquila earthquakes took nearly 3500 and 300 lives respectively.

The Cupola represents a serious engineering challenge to save the structure from future naturally occurring earthquakes that could doom the structure but yet ensure possible reinforcements do not create additional structural harm or in any way would deface the masterpiece. The seismic hazard analysis needed for the evaluation of the Cupola has some parallel with that facing LANL (Wong et al., 2007); both structures are potentially in the close or near-field of large normal faulting earthquakes. Consequently, strong motion data recorded in the near-field from normal faulting earthquakes is of great interest to LANL because of the nearby Pajarito Fault, a large rift bounding fault adjacent to Los Alamos. The worldwide strong motion database is very limited for moderate magnitude (M6-7) normal faulting earthquakes recorded in the near field (recorded at a distance within the source dimension of the earthquake). This data limitation is why Los Alamos could benefit from any collaboration with Italian scientists working on the Cupola and why LANLs seismic hazard experience can benefit the Cupola.

\section{Approach to Seismic Safety}

DOE has a graded approach to seismic safety depending on the possible consequences of the earthquake to life safety, the environment and economic and mission risks. Consequently a probabilistic approach (Cornell, 1968) is used with increasing stringent criteria depending on the facility risk to the public. The Cupola is unique for a structural evaluation because of its age; it has already experienced a number of potentially damaging earthquakes and survived. Most historical earthquakes affecting Florence have been local to Florence (MCS VI-VII in 1453 $\& 1895$ ) or in the Northern Apennines (Molin and Paciello, 2008). While its current desired lifetime is many hundreds of years longer than DOE facilities, there are a number of "design" criteria that would benefit the seismic analysis of the Cupola. For example, the goal of a seismic engineering assessment for the Cupola is to evaluate the structure for a suite of earthquake ground motions having alternate expected return periods: (1) a ground motion level (magnitude and distance) likely experienced by the Cupola without significant damage (e.g., 500-yr); (2) a ground motion level not experienced by the Cupola but that may cause significant damage (e.g., 1000-yr); (3) a ground motion level considerably higher (e.g., 2500-yrs) that would likely cause considerable damage or collapse. Each of these assessments may suggest different earthquake source and path resulting in a unique spectral shape affecting the Cupola. The purpose of the alternate levels of ground motion is to increase confidence in the adequacy of the engineering models of the Cupola and show that while a possible retrofit may be adequate to provide additional support for the structure for one level of ground motion, the retrofit does not increase the risk of structural failure at a higher level of ground motion. 


\section{Propagation of Uncertainty in Seismic Hazard Assessment}

The objective of a Probabilistic Seismic Hazard Assessment (PSHA) is to produce a quantitative description of the annual rate of exceedance of ground motion values, and the uncertainties associated with that ground motion. The 2007 LANL PSHA was completed as a Senior Seismic Hazard Assessment Committee (SSHAC, 1997) level 2 study with the participation of LANL geologists, seismologists, engineers and numerous subcontractors conducting geophysical and geological investigations at or near the laboratory. SSHAC is a well-defined procedure to conduct the PSHA that ensures variability and uncertainty are fully documented and incorporated in the final product. Careful documentation of the Italian seismic hazard assessments (e.g., assessments completed by the Istituto Nazionale di Geofisica e Vulcanologia) will allow the extraction of approximate site response factors and incorporation of site-specific response for the Cupola. Following a SSHAC process the full variability and uncertainty in data, methods and models is incorporated to ensure that the center, body and range of the technically defensible opinions are incorporated in the analysis. Incorporating uncertainty in the source, path and site models and parameters results in typically millions of hazard curves for each oscillator frequency which for each oscillator frequency are reduced to a weighted mean and fractile hazard for each ground motion level of interest.

A PSHA can be most simply envisioned by breaking down the problem by source, path and site. The sources include the location and activity rate, and magnitude distribution of area and fault sources. The path is defined by ground motion prediction equations (GMPEs) that contain dependent terms on source distance from site, earthquake magnitude and mechanism and path properties for crustal geometrical and anelastic attenuation. The site portion is the typically shallow low-velocity and highly damped path segment that modifies predicted time histories and spectra far out of proportion to the short travel path. Site amplifications can increase or decrease spectral amplitudes by an order of magnitude depending on oscillator frequency. Although Italian ground motion maps appear to be based on simplified measures (and appropriate for their intended purpose) such as the velocity or inferred shear-wave velocity in the topmost 30-meters (Vs30). For the Florence region, these site amplification studies can be decoupled from source and path models so that more site specific assessments can be determined without re-computing the seismic hazard from the source (Lee et al., 1998). Such an improvement in the site response model will ensure that resonant frequencies in the site response model are incorporated in the analysis of the Cupola. If a detailed breakdown of the Italian PSHA can be made available, then the generic site response model can be extracted and a site-specific model can be incorporated using already available geotechnical and geophysical data collected from Italian data sources.

For Los Alamos, the uncertainty (5th-95th fractile) in the final $5-\mathrm{Hz}$ hazard ranges from about 0.5 to $1.5 \mathrm{~g}$. This is a combination of source, path and site uncertainties. The hazard also shows that despite incorporating over 50 seismic sources, the hazard is dominated by the Pajarito Fault System. The hazard deaggregation also illustrates the magnitude and distance range of the earthquake that dominates the hazard and this is precisely the kind of information that is needed to develop ground motions for engineering analysis of the Cupola.

\section{Engineering Assessment Criteria for the Cupola}

In contrast to modern engineered construction having a lifetime of a few tens of years, the Cupola has survived a high seismic environment for over 500-years, with the hope of surviving hundreds of years in the future. This lifetime of an ancient structure in a high seismic environment presents a challenge to the engineering analysis and any proposed retrofit to the structure. It is possible that any retrofit to the Cupola that may benefit the structure for some lower level of ground motion may in fact result in additional damage or collapse potential at a higher level of ground motion. The challenge for the seismic input to the Cupola is to develop suites of ground motions (time histories/spectra) that should be considered for analysis that will ensure that any retrofit helps to improve the lifetime of the Cupola and does no harm in future earthquakes. 


\section{References}

Cornell, C.A. (1968). Engineering Seismic Risk Analysis, Bull. Seis. Soc. Am., Vol 58, 1583-1606.

Lee, R., W.J. Silva, and C.A. Cornell (1998). Alternatives In Evaluating Soil- and Rock-Site Seismic Hazard, Seis. Res. Lett.,Vol. 69, 81.

Molin, D. and A. Paciello (2008). Seismic Hazard Assessment in Florence City Italy, J. Earthquake Eng., Vol. 3 , 475-494.

Senior Seismic Hazard Analysis Committee (SSHAC), 1997. Recommendations for Probabilistic Seismic Hazard Analysis-Guidance on uncertainty and Use of Experts, U.S. Nuclear Regulatory Commission NUREG/CR-6327.

Wong, I., W. Silva, S. Olig, M. Dober, N. Gregor, J. Gardner, C. Lewis, F. Terra, J. Zachariasen, K. Stokoe, P. Thomas, and S. Upadhyaya (2007). Update of the probabilistic Seismic hazard Analysis and Development of Seismic Design Ground Motions at the Los Alamos National laboratory, URS Corporation, 25 May, 2007. 


\title{
The Seismic Response of Historic Masonry Buildings: General Issues
}

\section{Eva Coïsson}

\author{
Department of Civil Engineering and Architecture, University of Parma, Italy
}

\section{Damage and collapse modes}

Historic masonry buildings react to seismic actions with typical mechanisms [1]. To understand their behavior, the experience of real damage and collapse cases is fundamental, as these mechanisms are recurring. Experience has shown that these mechanisms can be summarized as follows:

Mode 0 (crumbling): this damage mode, mainly due to poor mortar, is very dangerous, as it can lead to the complete collapse of the building. The type of masonry which is more subjected to this collapse mode is the one made with rounded stones, because in this case the connecting role of mortar is higher. But the recent earthquake in the Emilia-Romagna region, characterized by bricks constructions, has shown that also in these cases poor mortar together with inappropriate masonry arrangement (with limited transversal connections, like three leaf masonry), can lead to complete crumbling.

Mode 1 (overturning), when the walls do react as solid blocks, but they open apart, rotating out of plane: this happens when the connections between the structural elements (walls, floor, roofs) are lacking. This is another very dangerous, brittle collapse type, also quite common.

Mode 2 (shear), when the first two cases are avoided. This last damage mode is less dangerous, as it develops dissipative effects in masonry and usually it leaves enough residual strength at least to stand the vertical actions.

\section{Modes and modeling}

An ideal model should be capable, once the characteristics of the materials (mortar, masonry, connectors, etc.) are inserted, to model all the three modes and to understand for which types or intensity of earthquake one mode will prevail over the others, or in which parts of the building each mode will occur. But it is not easy to find these parameters and it is not easy to model the effects of past events [2].

Therefore it is often more useful to consider these damage modes separately. It is better to have simple models focused on a specific problem than to try to understand everything with one single complicated model, much more difficult to be validated. The problems must first be identified by experts and only after they can be quantified by computers.

Taking into account the different collapse modes, these

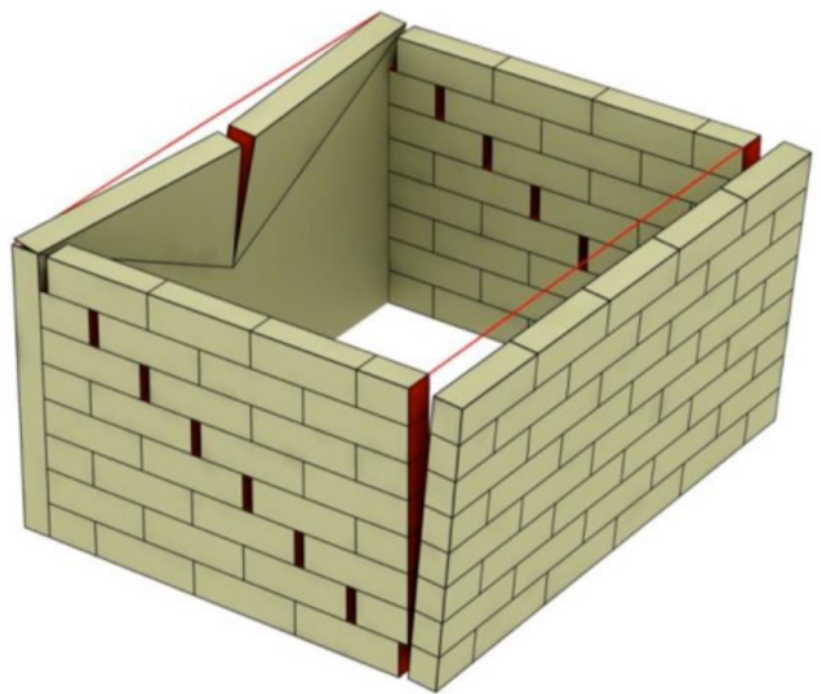

Figure 1: Mode 1 (overturning) and Mode 2 (shear) mechanisms in a simple masonry building. can be modeled in different ways:

Mode 0 (crumbling) cannot be modeled theoretically: it can only be inspected with on-site tests on materials.

Mode 1 (overturning) is easy to model, with cinematic approaches, once the sub-division of the whole building in single macro-elements has been made. But to identify these macro-elements it is necessary to inspect on site the possible material damages, the effect of past events, the building phases, the technical details. 
Mode 2 (shear) behavior can be quite easily followed by numerical modeling, as it considers a global behavior of the building, but this type of modeling really represents the structure only once the first two modes are excluded.

\section{Modeling and codes}

The most recent Italian law for the seismic protection of historic masonry buildings [3] warns against the uncritical use of numerical models, while it revalues the empirical approach, based on the deep direct knowledge of the building and of its history.

Simple modeling, but with a close contact with the reality of things, with the details, with history, with experience are considered more reliable than complicated modeling, whose parameters are often hard to find. This last route can be achieved only for very important buildings, but always in a mutual relationship with the direct knowledge of the building itself, which represents a real scale, real time experiment, whose results need to be correctly interpreted by the model.

\section{Codes and history}

To avoid the most common and most dangerous collapses, the codes concentrate in particular on «mode 1» mechanisms. In particular, for churches, it states that their behavior is characterized by the presence of macroelements, whose out-of-plane behavior can be then evaluated with simple yet effective models.
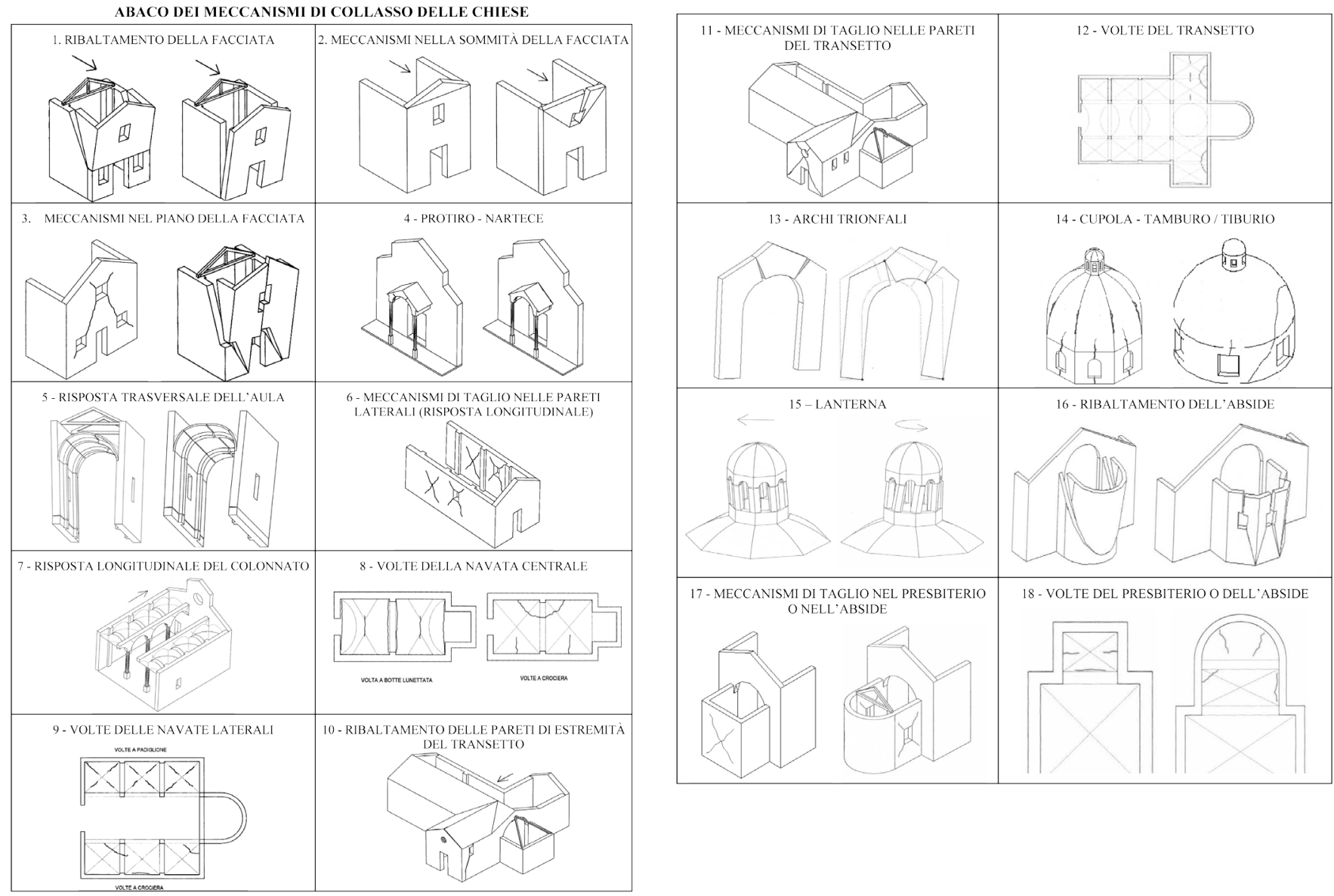

Figure 2: The collapse modes for churches depicted in the most recent Italian law for the seismic protection of historic masonry buildings. 
These typical collapse mechanisms shown by the 2011 codes are very similar to the ones depicted by the $18^{\text {th }}$ and $19^{\text {th }}$ century manuals: it is not a surrender or a step backwards, it is a revolution for applied engineering, a step forward to reconnect the centuries old experience with the modern knowledge.

\section{Learning from recent history}

The 2012 Emilia earthquake have highlighted some issues which are usually neglected by modeling, thus demonstrating how difficult and sometimes pretentious it is to try to reproduce through a numerical model every single aspect of the seismic reaction of ancient buildings to earthquakes.

In particular, the effects which have been observed are:

High vertical acceleration (up to $0.9 \mathrm{~g}$ ), in the densely populated area near to the epicenter: this lead the structures to "jump", reducing the frictional contribution (particularly at the supports) and the shear strength; moreover, resonance effects for horizontal structures like beams and trusses were probably induced [4].

Cumulative effects: the seismic sequence was characterized by two main shocks, at 9 days distance; many buildings were damaged by the first shake and collapsed under the second one.

Delayed effects: some buildings showed a significant increase in damage even months after the main shocks, maybe due to creep phenomena or crack propagation.

In conclusion, I believe that empiricism must once again become the basis for the structural analysis of historical constructions, but on this ancient basis nowadays new, powerful instruments can be applied to reach unprecedented results.

\section{References}

[1] A. Giuffré, "Seismic damage in historic town centres and attenuation criteria", Annali di Geofisica, Vol. XXXVIII, n. 5-6, Nov-Dec 1995.

[2] P. Roca, M. Cervera, G. Gariup, L. Pelà, "Structural Analysis of Masonry Historical Constructions. Classical and advanced approaches", Arch. Comput. Mathods Eng., (2010) 17:299-325.

[3] Direttiva del Presidente del Consiglio dei Ministri 9 febbraio 2011 - "Valutazione e riduzione del rischio sismico del patrimonio culturale con riferimento alle Norme tecniche per le costruzioni di cui al decreto del Ministero delle infrastrutture e dei trasporti del 14 gennaio 2008" (supplemento ordinario n. 54 alla Gazzetta Ufficiale n.47 del 26 febbraio 2011).

[4] P. Carydis, C. Castiglioni, E. Lekkas, I. Kostaki, N. Lebesis, A. Drei, “The Emilia Romagna, May 2012 earthquake sequence. The influence of the vertical earthquake component and related geoscientific and engineering aspects", Ingegneria Sismica, Anno XXIX - N. 2-3 - aprile-settembre 2012. 


\section{State of the Art in Numerical Modeling of Masonry Structures}

\section{Michele Betti and Gianni Bartoli}

\section{Department of Civil and Environmental Engineering (DICeA), University of Florence}

In recent years the structure research group of the Department of Civil and Environmental Engineering (DICeA) has analyzed the structural behavior of several historic masonry buildings in Tuscany, Italy. The research activities, depending on the specific case study, involved both experimental and numerical components according to a cross validation approach. Focusing the attention on the numerical activities, following numerical models were developed:

Brunelleschi's Dome (Florence). Numerical model built with the commercial F.E. code ANSYS. The final 3D identified model consisted of 82,492 nodes, 60,572 3D solid45 elements, 1,503 1D contact52 elements and 1,503 1D link10 elements corresponding to 241,635 degrees of freedom (DOFs).

Baptistery of San Giovanni (Florence). Numerical model built with both the commercial code ANSYS and the OpenSource F.E. software CODE ASTER. The final 3D ANSYS model consisted of 49,101 joints, 27,752 3D solid eight-nodes elements (main masonry walls), 9,444 shell four-nodes elements (pyramidal covering) and 14 1D beam two-nodes (internal columns), corresponding to 17,3505 DOFs Error!

\section{Reference source not found.}

Prince's Chapel (Florence). Numerical model built with ANSYS. The final 3D model consisted of 107,689 joints, 85,771 3D Solid45 elements, corresponding to 220,332 DOFs.

Basilica of Santa Maria all'Impruneta (Firenze). Numerical model built with the commercial code ANSYS. The final 3D numerical model consists of 27,779 nodes, 76,895 3D Solid45 elements, 1,751 2D Shell63 elements and 547 1D Beam44 elements, that correspond to 81,021 DOFs.

Cathedral of Siena (Siena). Numerical model built with the commercial F.E. code ANSYS starting from reduced and simplified to global and refined geometry of the fabrica. First Model (inner and outer masonry layers of the dome). The model consisted of 9,154 joints, 9,148 two dimensional finite elements (inner and outer shells, and lantern), 40 1D elements (stone trusses) corresponding to 26,883 DOFs. Second Model (dome and tambour). The model consisted of 25,723 joints, 69,695 three-dimensional elements (upper tambour), 9,455 two-dimensional elements (inner and outer cupola, lantern and main ribs), 136 $1 \mathrm{D}$ elements (40 stone trusses and 96 double columns), corresponding to 235,689 DOFs. Third Model (entire Cathedral). The model consisted of 170,496 joints and 343,747 finite elements, corresponding to $1,015,098$ DOFs.

Torre del Mangia (Siena). Numerical model built with the commercial F.E. code ANSYS. The final 3D identified model consisted of 33,691 joints, 69,647 3D solid eight-node elements (main masonry walls), corresponding to 992,243 degrees of freedom.

Torre Grossa (Siena). Numerical model built with ANSYS. The final model was built by means of solid45 elements (eight node isoparametric linear elastic elements) and it consisted of 24,730 joints, 22,417 3D solid45 elements, corresponding to $72,350 \mathrm{DOFs}$.

Palazzo Bourbon Del Monte (Siena). Numerical model built with both the commercial code SAP2000 and the OpenSource F.E. software CODE ASTER. The final 3D ANSYS model consisted of 16,210 shell elements, 832 spring elements and 16,486 joints.

Castel S. Niccolò (Arezzo). Numerical model built with ANSYS. The final 3D model consisted of 20,757 joints and 14,114 elements (solid65 and combin14) corresponding to 55,854 DOFs. 
To reproduce the non-linear behaviour of masonry it is possible to adopt a smeared crack approach. According to this technique (and in case of the F.E. code ANSYS) the Drucker-Prager plasticity criterion is usually employed and combined with the Willam-Warnke failure surface to account for the crushing and cracking phenomena. The material behaviour of masonry is then modelled as an isotropic medium with plastic deformation, cracking and crushing capabilities. This approach requires the evaluation of several parameters that, without a specific experimental investigation, should introduce uncertainties on the results of the analyses. Taking into account the difficulties in developing proper investigations on material properties on a monumental building a discrete crack modelling was adopted and preferred over a smeared crack approach (almost all data derived from in-situ tests allow information on the elastic material properties, without the input required for a proper definition of a smeared crack modeling).
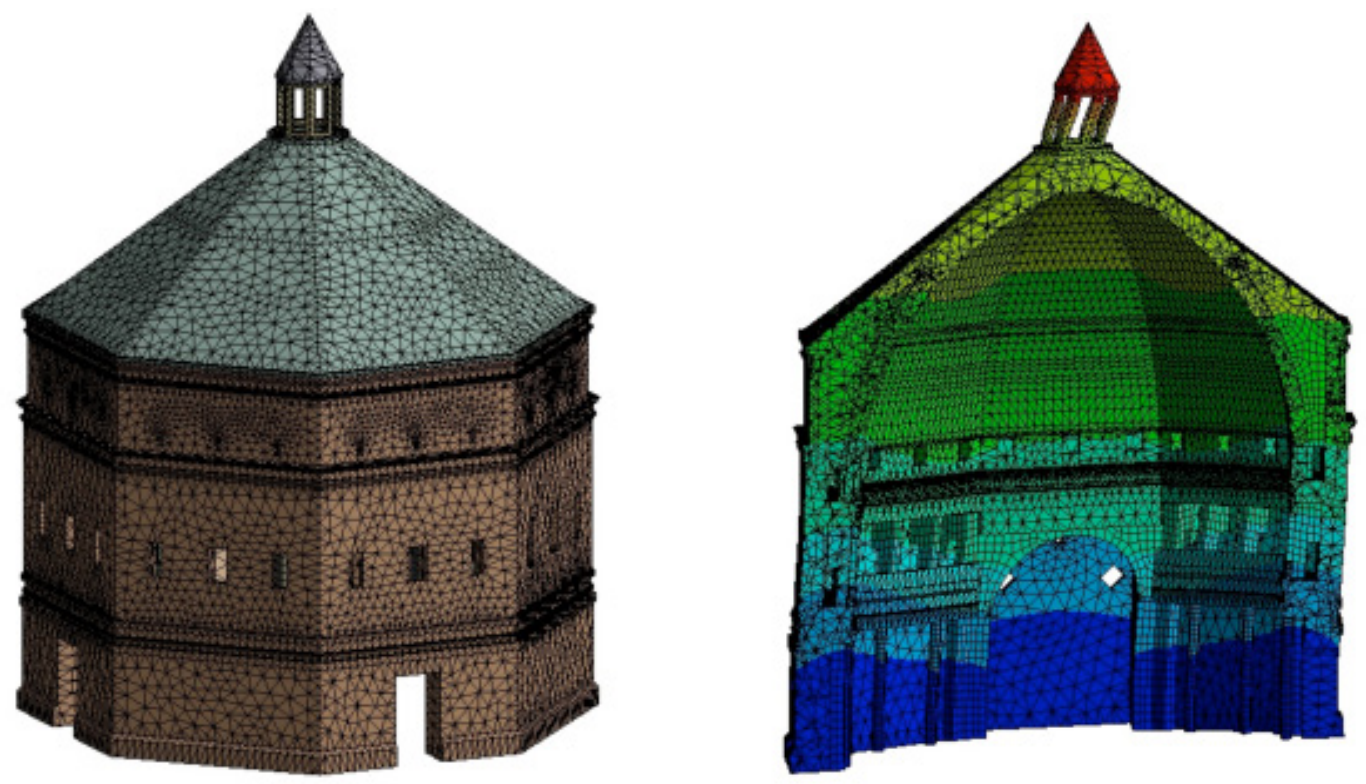

Figure 1. Numerical models of the Baptistery: left) mesh; right) first mode shape displacements.

The analysis of the structural behaviour of a monumental building under exceptional load like the seismic one requires an interaction (and comparison of results) between several modelling strategies (including simplified limit analysis). Moreover combination of results of numerical nonlinear models (and simplified modelling strategies) with the data obtained from long-term monitoring make possible an insight into the structural performance of the structure and to formulate proper strategies for its structural preservation. In numerical modelling of historic building several points should be taken into account, among them: a) Historic Masonry building are conceived mainly to withstand vertical loads (through geometrical rules); b) The values of stresses are often quite close of ultimate compression of the constituting masonry material; c) The complex geometry, the irregularities and the high degree of inhomogeneity and stress concentrations can promoting local collapses; d) Despite inhomogeneity it seemed acceptable to assume masonry as an isotropic material under horizontal and vertical axial loads, due to the influence of the disordered material that characterize the texture; e) Damage evolution during a dynamic excitation plays a crucial role in reducing the resisting geometry of the structure, thus activating higher vibration modes; f) Modelling the non-symmetry in tension and compression that characterizes the masonry material is of paramount importance: (1) Tension: the strength is very low, the response is brittle, and an early mechanical degradation is observed, without significant energy dissipation under cyclic loading (usually the tensile behaviour is rather fragile along the vertical axis and more ductile along the horizontal axis); (2) Compression: the material exhibits its maximum bearing capacity with a limited ductility and a progressive mechanical degradation once the peak value of strength is reached (the energy dissipation is essentially related 


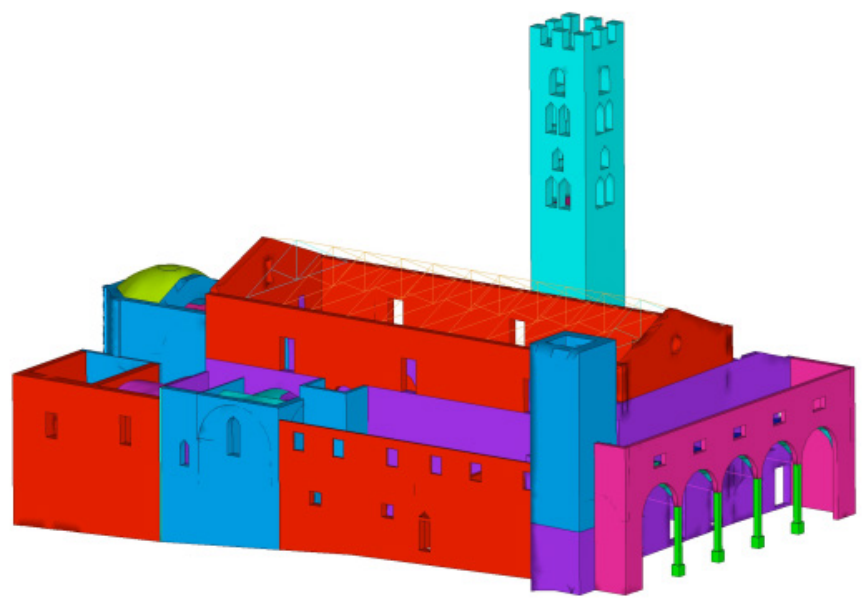

Figure 2. Numerical models of the Basilica of Santa Maria all'Impruneta.

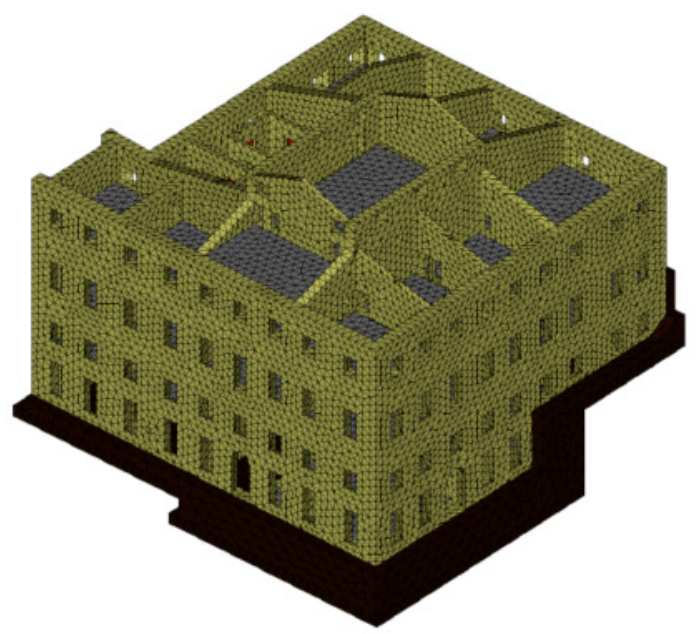

Figure 3. Numerical models of of Palazzo Bourbon Del Monte.

to the progressive crushing); g) When dealing with dynamic non-linear analyses, a softening model with damage is required to properly describe the dissipation of the seismic energy through repeated cycles of inelastic deformation; h) Constitutive laws must be able to reproduce the distinctive aspects of the masonry material in the inelastic range: (1) very low tensile strength; (2) significant post-elastic orthotropy plus effects related to specific masonry textures; (3) different rules for post-elastic axial and shear damage; (4) different dependence of the shear strength on the vertical and horizontal axial stress components; (5) hysteretic energy dissipation due to cyclic loading; i) Soil-structure interaction is topical (especially in the dynamic range) : large scale sensitivity analyses should be carried out on each case study to have a better insight into the structural response when increasing portions of interacting soil are considered.

\section{References}

[1] Bartoli G., Betti M. 2013. Cappella dei Principi in Firenze, Italy. Experimental Analyses and Numerical Modelling for the Investigation of a Local Failure. ASCE's Journal of Performance of Constructed Facilities, 27(1): 4-26.

[2] Bartoli G., Betti M., Facchini L., Orlando M. 2012. Non-destructive characterization of stone columns by dynamic test: Application to the lower colonnade of the Dome of the Siena Cathedral. Engineering Structures, 45: 519-535.

[3] Fratini M., Pieraccini M., Betti M., Bartoli G., Atzeni C. 2011. Assessment of vibration reduction on the Baptistery of San Giovanni in Florence (Italy) after vehicular traffic block. Journal of Cultural Heritage, 12(3): 323-328.

[4] Betti M., Vignoli A. 2011. Numerical Assessment of the Static and Seismic Behaviour of the Basilica of Santa Maria all'Impruneta (Italy). Construction and Building Materials, 25(12): 4308-4324.

[5] Betti M., Orlando M., Vignoli A. 2011. Static Behaviour of an Italian Medieval Castle: Damage Assessment by Numerical Modelling. Computers and Structures, 89(21-22): 1956-1970.

[6] Betti M., Bartoli G., Orlando M. 2010. Evaluation study on structural fault of a Renaissance Italian Palace. Engineering Structures, 32(7): 1801-1813.

[7] Betti M., Vignoli A. 2008. Modelling and analysis of a Romanesque church under earthquake loading: assessment of seismic resistance. Engineering Structures, 30(2): 352-367. 


\section{The Numerical Analyses of Santa Maria del Fiore Dome: State of the Art}

\section{Gianni Bartoli and Michele Betti}

\section{Department of Civil and Environmental Engineering (DICeA), University of Florence}

Since early nineties, several attempts have been made to explain the cause of the complex crack pattern present on the Brunelleschi's Dome in Florence. Some very first numerical model were developed in 1980 at ENEL-CRIS (ENEL is the Italian National Agency for Electric Power, while CRIS is the Italian acronym for Structural and Hydraulic Research Centre) by a group of researcher leaded by Michele Fanelli and Gabriella Giuseppetti and in cooperation with the Department of Civil Engineering of the University of Florence, under the supervision of Prof. Andrea Chiarugi. Due to symmetry reason and to limited computational resources, $1 / 4$ of the whole dome was modeled in the framework of a Finite Elements approach, by means of a software that was at that time used for the analysis of large dam structures. The analyses were performed on the undamaged structure, and they very clearly shown that main cracks appearance was essentially due to the action of the self-weight of the dome. The position of the cracks was explained by analyzing those areas where in the linear elastic model tensile stresses arose. Due to the cracks appearance, the behavior of the dome changed into a more complex one, as strong flexural stresses due to the presence of the bending moments were present. The model was also used to give a first explanation on the behavior of the dome under thermal loads. A different approach was used in 1994 by Chiarugi,
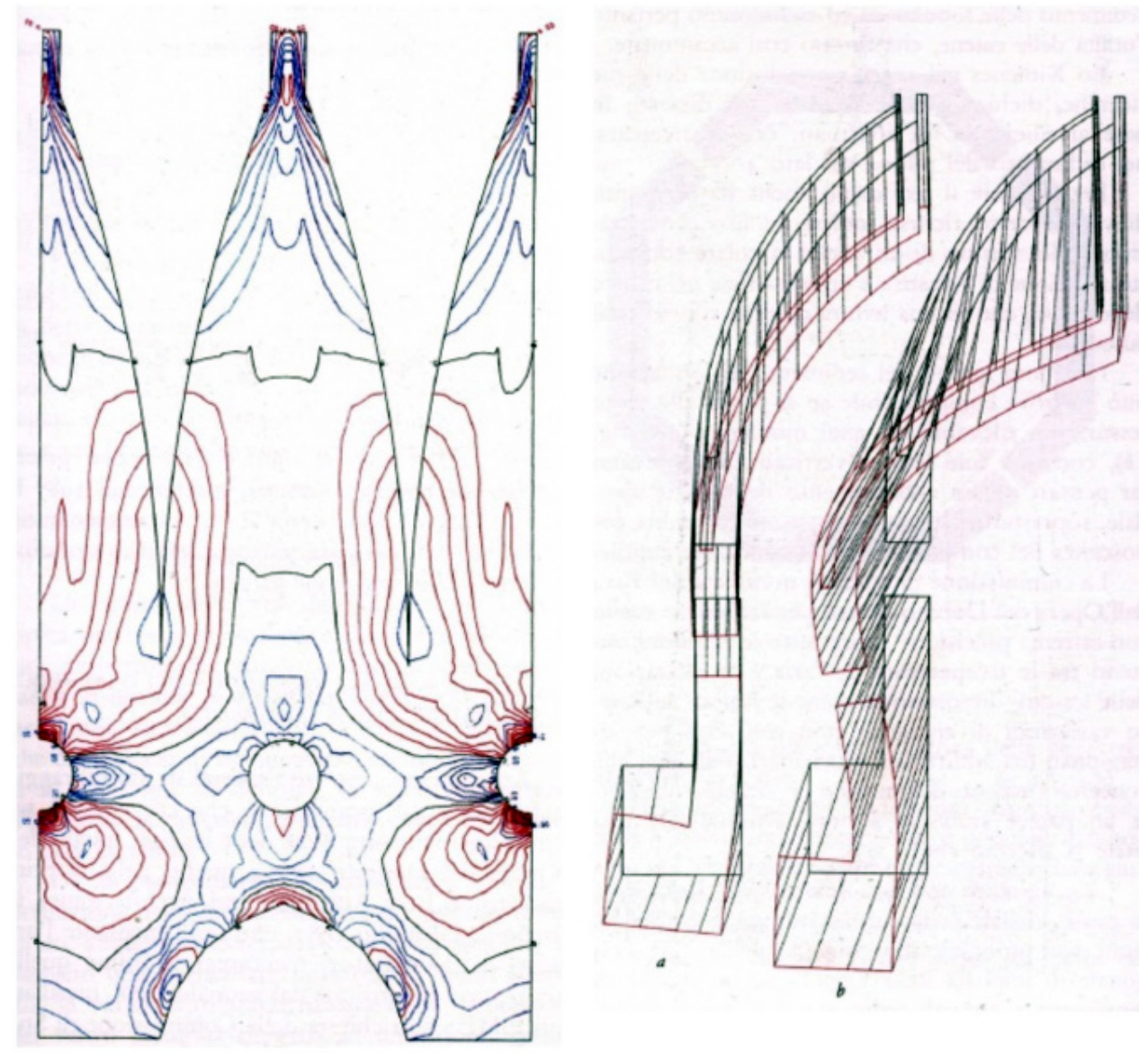

First numerical models of the dome: left) analysis of the horizontal stress distribution under self-weight; right) comparison of the deformed shape in the vertical plane between undamaged and damaged states. Chiarugi, A., Bartoli, G., Bavetta, F. 1995. 


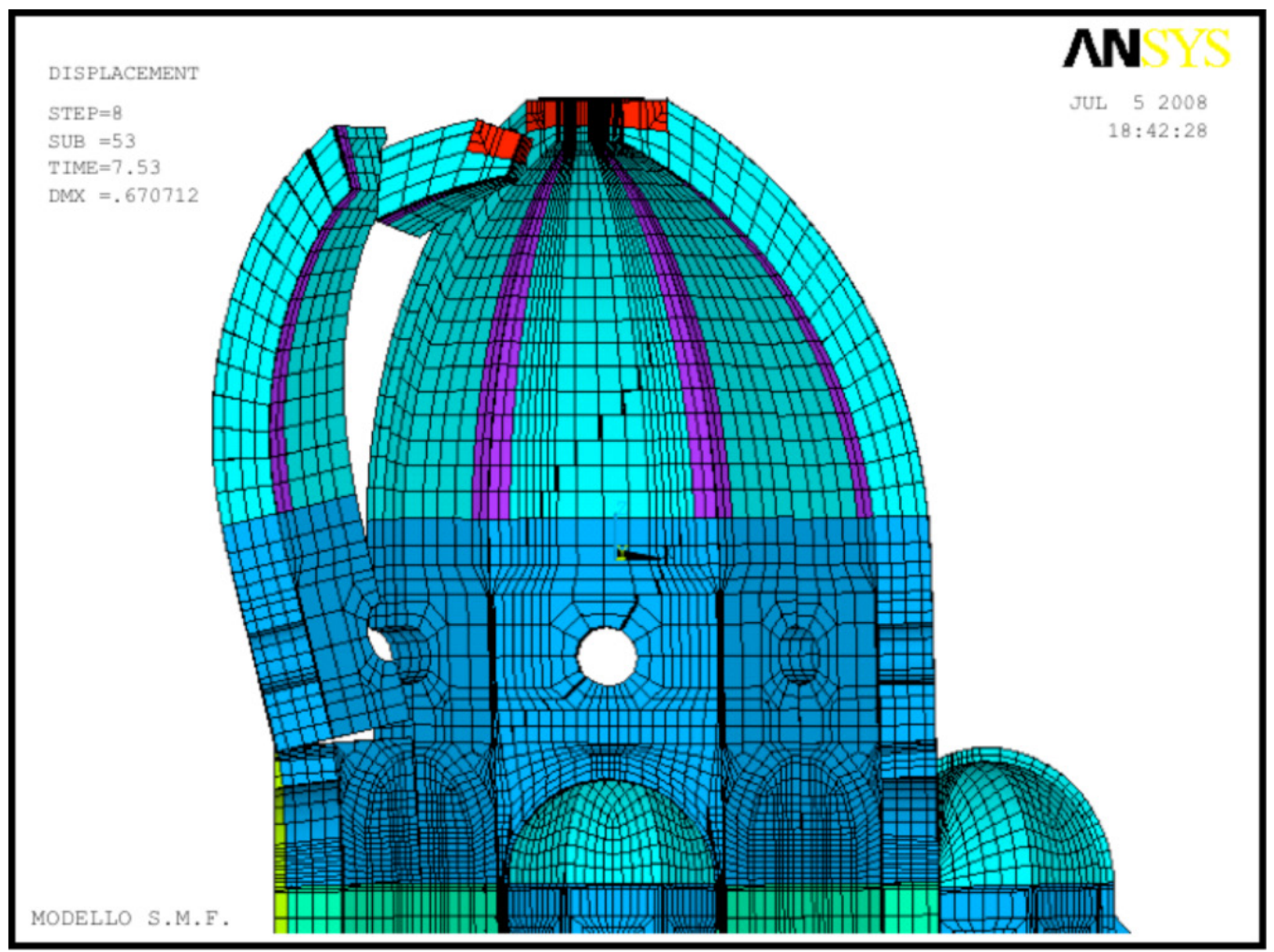

New numerical model of the dome: analysis of the collapse mechanism under increasing horizontal loads proportional to mass distribution.

Bartoli and Bavetta, as the dome was modeled by means of several plane elements able to reproduce the complex geometry of the cross section of the dome (two separate layers strongly connected by corner and side ribs); the model was used to confirm the self-weight as the main cause for the cracks appearance and to explain the non uniform behavior of the cracks' edge movements due to cyclic thermal loading. As a matter of fact, along the main cracks, at some points there is a closure of the cracks while at different levels the cracks is opening, under the same external difference of temperature. The model was able to reproduce the observed phenomenon, once more due to the different behavior of the "cracked" dome with respect to the theoretical undamaged one.

In 1992 an extensive Topographical and Photogrammetric Survey of the whole Dome was commissioned by the "Soprintendenza" (the local authority of the Cultural and Heritage Ministry which is in charge of the conservation of all the Monuments in Florence).

The results of the survey were then used to develop a quite complete finite elements model of the dome, with an improved geometry (refinements to consider the confining substructures of the dome). The model was built by using a commercial software (ANSYS); 3D elements (solid45) were used to model the whole structure, while gap elements (contact52 \& link10) were introduced in those areas where cracks appeared. The final 3D identified model consisted of as many as 241,635 DOFs. Linear elastic elements were used to take into account the soilstructure interaction, while the restraint offered by the main nave was reproduced with an elastic layer whose stiffness was evaluated according to the stiffness of the main nave.

On the model a succession of liner elastic analysis were performed. At each step of the analysis, the tensile stress state (in terms of main stresses) was checked; in those zone where the value exceeded a given threshold (fixed at $0.2 \mathrm{~N} / \mathrm{mm}^{2}$ ) some gap elements were introduced and the analysis was restarted. At the end of several iterations, no more excessive tensile stresses are present in the model, while gaps opened at those locations where cracks appeared. The final configuration was in a very good agreement with the known crack pattern. In order to have a 
reliable estimation of the presence and positioning of minor cracks, it was necessary to reproduce the succession of the stages during the erection of the monument. If the self-weight of the structure is applied "as a load" on the whole model, unrealistic stress distribution appeared, while a more reliable stress pattern appears when dead load are applied in the same way as the structure was built.

A further model identification was performed by using some results from an experimental survey executed in 1987, where the dynamic behavior was checked by measuring at 7 different locations the dynamic vibration induced by environmental loads (wind loads); during 24 hours recording it was possible to appreciate the different natural frequencies along the two main directions as well as the poor level of connection between the two main horizontal modes, then confirming that main cracks divide the dome into separate structures (in fact, due to the main cracks, the monument has no more a "dome" behavior but it is closer to four arches connected at both tambour and lantern levels).

As a final step of the analysis, on the identified model (where the elastic characteristics were tuned in order to reproduce the first modal frequencies), a horizontal load was applied to the model, as to simulate the effects of possible seismic loading on the monument. In the framework of a pushover analysis (incremental non-linear analysis) two systems of orthogonal forces (which are not acting simultaneously) lying in the horizontal plane were applied. Horizontal forces were distributed along the monument proportionally to masses, so as to reproduce the effect of a uniform horizontal acceleration. Analyses were performed with the same procedure described for the static loading, i.e. by checking the tensile main stress state and then introducing, when necessary, gap and link elements where stresses were too high. The way in which the dome can reach the collapse (at the final level of acceleration) can be used to identify the collapse mechanism and to estimate the vulnerability of the monument.

\section{References}

Chiarugi A., Fanelli M., Giuseppetti G. 1983. Analysis of a Brunelleschi-Type Dome Including Thermal

Loads. Proc. IABSE Symposium on Strengthening of Building Structure, Diagnosis and Therapy, Zurich, Swiss, pp. 169-178.

Chiarugi A., Fanelli M., Giuseppetti G. 1993. Diagnosis and strengthening of the Brunelleschi dome. Proc. IABSE Symposium on Structural preservation of the architectural heritage, Rome, Italy, pp. 441-448.

Chiarugi, A., Bartoli, G., Bavetta, F. 1995. Brunelleschi's Dome: Analysis of Deformations due to Thermal Loads. In Spatial Structures: Heritage, Present and Future, Proceedings of IASS International Symposium 1995 , Milano, Italy, pp. 1181-1188.

Bartoli, G., Betti, M., Borri, C. 2013. Numerical modelling of the structural behaviour of the Brunelleschi's Dome of Santa Maria del Fiore, International Journal of Architectural Heritage (in review). 


\title{
Multiscale Homogenization for Masonry Mesostructure
}

\author{
${ }^{1}$ D.J. Luscher, ${ }^{2}$ David L. McDowell, ${ }^{1}$ Curt A. Bronkhorst
}

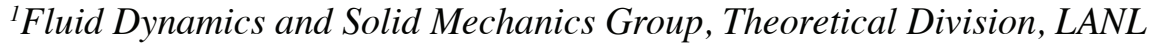
${ }^{2}$ G.W. Woodruff School of Mechanical Engineering, Georgia Institute of Technology

All materials are heterogeneous at various scales of observation. While material heterogeneities are interesting in and of themselves, it is ultimately through their influence on non-uniform response and microstructure evolution that they have profound impact on continuum thermomechanical response at macroscopic "engineering" scales. That many materials can be treated as homogeneous continua owes to the distinct separation of the scale of the problem under consideration and the scales at which actual heterogeneities affect physical processes. These physical processes include various sources of inelastic behavior such as nucleation and growth of cracks, and frictional slip, to name a few. Historical approaches to model such processes that reflect an intimate coupling of physical scales consist of phenomenological constitutive relations that are developed either empirically or by analytical micromechanics and subsequently fit to experiment. A potential shortcoming of such approaches is that the developed models may not accurately reflect the physical processes occurring at various scales and, in some cases, are little more than highly nonlinear curve fits to limited sets of data. In order to more accurately predict the thermomechanical response of materials as their microstructure evolves, it is necessary to treat this behavior as a multiscale process thus integrating the physical understanding of material behavior at various physical (length and time) scales.

Explosive growth in computational power coupled with innovation in numerical modeling has enabled detailed modeling efforts to explore and quantify the thermomechanical response of materials across a multitude of physical scales for a variety of inelastic processes. Multiscale modeling has inspired a new vision of being able to develop constitutive models for use at physical scales common to engineering problems using detailed information developed from a hierarchy of models at finer scales. Recent advances have been made in this area with emphasis on simultaneously linking numerical models of processes occurring at each scale. Such approaches offer advantages in avoiding constitutive complexity and reducing uncertainty at engineering scales at the cost of tremendous computational burden when compared to historical phenomenological engineering-scale models.

An alternative approach is to build constitutive models from successive homogenization of modeling conducted at other scales in a hierarchical fashion. This approach results in constitutive models at the largest scales that reflect the complexities of processes at finer scales in some homogenized sense without the need to conduct simulations at all scales simultaneously. However, in order to build the heterogeneous response of materials into computational models for use at engineering scales, for example in finite element simulations of system response, numerical modeling conducted at each scale must be arranged in a formal hierarchy such that fundamental quantities of the physical laws governing each scale are preserved across scale transitions. In fact, many recent advances made both in concurrent scale linking and hierarchical transitions in scale are lacking in their formality and rigor when accounting for physical quantities that enter balance laws at separate scales. Additionally, heterogeneous response of materials is inherently nonlocal; this nonlocal nature of multiscale response should be reflected in such a hierarchical homogenization scheme.

At the core of this framework is a set of principles which enforces kinematic consistency and scale invariance of mass, momentum, and energy. Thermodynamics of irreversible processes, in particular Internal State Variable (ISV) theory, is employed to ensure common representation of free energy and dissipation at all scales within a hierarchy. A second order Taylor series kinematic decomposition is employed at the coarse scale resulting in a nonlocal second gradient continuum description of the coarse scale material response. This aspect of the framework introduces an implicit material length scale associated with the dominant length scale of material response. The critical aspect of this framework is the selection of physically meaningful ISVs and the associated constitutive description of their irreversible evolution. 
It is envisioned this nonlocal multiscale homogenization framework can be applied to the material and structural hierarchy building in scale from brick and mortar to composite masonry, and ultimately, the engineeringscale response of the Cupola di Santa Maria del Fiore in a manner depicted by Figure 1. The crucial aspects of continued research and development to enable the application of this multiscale framework are (1) identification of an appropriate set of internal state variables (e.g., characteristics of cracks and slip deformation) and (2) identification from mesoscale simulations of the kinetical relationships governing ISV evolution.

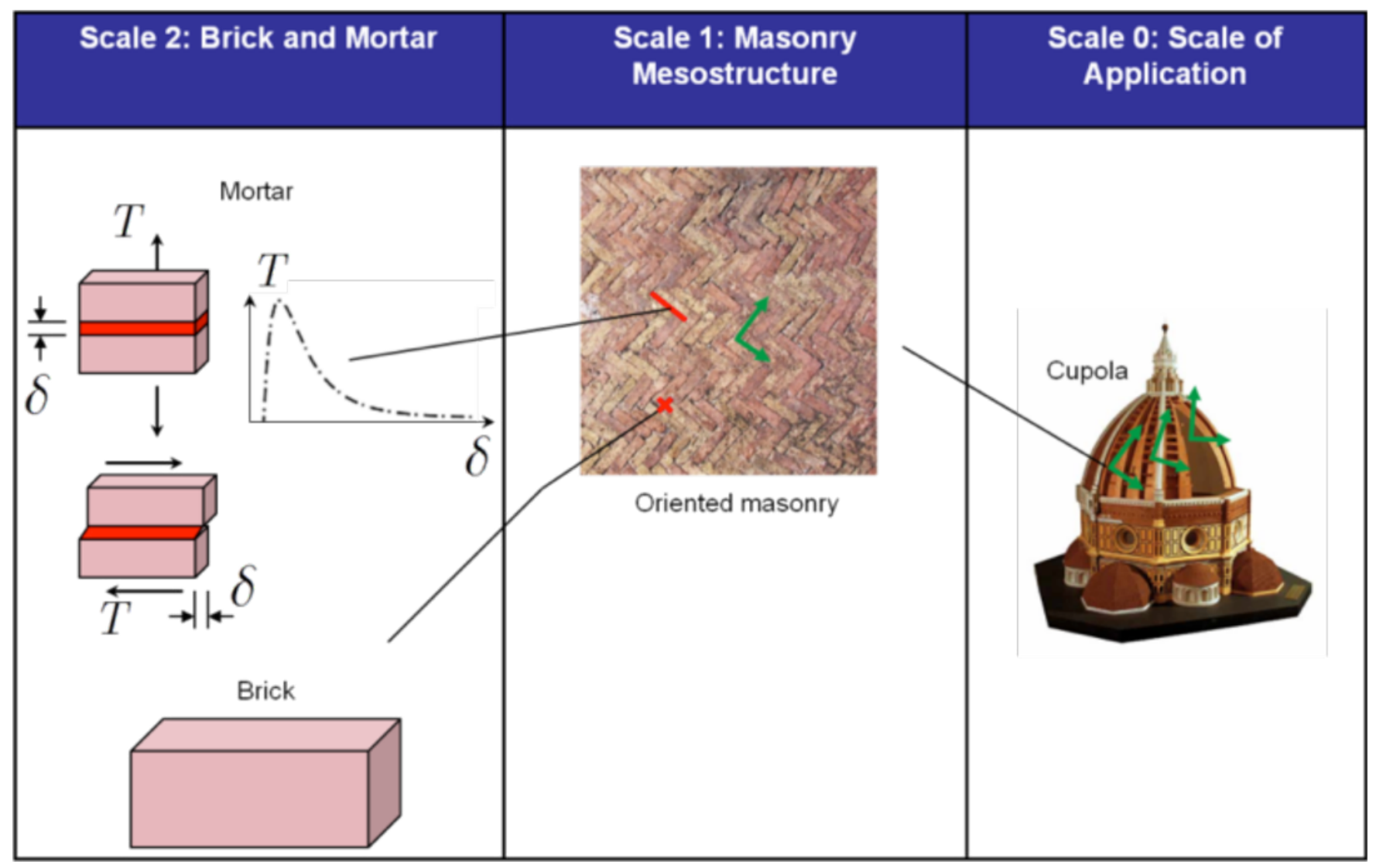

Figure 1. Depiction of multiscale hierarchy for Cupola di Santa Maria del Fiore. 


\title{
Fracture Model for Masonry and other Frictional Materials
}

\author{
Alek Zubelewicz \\ Theoretical Division, Los Alamos National Laboratory, \\ Los Alamos, New Mexico
}

\section{Introduction}

The commonly used phenomenological constitutive models rely on a long-term trial-and-error approach, which led to the development of physically and numerically robust material descriptions. The phenomenology means that the models are "good" in the domain already verified by experiment. Quite often though, extrapolation of the models into the regimes not tested can be troublesome. For instance, these models don't generally account for specific mechanisms of frictional deformation in comprehension and shear. Geomaterials and manmade materials seem to provide an example for such difficulties. In masonry, we observe complex fracture mostly in the area of mortar but some cracks are splitting bricks. Also, the frictional deformation is dominant in the mortar, where the strain rate and, possibly, humidity play important role. We break the phenomenology and, instead, construct a mechanisms-based model that includes the frictional deformation mechanisms, while capturing fracture in masonry.

\section{Mechanisms-based approach}

We adapt our earlier results [1] and construct the mechanisms-based visco-plasticity model with built-in fracture in the framework of a tensor representation theory [2]. First, physics-based insight dictates the selection of relevant mechanisms of inelastic deformation, in here due to plasticity and twinning. Next, the magnitudes of the plastic flow and twinning are determined in terms of appropriate invariant strain rates. In our description, we enforce the principle of objectivity and, from there we derive equivalent (invariant) stresses compatible with plastic deformation and twinning. We emphasize that the invariant measures are derived and not assumed. In our model, the equivalent stresses are coupled with the equivalent strain rates. Also, we include the contribution of the dynamic overstress, which plays a role when the rate of the energy redistribution and frictional dissipation is slower from the rate the energy that is pumped into the material. This phenomenon is likely to occur during an earthquake. Again, the formula for the overstress is derived and is based on thermodynamics considerations [3]. Thus, the rules of frictional flow along with the rate dependent constitutive relations and, lastly, the dynamic overstress, complete the description of the inelastic behavior of geomaterials. The visco-plasticity model has unique features, among which is the ability to capture the brittle fracture in an elastically isotropic material and strain rate contribution is projected from quasi-static up to extreme conditions.

\section{Brittle fracture}

A frequent assumption is that brittle fracture arises from a set of non-interacting penny-shaped micro-cracks randomly distributed in an otherwise homogeneous material [4]. Since the crack opening strain is collected from the individual micro-cracks, these descriptions are suitable for predicting the material's responses at early stages of the damage process. The cracks are characterized in terms of the crack surface area, while their orientations are defined in terms of stresses. One open issue in brittle materials is that these models predict an unlimited strength under bi-axial compression. This prediction seems unrealistic and, in fact, experimental observations gathered for various brittle materials provide arguments to the contrary $[5,6]$. The penny-shape crack approach has been further extended in Ref. 7 but the previously mentioned concern of the non-interacting micro-cracks remains unsolved. In these constitutive models, fracture processes are built into the constitutive description by degrading either the material's strength or elastic constants such as shear modulus. 
Introduction of the micro-plane model [8] marks a significant progress in the understanding of the behavior of brittle/frictional materials. The model predicts the damage initiation and progressive growth and it captures fracture mechanisms occurring within a representative volume element (RVE) [9]. However, the introduction of RVE is a troublesome assumption, especially when considering an advanced stage of the post-critical behavior. The RVE homogenization technique fails at conditions where the cracks break up the volume. Also, the microplane model is quite complex and may present a challenge when applied to a large-scale numerical analysis. A relatively simpler model based on an analogous idea is proposed in Ref. 1. In this description, the fracture processes are monitored in terms of stress tractions along the dominant load directions, while the stresses are acting on the crack opening displacements. As in many other cases, the fracture planes are co-rotational with principal stresses and, therefore, this model produces fracture that is stress-co-rotational, thus isotropic. Despite this deficiency, the model is strong in its simplicity and surprisingly good predictability.

In geomaterials and also manmade frictional materials, fracture is often assumed to follow the Mode I mechanism. However, it has been long known that other brittle fracture mechanism is present in compression converting the material into rubble.

\section{References}

A. Zubelewicz, A. and Z.P. Bazant, ASCE J. Eng. Mech. 113, 398 (1987).

A. Zubelewicz, J. Mech. Phys. Solids, 41, 1711 (1993).

A. Zubelewicz, Phys. Rev. B, 77, 214111 (2008).

Q.H. Zuo and J.K. Dienes, Int. J. Solids Struct., 42, 1309 (2005).

J.-C. Maso and J. Lerau, Int. J. Rock Mech. Min. Sci. and Geomech. Abstr. 17, 109 (1980).

C. Ehm and U. Schneider, Cement and Concrete Research, 15, 27 (1985).

Q.H.Zuo, F.L. Addessio, J.K. Dienes, and M.W. Lewis, Int. J. Solids Structures, 43, 3350 (2006).

Z.P. Bazant and J. Ozbolt, ASCE J. Eng. Mech., 116, 2485 (1990).

M. Ostoja-Starzewski, Microstructural Randomness and Scaling in Mechanics of Materials, (Chapman \& Hall/ CRC Press) (2008). 


\title{
Analyzing and Modeling the Response of Historical Monuments: Open Issues
}

\author{
Gianni Bartoli and Michele Betti
}

Department of Civil and Environmental Engineering (DICeA), University of Florence

Apart from all the modeling problems related to the numerical analysis of historical masonry monuments, there are some additional unresolved issues which can be addressed.

\section{Modeling of temperature changes considering both spatial (thermal gradients through wall) and temporal fluctuations}

By the monitoring of large structures, different recorded data can be related among them, such as temperature and cracks width variation. One of the major problems is to find a suitable modeling of the temperature distribution over the whole monument and along the thicknesses of its elements. Monitoring systems give us the temporal evolution of temperature at some specific locations, while a "continuous" temperature pattern should be used as a loading condition for a numerical model in order to be able to reproduce the evolution on the amplitude of cracks during time. Some general tendencies can be extracted from data analysis (such as correlations among temperature at different locations, time-shifts in time evolution of the phenomenon due to thermal inertial effects, and so on), but a suitable way of modeling temperature input is not yet available. From data analysis of temperature along Santa Maria del Fiore Dome, it was observed that temperature distribution on the masonry was almost perfectly correlated along both meridian and parallel directions, but there was a certain loss of correlation along the radial direction (this means that there is a time delay between the temperature distributions at different layers within the thickness of the structure): moreover, there is of course a "general" (obvious) time-shift between temperature of the internal air volume and temperatures along the masonry, this causing a time-shift between displacements of the cracks' edges and temperatures (Bartoli et al., 1996). So, generally speaking, if the behavior of the structure under thermal loads has to be reproduced, a simple "uniform" (in both space and time) temperature distribution (even if a certain gradient can be assumed along the thickness to account for difference between external and internal air temperatures) is not able to give suitable results when applied to a Finite Element Model (FEM) of the structures. A mixed non-stationary thermodynamic (heat transfer) and structural FE model should better reproduce the observed phenomena.

Moreover, if such a model could be built, this could be used also in the framework of a Structural Health Monitoring (SHM) procedure: information from synchronous recordings of both temperatures and other static quantities (such as cracks' width variations) could be utilized for both controlling the logged data and tuning the characteristics of the model, then allowing a certain control on possible structural damaging evolution.

\section{Creep and thermal "fatigue"}

Long-term phenomena leading to progress deterioration during historical periods must be accounted for in order to understand the actually existing damage.

The effect of creep under long term constant stress may induce significant, cumulative damage in rock-like materials. It has been measured that accumulation of damage (eventually leading to collapse) may occur for stress values significantly lower than the normal strength obtained by standard monotonic compression tests (such phenomena could start at $40 \%-50 \%$ of the normal strength value).

In several cases, large existing deformations in monuments can only be explained by historical processes developed in the term of several centuries, and, besides the possible creep, the effect due of the thermal cycles experienced in such a long term could be even more important. As a matter of fact, a very small remaining increment produced after each cycle might well justify, for accumulation, the current deformational condition (Roca, 2001). 
From an experimental point of view an extensive experimental campaign started after the Pavia Civic Tower collapse in 1989 has highlighted that if the development of a secondary creep can start at $40 \%$ of the estimated material peak stress, a possible tertiary creep starts at about $70 \%$ of this value. Moreover, crack propagates and failure develops in a relatively long time, then the evolution of cracks (especially vertical ones) should be carefully analysed as the possibility of continuous damage with the consequence of a future sudden collapse cannot be a priori ruled out (Anzani et al., 2000-2010).

Other analyses showed that several aspects (such as moisture diffusion and carbonation) can evolve during a long period of time, in the order of magnitude of some centuries, and then mechanical characteristics could be strongly time-dependent (Ferretti et al., 2006a-2006b)

Then the needing of both definition and/or tuning of mechanical models to represent the long-term evolution of these phenomena is evident from experimental results. From one side, it should be studied if reinforced concrete (RC) creep models are suitable for describing the long-term behaviour of masonry, and how the necessary parameters can be tuned from experimental data. From another side, it could be interesting to understand whether or not a sort of "thermal fatigue" could be present in historical masonries.

If such models were available, it could then be possible to explain if a certain rate of increasing width on existing cracks (i.e. 5.5 or $7.0 \mathrm{~mm} /$ century as observed in the Santa Maria del Fiore Dome) is admissible for the monument and which is the threshold over which some interventions have to be planned.

\section{Dependence of natural frequencies from temperature, humidity, and damage}

Modal parameters are often sensitive to changing environmental conditions such as temperature and humidity. While dependence on damage is being investigated by several authors, dependence on environmental conditions is observed but not yet modeled.
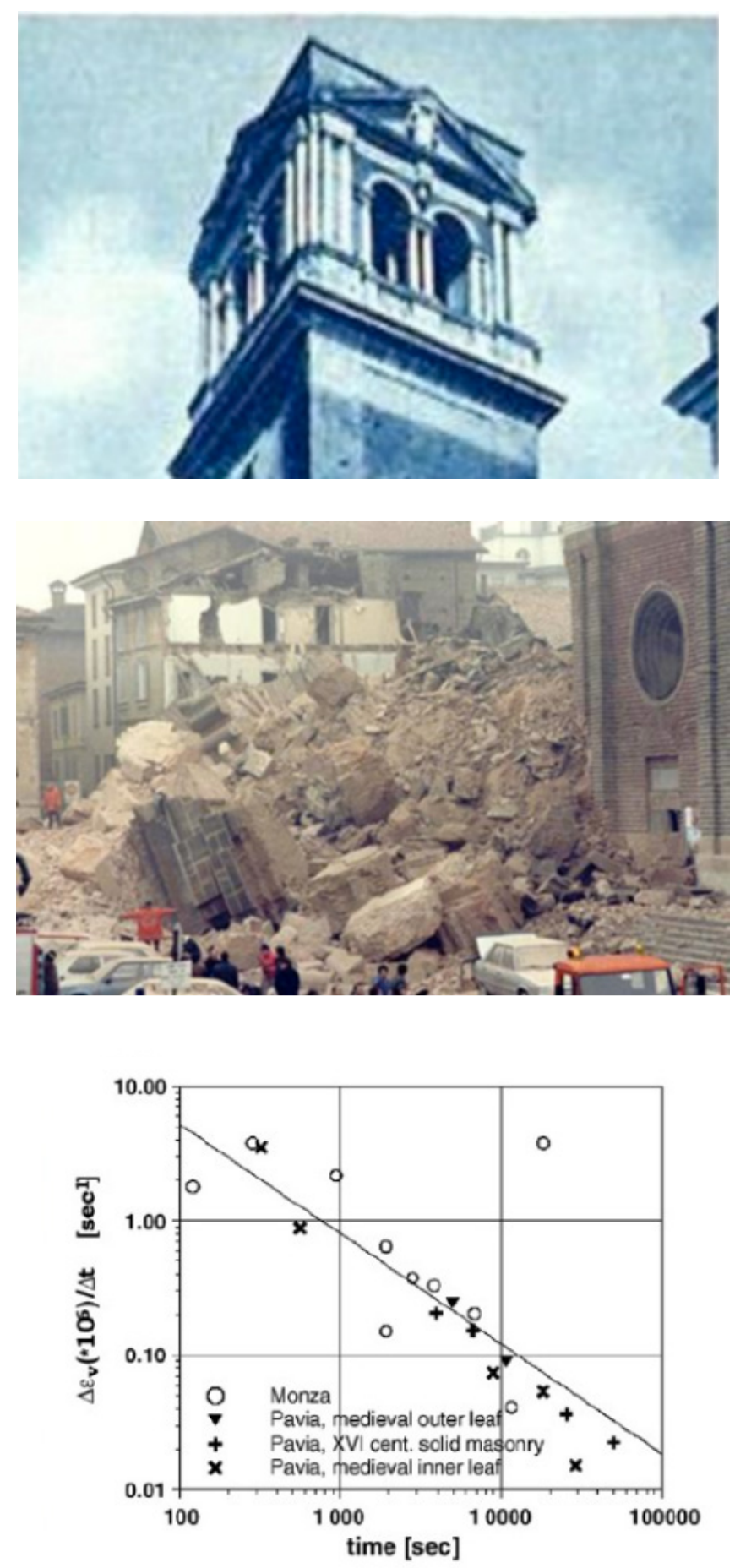

Civic Tower of Pavia: the structure before the collapse (top); the collapsed structure (middle); (bottom) results obtained from some pseudo-creep tests (strain rate vs. total time of last load step). (From Anzani et al., 2010) 
In some reference cases it has been observed that (Ramos et al., 2010):

- frequencies increase for increasing temperatures (up to $0.1-0.2 \mathrm{~Hz}$ every $20^{\circ} \mathrm{C}$ )

- frequencies decrease for increasing humidity (about $0.05 \mathrm{~Hz}$ every 50\%)

Also in this case, research is needed for the definition of a suitable physical model able to explain such tendency.

a

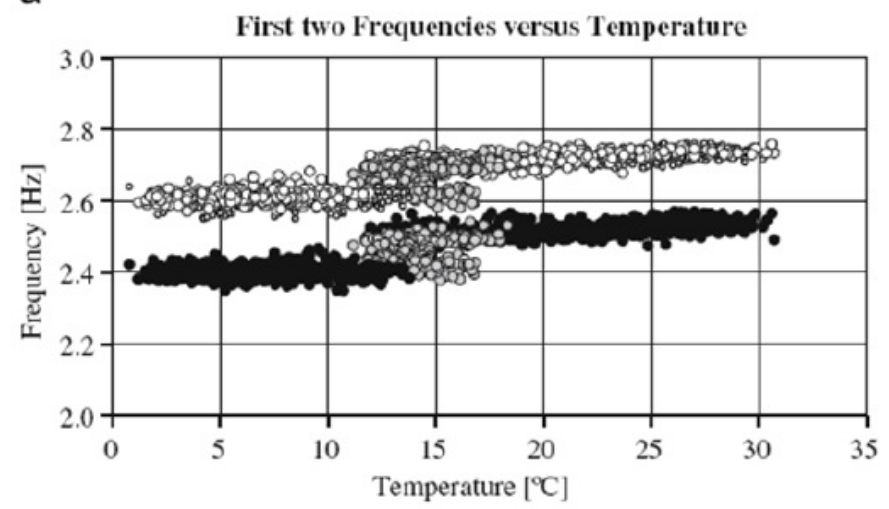

b

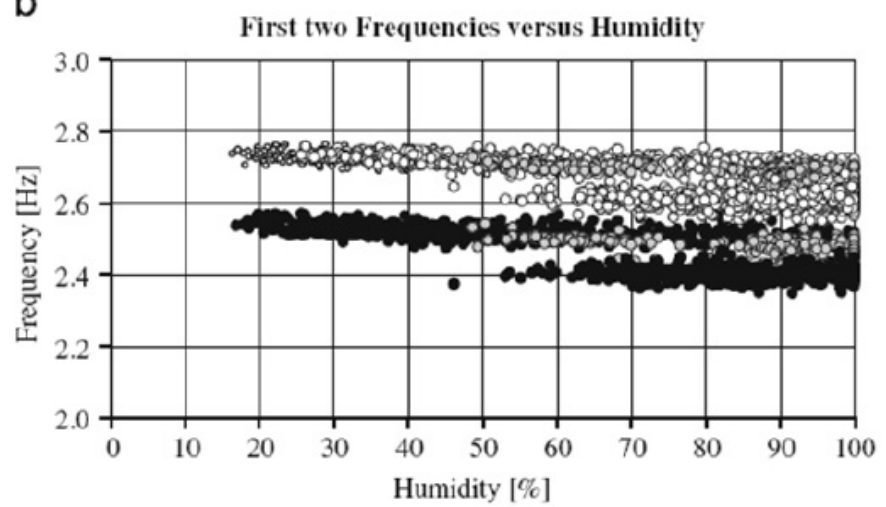

Environmental effects: (a) temperature and (b) relative air humidity. Black dots correspond to the first frequency, white dots to the second frequency, and gray dots to the transition period of each frequency. (From Ramos et al. 2010)

\section{References}

Anzani, A., Binda, L., Mirabella Roberti, G., 2000. The effect of heavy persistent actions into the behaviour of ancient masonry, Materials and Structures/Materiaux et Constructions, 33(228), pp. 251-261.

Anzani, A., Binda, L., Carpinteri, A., Invernizzi, S., Lacidogna, G., 2010. A multilevel approach for the damage assessment of Historic masonry towers, Journal of Cultural Heritage, 11(4), pp. 459-470.

Bartoli, G., Chiarugi, A., Gusella, V. 1996. Monitoring systems on historic buildings: the Brunelleschi Dome, Journal of Structural Engineering, ASCE, 122(6), pp. 663-673.

Binda, L., Saisi, A., 2002. State of the Art of Research on Historic Structures in Italy, Proceedings of 11th Advanced Research Initiation Assisting and Developing Networks in Europe (ARIADNE) Workshop, May 20-26, 2002.

Ferretti, D., Bažant, Z.P., 2006a. Stability of ancient masonry towers: Moisture diffusion, carbonation and size effect, Cement and Concrete Research, 36, pp.1379-1388.

Ferretti, D., Bažant, Z.P., 2006b. Stability of ancient masonry towers: Stress redistribution due to drying, carbonation, and creep, Cement and Concrete Research, 36, pp. 1389-1398.

Ramos, L.F., Marques, L., Lourenço, P.B., De Roeck, G., Campos-Costa, A., Roque, J. 2010. Monitoring historical masonry structures with operational modal analysis: Two case studies, Mechanical Systems and Signal Processing, 24(5), pp. 1291-1305.

Roca, P., (2001). Studies on the structure of Gothic Cathedrals, Historical Constructions, P.B. Lourenço, P. Roca (Eds.), Guimarães, pp. 71-90. 


\title{
Application of the Combined Finite-Discrete Eelement Methodology (FDEM) to the Preservation of Significant Historical Structures
}

\author{
Esteban Rougier ${ }^{l}$, Earl E. Knight ${ }^{l}$, Zhou Lei $^{l}$ and Antonio Munjiza ${ }^{2}$ \\ ${ }^{1}$ Geophysics Group, Los Alamos National Laboratory, Los Alamos, New Mexico \\ ${ }^{2}$ Department of Engineering, Queen Mary, University of London, United Kingdom
}

\begin{abstract}
Architectural and engineering geniuses of ancient times have left to the world an important heritage of stone, masonry and other structures ranging from temples, churches, mosques, pyramids to aqueducts, palaces, and dams. Preserving these for future generations is one of the more important challenges facing modern civilization. Many external actions (i.e. vibrations from traffic, earthquakes, etc.) can be a cause of either gradual or catastrophic damage. Modern engineering design practices usually utilize the ultimate limit states analysis for a structure as a whole. By using the theory of probability for design parameters such as loads and material properties, one can arrive at the probability of a catastrophic failure of a structure given a particular event. The problem with applying these to significant historical structures is that the computational tools available are at times somewhat limited for ancient structure analyses purposes simply because of the specific and innovative ways the structures were built. In this report, using the Los Alamos MUNROU package it is demonstrated that the combined finite discrete element method (FDEM) can offer some unique capabilities in modeling the ultimate limit state of historical buildings; each individual stone blocks or stone anchors could potentially be captured with accurate representation of frictional energy dissipation under transient dynamic loads. Our work here focuses on an initial cursory analysis of the potential earthquake threat posed to one of the most famous historical structures, the Santa Maria Del Fiore Dome in Florence.
\end{abstract}

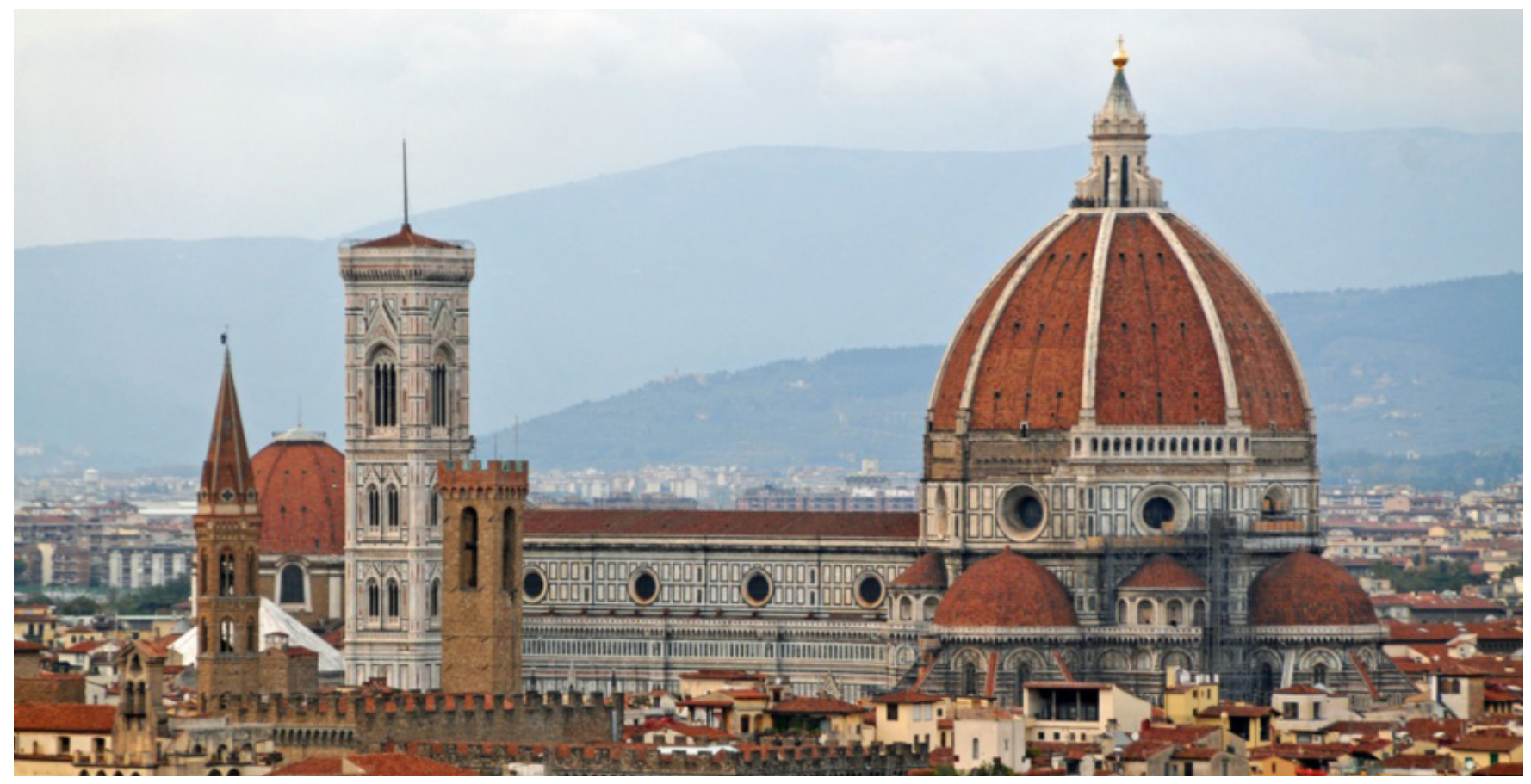

Figure 1. The Cathedral of Santa Maria del Fiore and the Brunelleschi's Dome. 


\section{Ancient structures in general}

Modern structural engineering design codes are based on the ultimate limit state analysis often coupled with structural reliability analysis. As such, they are designed for modern materials and modern construction methods. Engineers and architects of ancient times tended to build their monuments from the locally available limestone or granite resources, while in other locations even soft sandstone was used. Where stone was not readily available, ancient builders used bricks. In all cases, either iron, timber, or lead were used to further strengthen the structure. Also, mortars ranging from bituminous mortar (used by Babylonians) to limestone-based mortar and even cementbased mortar (used by Romans) were utilized to keep the blocks together.

Ancient structures hundreds to thousands years old can be found in all parts of the world. As such, they have survived wars, extreme weather, earthquakes, floods, and many other natural and human-made disasters to such an extent that many wonder: How is this possible? There are several reasons for this. The most obvious one is that time has served as a "natural" selection mechanism through which the weaker monuments have simply been eliminated and only the most robust ones have survived. But, there is another factor that has played an important role in preserving ancient monuments and it is the mastery of the building craft by its creators. The builders had to use materials such as stones or bricks, which are durable in comparison to modern man-made materials, such as steel. In addition, they could not afford the luxury of tension bearing structural elements with few builtin redundancies, which characterize modern structures. As a result, the structures are in general dominated by compression stresses. When these stresses are coupled with dynamic loads they produce high energy absorption mechanisms for earthquakes or lightening loads, as the key energy dissipation mechanism is friction. Unlike structural members loaded in tension, compression loaded structural members can absorb a much larger amount of energy before reaching the collapse point. The energy can be increased by few orders of magnitude when compared to permanent deforming of the material, which is dominant in modern structures. This is probably the most important reason why these monuments have survived for millennia.

Preservation of architectural heritage in modern societies is considered a major issue since, in addition to their historical value, historical buildings significantly contribute to a country's economy. Preserving historic constructions is therefore not only a cultural requirement but also an economic and developmental demand. While the structural behavior analysis of modern structures is a relatively simple task (thanks both to the presence of standard software and inherent literature), the prediction of the structural response of historical buildings is a more challenging task.

The above considerations highlight the need for specific modeling, analysis and experimental strategies for each historic masonry structure. In order to be able to preserve these structures, we have to understand the dynamic load bearing mechanisms, energy dissipation mechanisms and other mechanisms that help these structures survive, for instance, an earthquake, while modern buildings next to them collapse. On this regard, in the following sections of this report, a cursory demonstration of the application of the combined finite discrete element method to the analysis of historical structures is presented.

\section{The Combined finite-discrete element method in a nutshell}

The combined finite-discrete element method is a numerical method that brings together, under the same computational framework, the techniques and algorithms introduced both by the finite element method (FEM) and by the discrete element method (DEM).

In the FEM the solid bodies are discretized into a number of elements that deform in accordance with the prescribed boundary and loading conditions (Figure 2-b). The DEM in its original version, on the other hand, deals with a large number of rigid particles that interact with each other through contact and cohesion laws, (Figure 2-a). When these two techniques are combined, the solid bodies can be modeled as a collection of deformable particles that are bonded with each other, (Figure 2-c). This bonding is numerically represented 

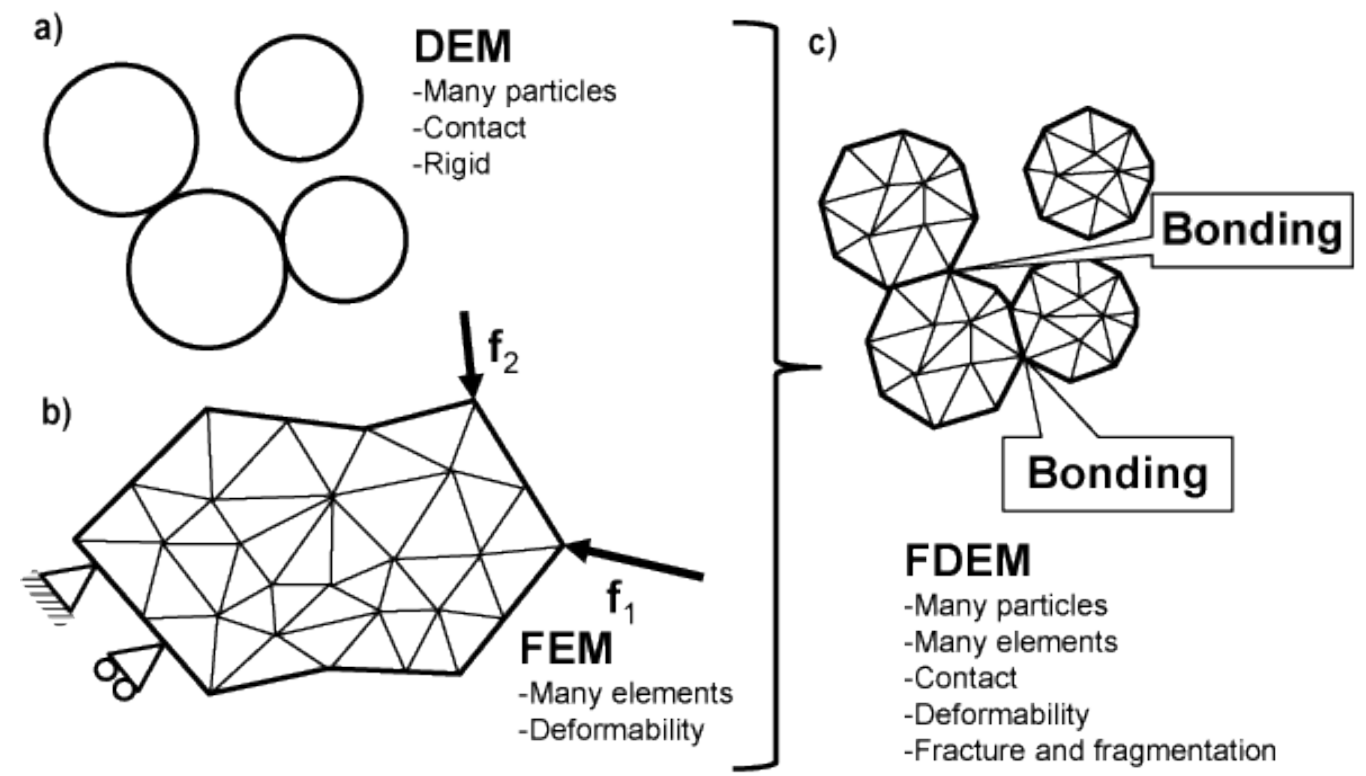

FDEM
-Many particles
-Many elements
-Contact
-Deformability
-Fracture and fragmentation

Figure 2. Main features of the combined finite-discrete element method.

by a series of cohesion points that are located along the boundaries of the deformable particles. The cohesion between any two particles is described as a combination of two main components: normal cohesion and tangential cohesion, Figure 3. Under a particular set of boundary and loading conditions these bonds may be strained to the point where they reach their maximum strength, i.e. $\sigma_{\text {tensile }}$, Figure 4 . If the bond is continued to be strained, a strain softening process occurs, eventually leading to breakage of the bond, i.e. fracture.

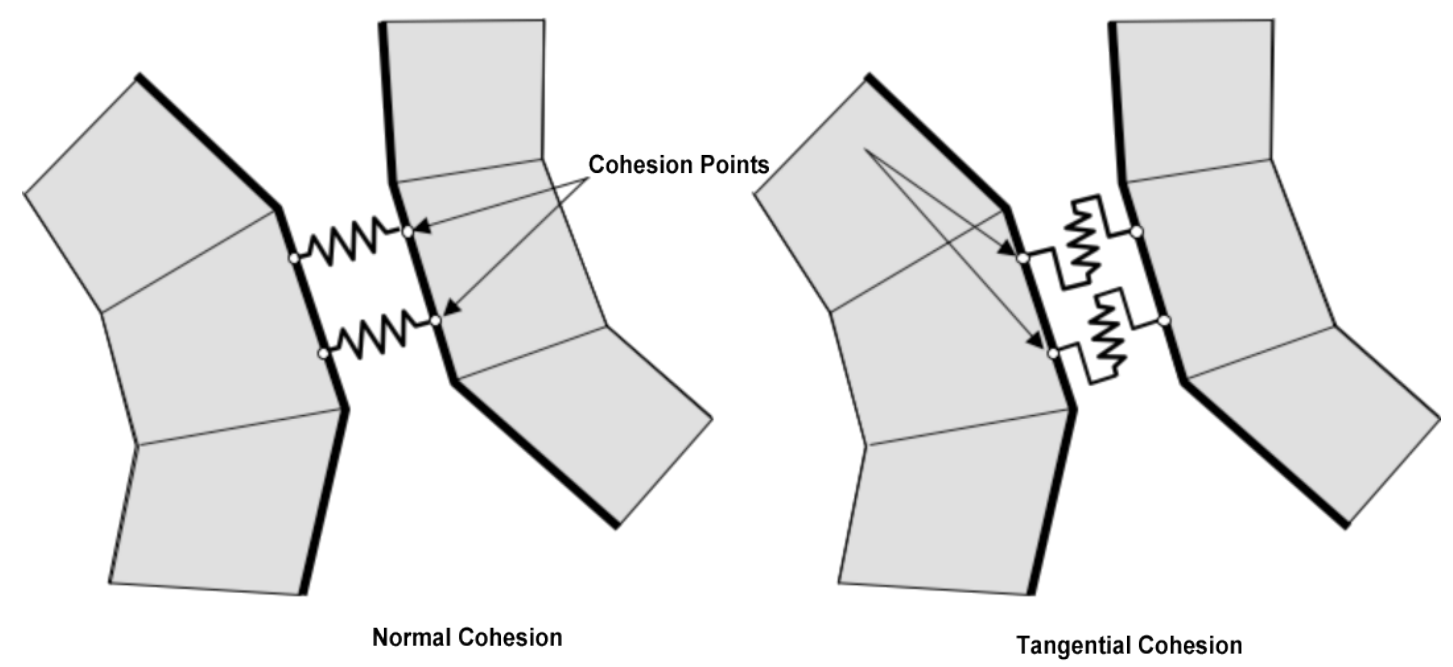

Figure 3. Cohesion features of the combined finite-discrete element method. 


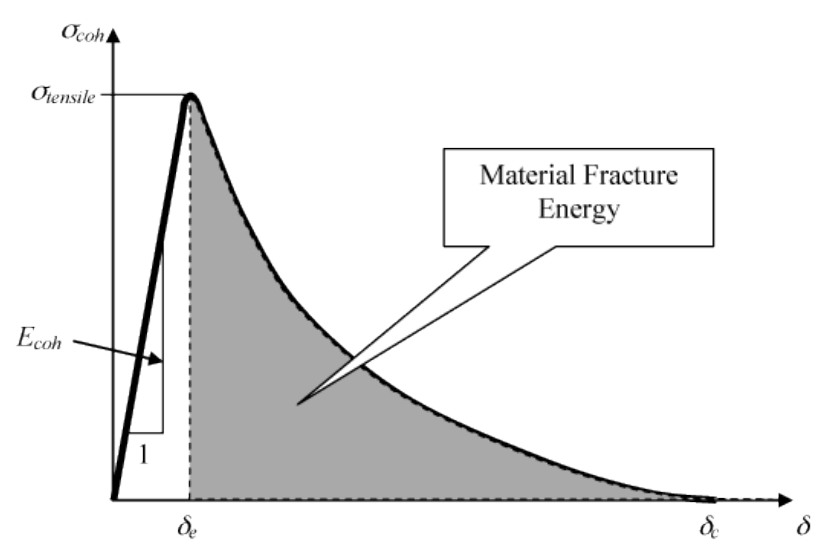

Figure 4. Main features of the combined finite-discrete element method.

\section{Exploratory FDEM simulations using MUNROU}

In recent years at Los Alamos National Laboratory, the FDEM and computational mechanics of discontinua have been brought to a new level through the development of a "state of the art" next generation of computer software called MUNROU. In this work, MUNROU has been, for the first time, employed to analyze a portion of a full scale ancient building, i.e. the Dome of the Santa Maria del Fiore Cathedral.

The FDEM Model. The exploratory numerical model for the dome is shown in Figure 5. Even though the FDEM model of the dome is axially-symmetric (unlike the real dome, which has eight webs, see Figure 1), the meridian curve of the model of the dome resembles that of the Brunelleschi's dome. It is worth noting that in this numerical model there are no pre-existing cracks, i.e. the dome is initially intact. The mesh was created using the Cubit toolkit and it comprises of around 150,000 solid 3D finite elements. The dome was subjected to an earthquake-like horizontal shaking load.
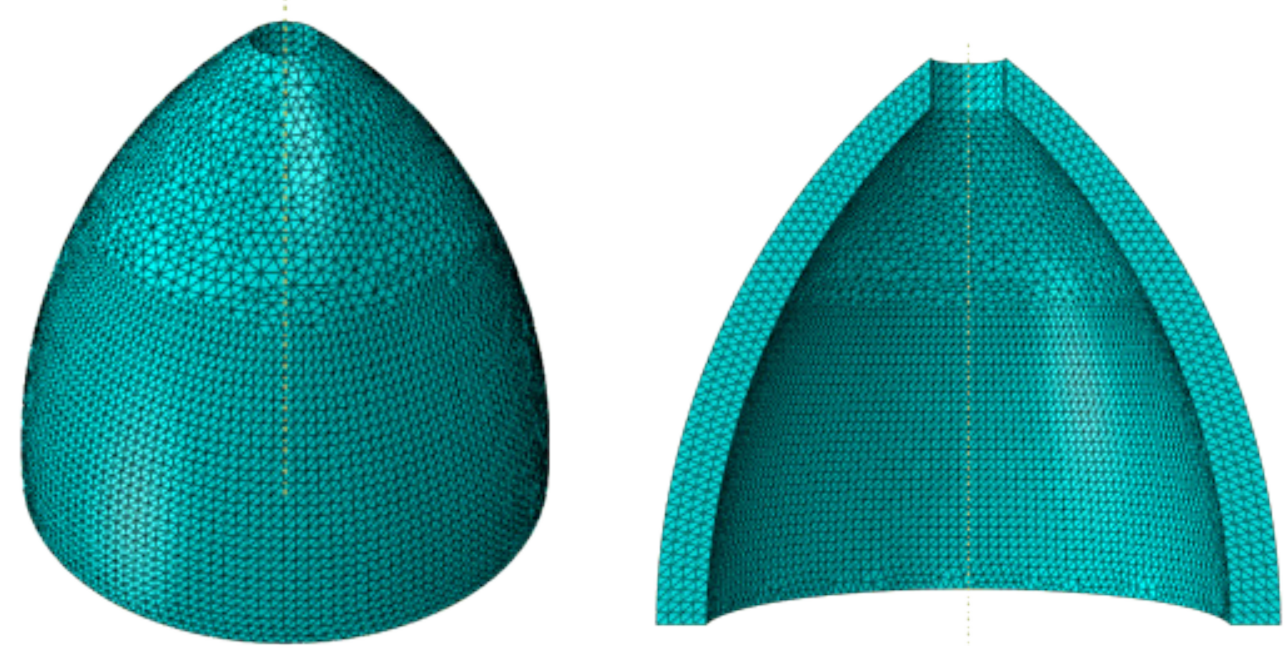

Figure 5. Two different views of the FDEM model of the top part of the cupola. 


\section{The Results}

The obtained initial stress wave propagation in the dome, together with the velocity field, is shown in Figure 6. Later stages of the wave propagation along with the resultant fracture pattern are shown in Figure 7.

Obtained Fracture Patterns. The zoomed in view of the fracture patterns is shown in Figures 8 and 9. A further detailed view is shown in Figure 10. It is important to note that the dome has survived the load, despite the development of an extensive fracture map.
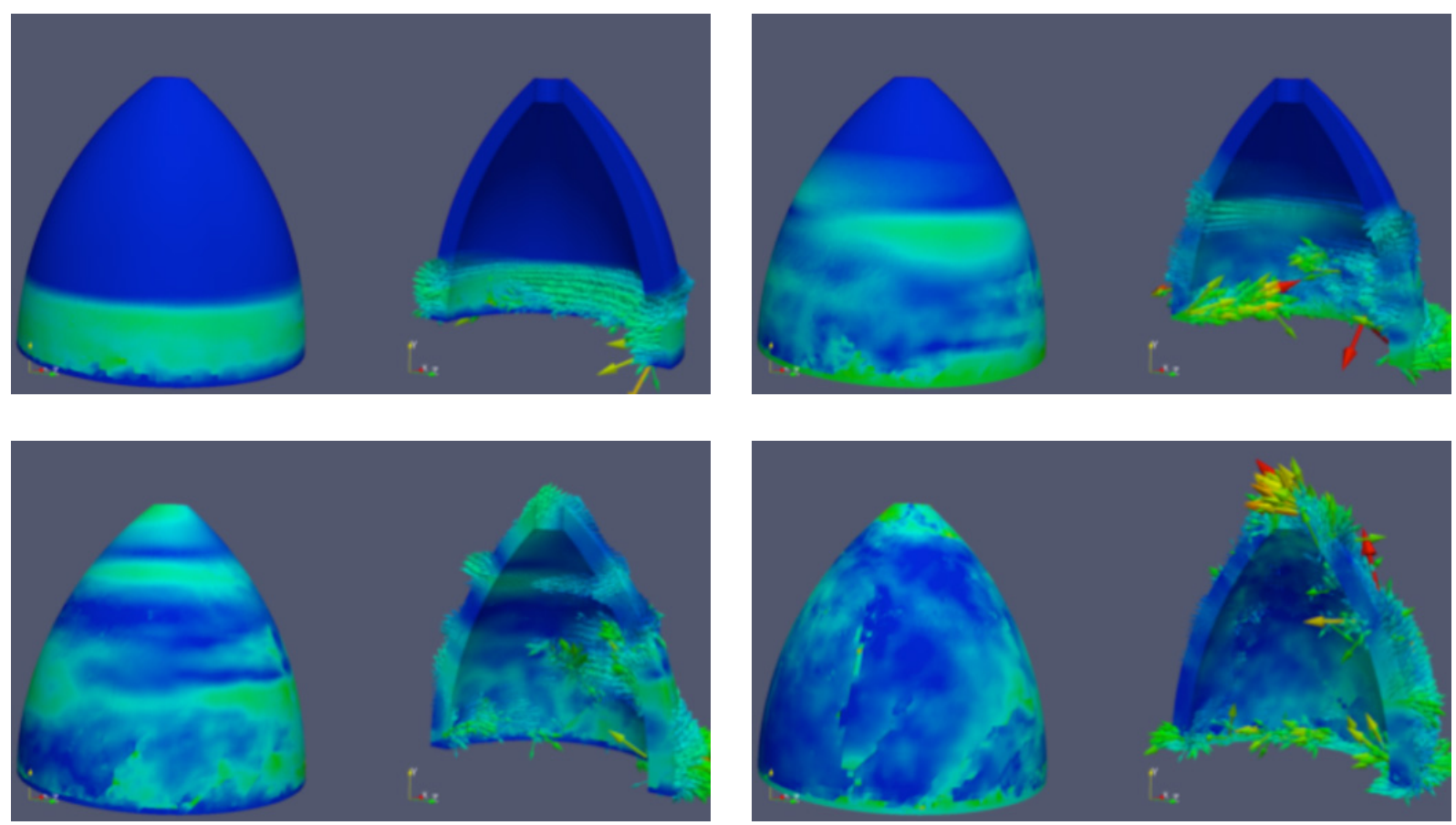

Figure 6. Initial stress wave propagation through the dome.
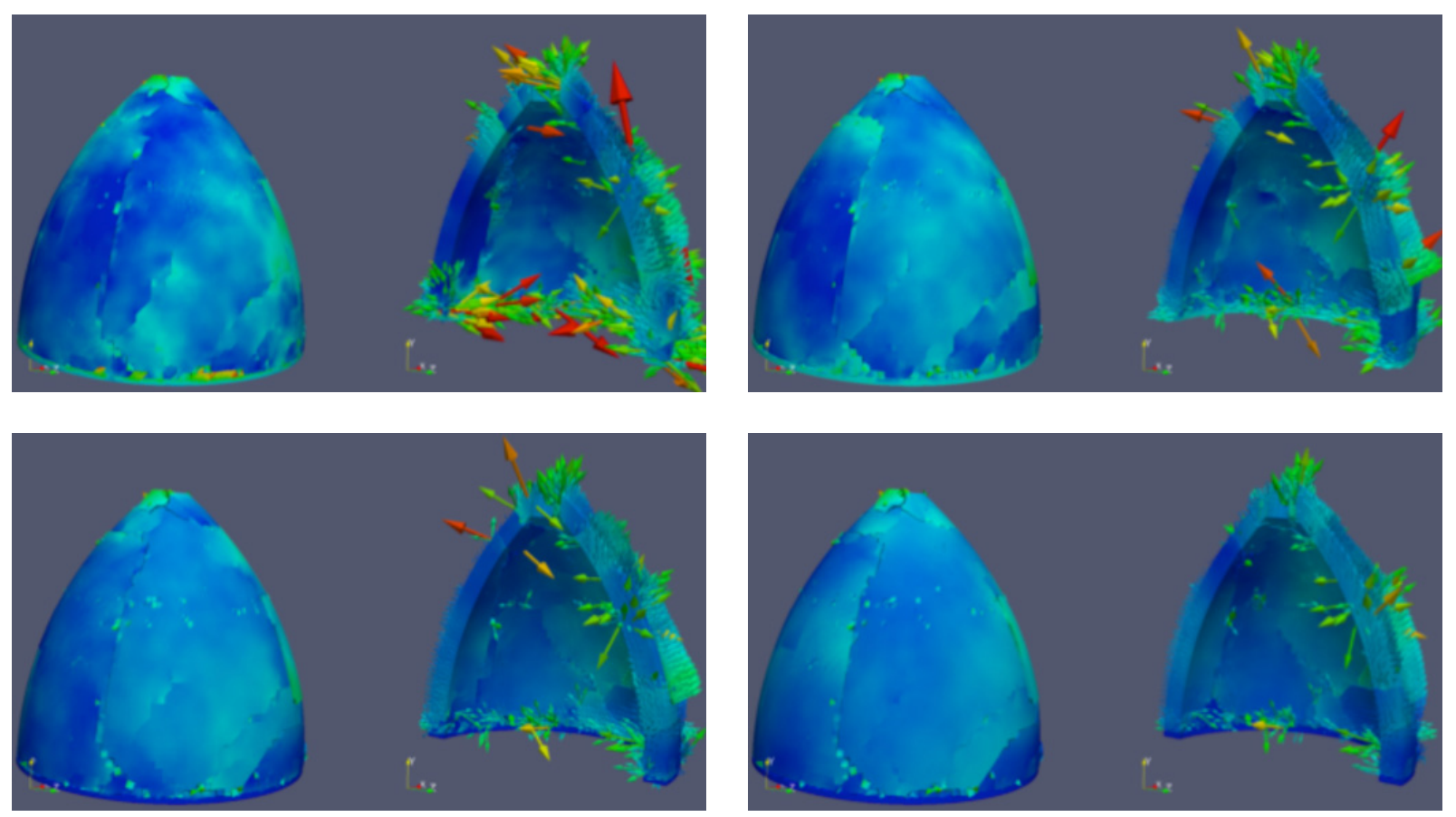

Figure 7. Later stages of stress wave propagation, including fracture inside the dome. 

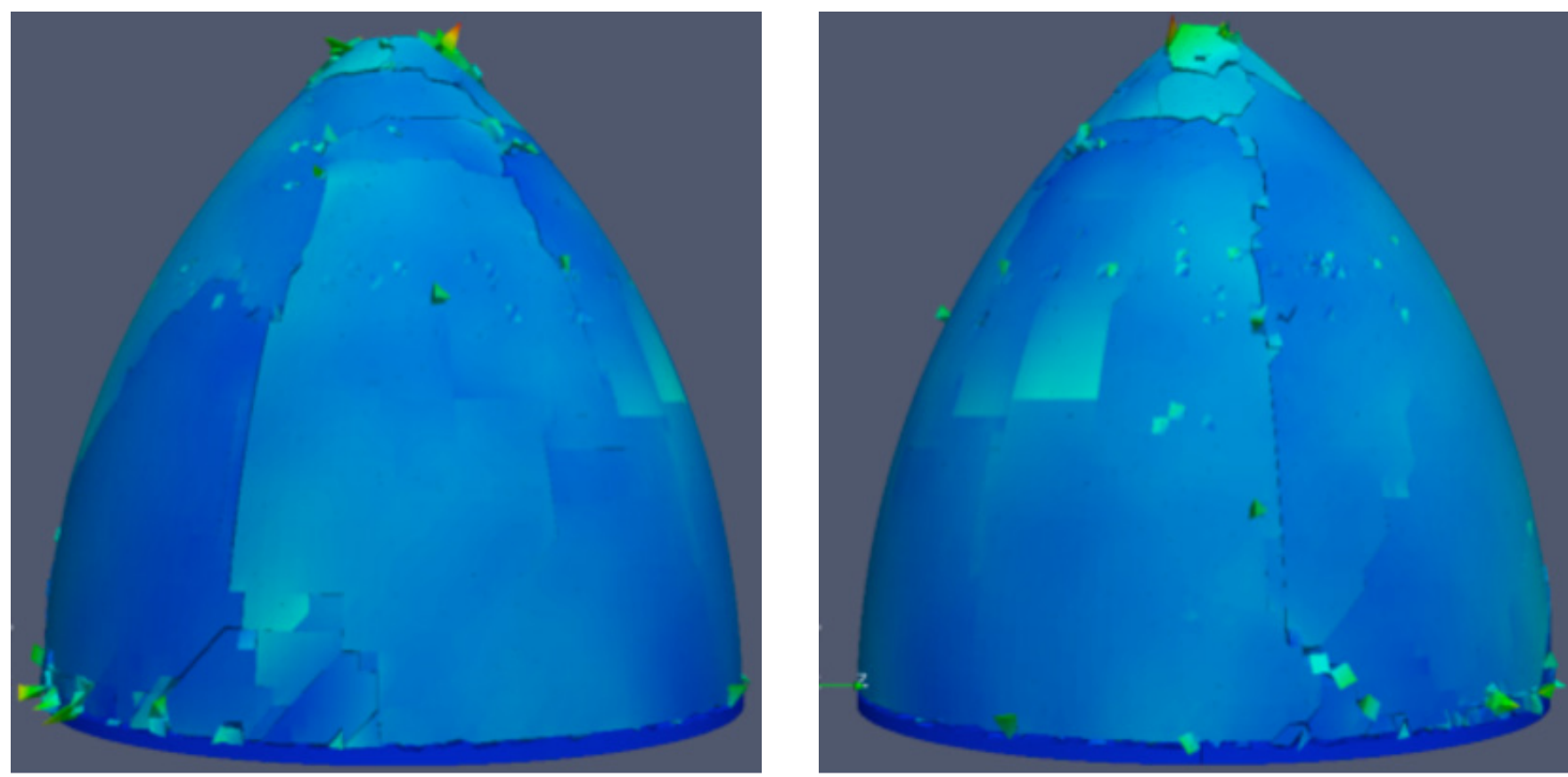

Figure 8. FDEM Simulation results showing the final state of fractures on the dome looking at it from the outside (enhanced displacements).
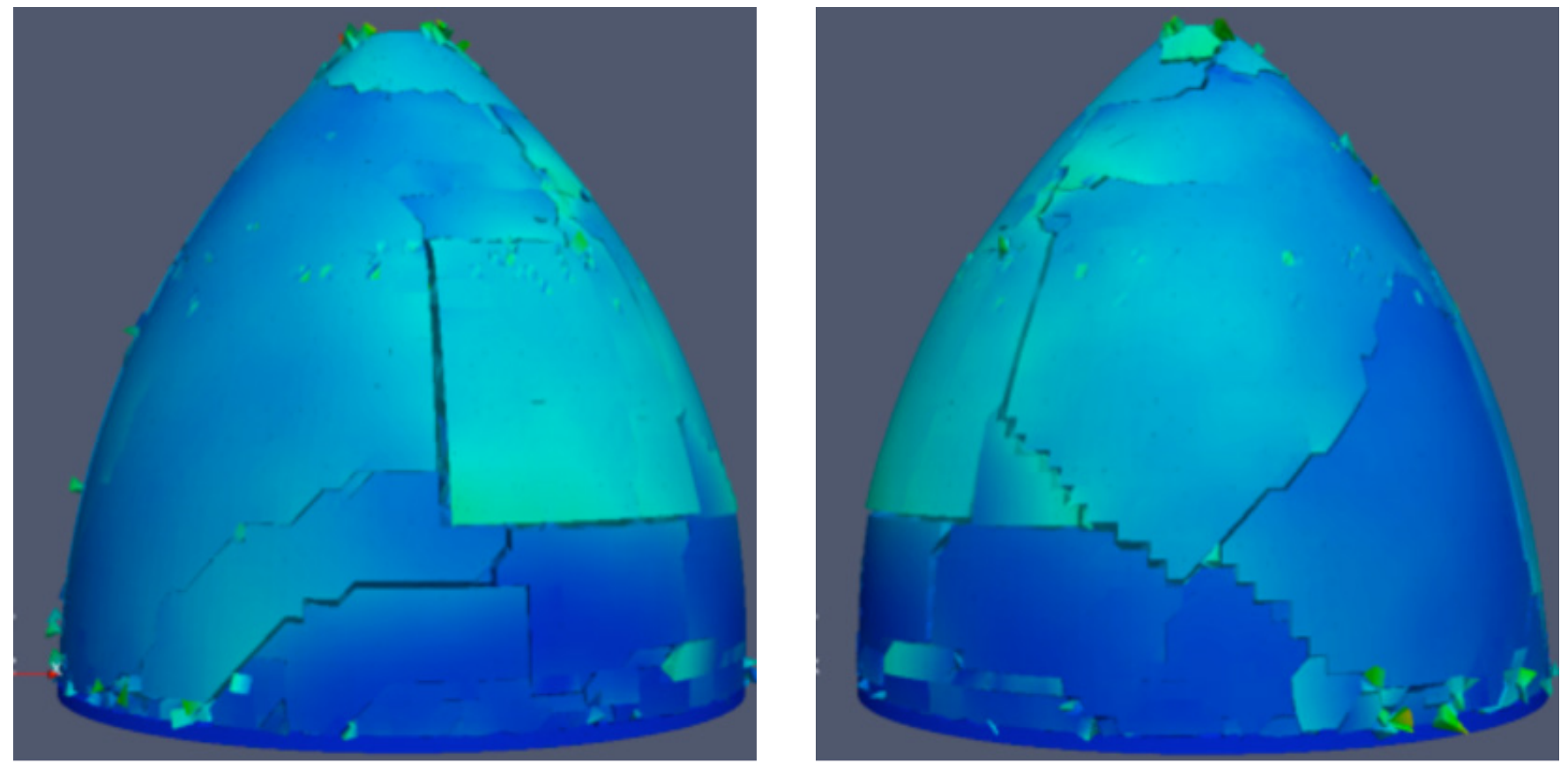

Figure 9. FDEM Simulation results showing the final state of fractures on the dome looking at it from the outside (enhanced displacements). 

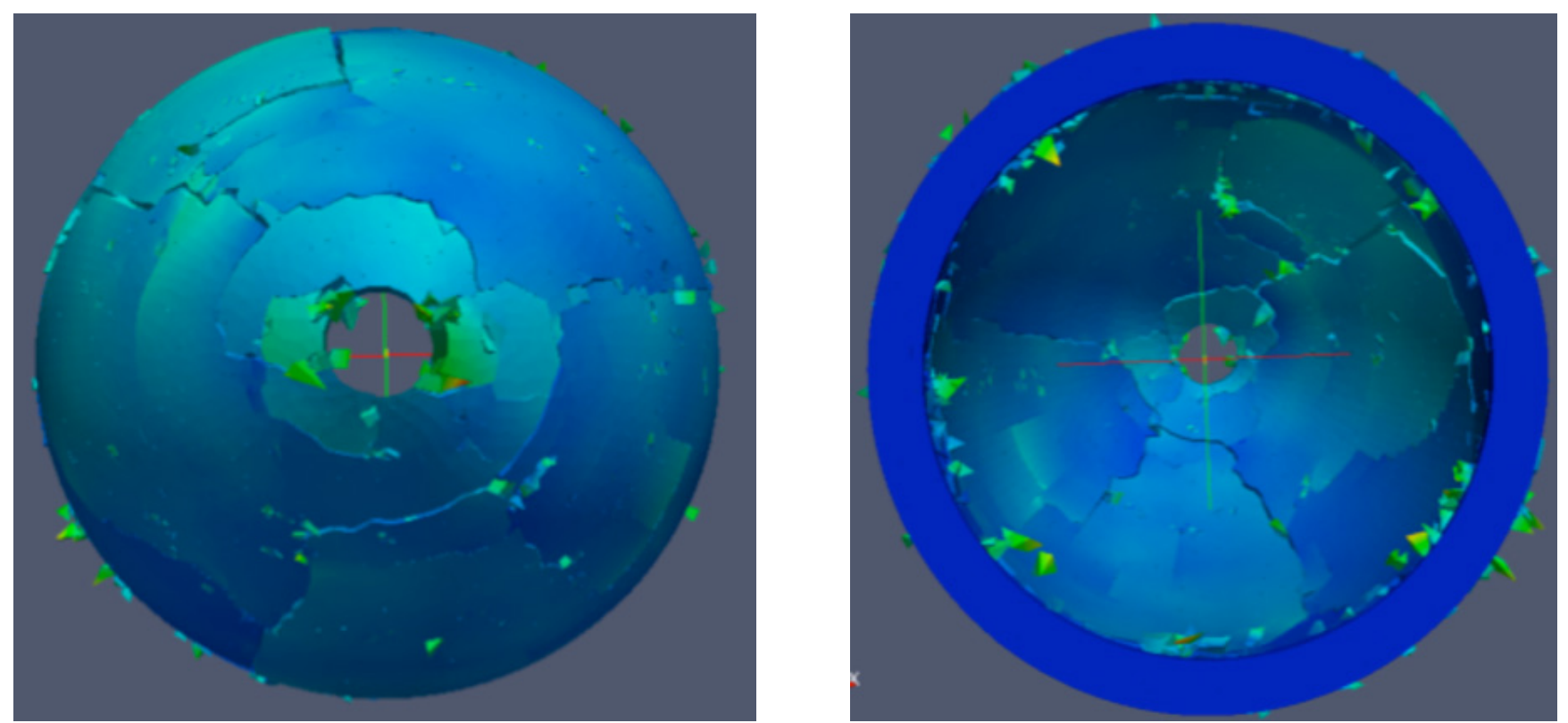

Figure 10. FDEM Simulation results showing the final state of fractures on the dome looking at it from the bottom.

\section{Conclusions}

The exploratory results shown in this report show the unique analysis capabilities that the FDEM can bring to engineers and preservationists as they battle the elements of time and nature. The cursory results obtained are intended only for demonstration purposes but they do show that now is the time to employ computational and theoretical approaches that employ advanced discontinua-based software tools. That stated, much work needs to be done before anybody can claim to model the collapse of such a complex structure accurately. These include material modeling, multiscaling analysis, benchmarking and validation efforts and many other aspects. As for the FDEM approach, it will benefit from tailor-made experimental approaches that would both validate and guide computational developments. The cause is a noble one and it requires international collaboration, as well as funding. 


\section{Evolution of Structural Design and Potential Design Changes}

\section{Kelsey Souza}

\section{Los Alamos National Laboratory, Los Alamos, New Mexico}

Possible collaboration with Los Alamos National Laboratory for rehabilitation of Brunelleschi's dome in the Santa Maria del Fiore Cathedral can extend beyond only modeling and use of sensors. LANL has engineering expertise available to analyze results of the modeling, asses risk, design experiments for model validation, and develop rehabilitations options.

Historically, the Cupola has had surprisingly few renovations. This is exceptionally notable due to its nearly 600 year lifespan. Cracks had already formed by 1639 when small repairs were made such as plaster filling and metal clamps over the cracks. In 1976 a study was performed that determined traffic had an influence on vibrations in the Cupola. As a result, an ordinance was put into effect by the Minister of Cultural Heritage to reduce traffic in the area. Interestingly, when scaffolding was installed to restore the Fresco in 1980, crack propagation slowed for many years until the scaffolding was removed.

The challenges facing the Cupola stem from the use of unreinforced masonry. While this building material enabled Brunelleschi to construct such a massive dome, unreinforced masonry is weak in tension which leads to cracking when tensile stresses exceed the limited masonry tensile strength. The material is especially susceptible to damage from seismic loading due to its heterogeneity and many surfaces between different materials (stones to mortar connection). Self weight of the structure has lead to deformation and cracking. Fatigue loading, such as thermal variations, has caused creep in the structure causing to expand. The Cupola can be sectioned into rings that are subjected to combined thrusting and bending forces. To prevent growth propagation in existing cracks and new cracks from forming, stresses from these loads must be mitigated by insertion of new structural components to add tensile strength. This must be accomplished while meeting the most important criteria: preserving the cultural aesthetic of the cupola and preserving Brunelleschi's vision. The most difficult task will be finding a balance between preservation of the original structure while strengthening the dome to prevent cracks.

Once the model has been developed to show the current stresses in the Cupola and the probability of various loading scenarios and failure modes, engineers from LANL can analyze if and where retrofits should occur in the structure. Some possible options include installation of external buttresses, reinforcing rings, and fiber reinforced polymers. While external buttresses will increase lateral stability and help transfer seismic loads to the foundation, they can be discarded as a retrofit option simply because they are obtrusive and cannot serve the purpose of preserving the cultural and historical significance of the Cupola and Brunelleschi's vision. Steel reinforcing rings are likely the best option. Tensioned rings placed on the interior between the two domes of the Cupola will constrain bulging and outward thrust caused by the dead weight of the structure. This will provide the needed tensile resistance to the masonry that will counter tension caused by bending of ring sections of the dome and outward thrust.

They can be installed discretely in between the interior and exterior domes without damaging the existing structure and can be placed at any one or many locations as determined necessary by the modeling and analysis process. Another rehabilitation option is the use of fiber reinforced polymers. These have been successfully used at the LANL for reinforcing columns in one of the plutonium facilities and to preserve historical unreinforced masonry structures in seismically active regions of southern California. They are easy to install, require no drilling, can increase strength of concrete or masonry by 20 to $30 \%$ in compression and $50 \%$ in tension, and can be installed discretely in the corridor between the two domes of the Cupola. They weakest point in FRPs applications is in the epoxy used to attach the polymers and the gain in strength will not be as large as with the rings or external buttresses. Whichever retrofit is ultimately chosen, analysis of the effect of added reinforcement, 
including how the forces will be redistributed in the structure, must be carefully considered. New force distribution may cause unexpected or new cracking. Any new components installed must also be analyzed for its own failure modes.

Alternatively, no retrofit may be the best solution. Dead loads are suspected to have caused the current cracks that exist in the cupola. Bracing and stiffening the Cupola using these methods will prevent future growth of cracks due to dead loads. However, stiffening of the structure reduces ductility which is critical during dynamic loading such as an earthquake. Under seismic loading, it is best to retain the ductility of the structure. A balance of these two needs will need to be assessed after completion of the model. Despite the large cracks that already exist, leaving the structure as is may be the best solution to mitigating risks from the combined effects from both static loads and dynamic loads.

Other capabilities of Los Alamos National Laboratory include expertise in Probabilistic Seismic Hazard Determination (PSHA), Structural Health Monitoring (SHM) including a partnership with University of California San Diego (which boasts experimental facilities including the world's largest outdoor shake table and a shake table with 6 degrees of freedom), design of experiments, and the Material Science and Technology division including capabilities such as forensic materials testing/modeling.

\section{References}

Brunelleschi's Cupola: Past and Present of an Architectural Masterpiece by Giovanni Fanelli and Michele Fanelli

Seismic Evaluation and Retrofit of the 16th Century Mihrimah Sultan Mosque by C. Ustundag, H. Sesigur \& F. Cili of Istanbul Technical University

Seismic Retrofit of Unreinforced Masonry Buildings by Rakesh K. Goel of Cal Poly State University, San Luis Obispo
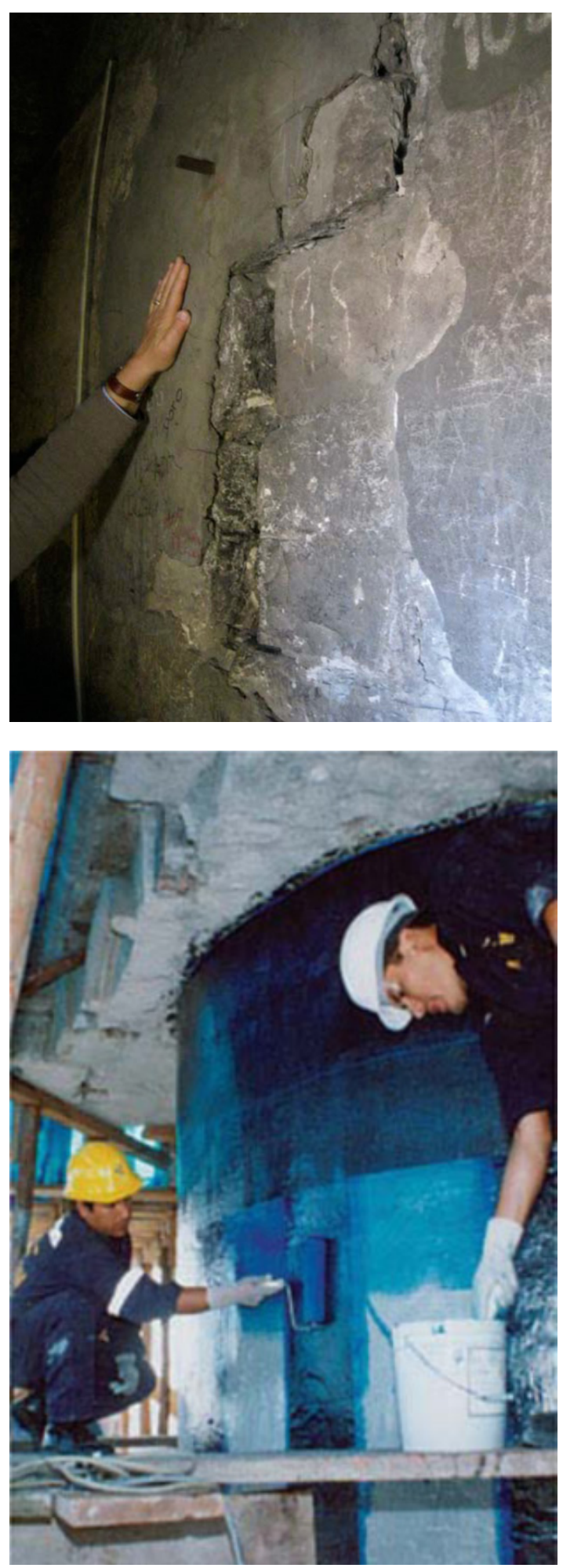


\title{
Imaging Internal Structural Features of Santa Maria del Fiore with Cosmic Ray Muons
}

\author{
Cas Milner, Jeff Bacon, Konstantin Borozdin, Elena Guardincerri, Haruo Miyadera, \\ Christopher Morris, and John Perry
}

\author{
Muon Imaging Team, Los Alamos National Laboratory, Los Alamos, New Mexico
}

\begin{abstract}
Since its construction in 1436, the cupola of Santa Maria del Fiore in Firenze, Italy has developed significant cracks caused by earthquakes. Mathematical models are being developed to study how the building shakes in earthquakes and also how it could be stabilized against further damage by the addition of reinforcing structures. Descriptions of the location, structure and size of cracks and existing internal reinforcements are important ingredients in these models, but since these data have been gathered from visual inspections and historical records, they may be incomplete. In this note, we describe how measuring the passage of cosmic ray muons through the structure could, for the first time, yield important information about internal damage, or unknown internal structures. The muon technique is non-invasive, and uses naturally occurring cosmic rays.
\end{abstract}

\section{Introduction}

Cosmic ray muons penetrate deeply in material, with some passing completely through very thick objects. This penetrating quality is the basis of two distinct, but related imaging techniques.

The first measure of the number of cosmic ray muons transmitted through parts of an object. Relatively fewer muons are absorbed along paths in which they encounter less material, compared to higher density paths, so the relative density of material is measured. This technique is called muon transmission (MT) imaging - essentially measuring the muon-shadow of an object - and has been used to infer the density and structure of a variety of large masses, including mine overburden 1 , volcanoes ${ }^{2}$, and pyramids ${ }^{3}$.

In a second, more recently developed technique, the angular deflection of muons inside an object is measured by trajectory-tracking detectors placed on two opposing sides of the structure. Muons are deflected more strongly by heavy nuclei, and the multiple Coulomb scattering distribution width $\left(\theta_{\mathrm{O}}\right)$ is approximately proportional to the nuclear charge ${ }^{4}$,

$$
\theta_{0}=\frac{13.6}{p \beta} Z \sqrt{L}
$$

where $\mathrm{Z}$ and $\mathrm{L}$ are the material nuclear charge and radiation material thickness, $\mathrm{p}$ and $\beta$ are the muon momentum and velocity.

Because larger scattering angles are associated with high- $\mathrm{Z}$ materials, a map showing regions of relative deflection will identify the location of (for example) iron, in contrast to lighter nuclei composing stone or brick. This is the basis of muon scattering radiography (MS), a technique developed and commercialized by LANL and an industrial partner to inspect shipping containers for the presence of smuggled material. In separate work, following the reactor accident at Fukushima Daiichi, Japan on March 11, 2011, the LANL team has been establishing capabilities of the MS technique to image the location of damaged fuel within the reactors. LANL simulations and demonstration measurements have shown that metal masses as small as $\sim 15 \mathrm{~cm}$ will be detectable through the 6-m of concrete surrounding the reactor vessel.

In this note, we discuss applying the MS technique to the task of measuring unknown or hidden structures or cracks within Il Duomo di Firenze (Cattedrale di Santa Maria del Fiore). Features which may be measured with 
this technique include a) internal structure of cracks, b) presence or absence of iron brackets joining internal stone structures, c) wooden reinforcement structures, and d) internal structure of foundation. This technique is probably the only way to gently and non-invasively observe these features, and provide crucial data necessary to improving mathematical models of the structure.

\section{Project Description}

The project will be accomplished in phases:

Phase 1 will be a preliminary physics simulation of reconstructed images of internal features of Il Duomo, derived from muon scattering. A feature of interest, most likely metal straps joining stone blocks (macigno), concealed by bricks or stone, will be selected. Drawings will be supplied to the LANL group by collaboration architects, and a model of the object will be constructed in the GEANT4 simulation platform. The goal of this study will be to demonstrate the spatial resolution and material contrast which can be achieved with the technique - and to generate a sample simulation image. A example of this kind of simulation is shown in Figures 1 and 2, for imaging a nuclear reactor with cosmic ray muons.

In Phase 2, we will construct a full-scale model of the structure simulated in Phase-1 and measure it using an existing muon radiographic system at LANL. This will provide experimental confirmation of the technique and demonstrate images can be made at the Duomo site.

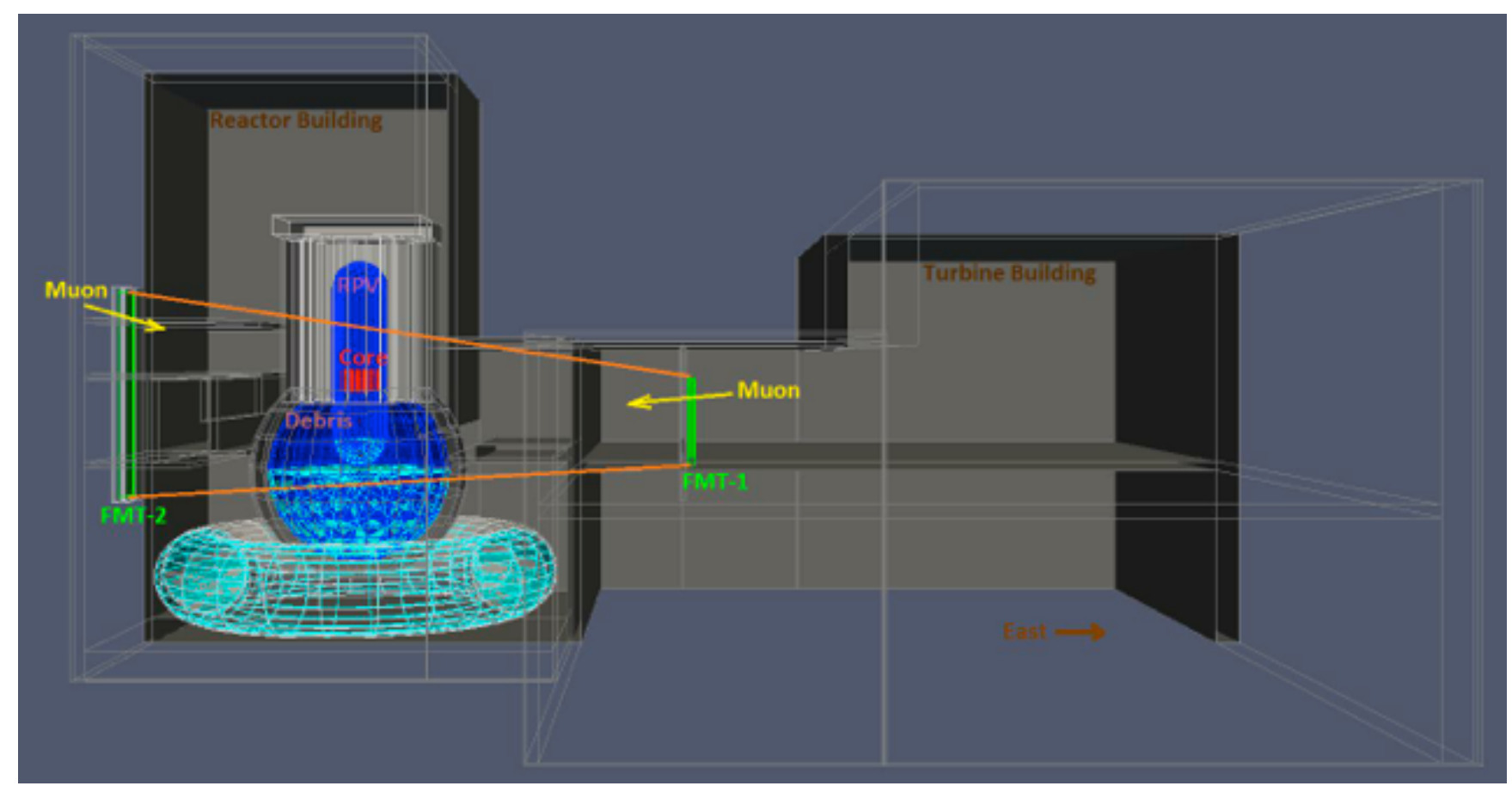

Figure 1: Graphical representation of GEANT4 simulation of muon scattering radiography system arranged for measuring location of fuel inside a nuclear reactor. Muon detectors are shown in green and labeled "FMT-1", and "FMT-2".

In Phase 3, a site measurement will be made using a dedicated muon radiography system. The initial measurements will be made on parts of the structure studied in Phases 1 and 2. A custom apparatus may be required by special installation demands of the site. The result of Phase 3 will be images showing the existence or absence of key structural components. 


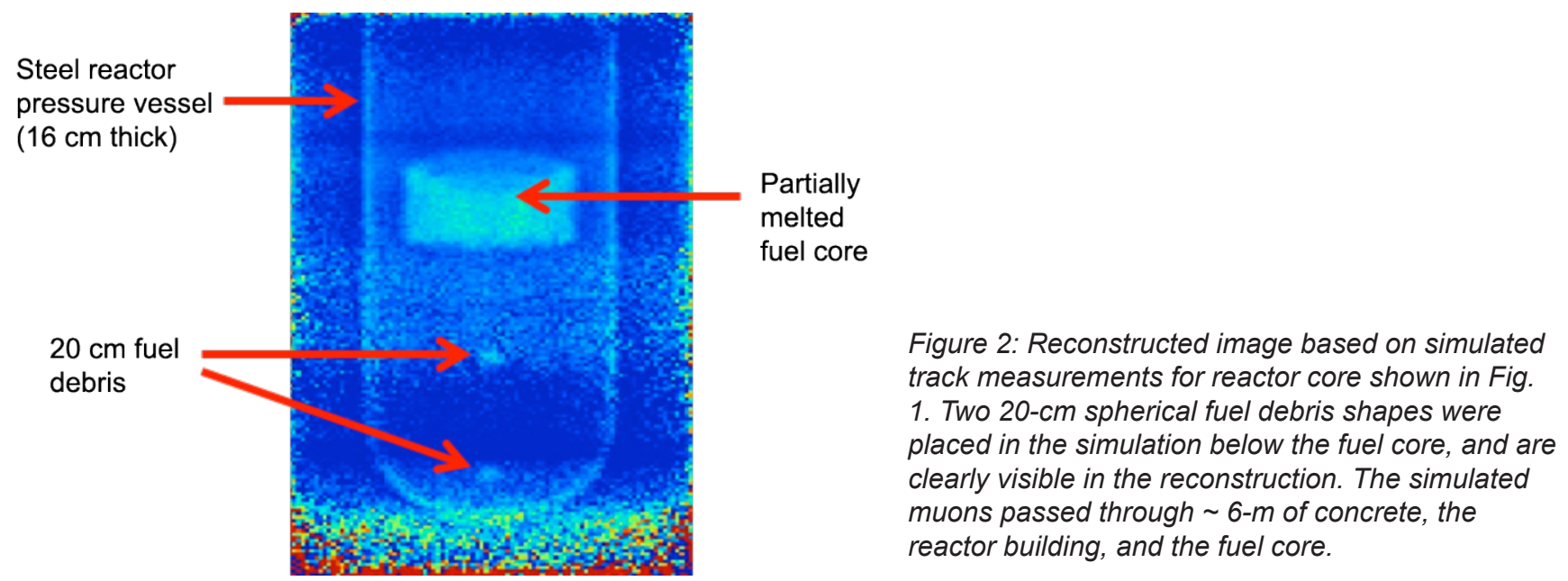

\section{Measurement Apparatus}

Initial testing will be done with a muon tracking system already developed by LANL. The technology has been previously described. The trajectories of cosmic ray muons will be measured with two tracking detector sets composed of gas-filled ionization drift tubes. Each tracker set has coverage area of 1.2-m square, and is approximately 0.6-m thick. If system dimensions cannot be accommodated in the required locations at the Duomo site, a new system will be constructed in pieces which can be assembled on site. Muon track positions will be determined with an uncertainty of less than $0.2 \mathrm{~mm}$.

\section{Anticipated Results}

- Establishing muon scattering radiography as a powerful tool for assessing internal structures of buildings

- Measurement of critical internal structures of Il Duomo di Firenze, including the possible discovery of unknown cracks or reinforcement devices

- Provide data improving simulations of building shake-response to earthquakes.

\section{References}

${ }^{1}$ E.P. George, Commonwealth Engineer, 455 (July 1, 1955).

${ }^{2}$ K. Nagamine, M. Iwasaki, K. Shimomura, K. Ishida, NIM Phys. Res. A 356, 585-595 (1995).

${ }^{3}$ L. W. Alvarez, J. A. Anderson, F. Elbedwe, J. Burkhard, et al., Science (USA) 167 (3919), 832 (1970).

${ }^{4}$ V. Highland, NIM 129 497-499 (1975).

${ }^{5}$ C. Morris, C. Alexander, J. Bacon, K. Borozdin, et al., Science \& Global Security 16 (1), 37-53 (2008).

$6_{\text {http://www.decisionsciencescorp.com/ }}$

${ }^{7}$ K. Borozdin, S. Greene, Z. Lukic', E. Milner, H. Miyadera, C. Morris, J. Perry, "Cosmic Ray Radiography of the Damaged Cores of the Fukushima Reactors”, Phys. Rev. Lett. 109, 152501 (2012).

${ }^{8}$ http://en.wikipedia.org/wiki/Geant4

9 J.A. Green, et al.,"Optimizing the tracking efficiency for cosmic ray muon tomography”, 2006 IEEE Nuclear Science Symposium Conference, LA-UR-06-7556 (2006). 


\title{
Probabilistic Framework for Computational Modeling
}

\section{Michael W. Salmon}

\author{
Los Alamos National Laboratory, Los Alamos, New Mexico
}

\section{Purpose}

The purpose of this paper is to summarize the main points presented in a workshop paper (Salmon, 2013) held at Los Alamos National Laboratory on February 13-February 15, 2013. The workshop was held on the structural cracking of the Cupola Di Santa Maria Del Fiore.

Brunelleschi's Dome was completed in 1434 under the design and supervision of Filippo Brunelleschi (Bartoli, Betti, Borri, p. 3). It is considered to be one of the world's largest unreinforced brick domes. The base of the dome is supported on an octagonal support structure that is approximately 44 meters in diameter. The top of the dome is approximately 30 meters above the base.

Domed structures such as the Cupola Di Santa Maria Del Fiore are mainly compression structures. Both meridional and hoop compression (thrust) must be reacted either by heavy stiff supporting structures, such as the roman pantheon, or they can be counteracted by steel reinforcing. The tension in the steel reinforcing resisting the resulting thrust set up by gravity loads. It is not uncommon for cracks to form due to deformations in the dome caused by dead loads.

The Cupola Di Santa Marie Del Fiore has many cracks. The major cracks are on the webs numbered 4 and 5),with a maximum crack width of about $6 \mathrm{~cm}$ (Blasi and Ottoni, p. 2). The cracks were first recorded by Gherardo Silvania in a report dated 18th September 1639. Additional cracks have occurred in the dome due to either differential settlement of the dome, earthquake induced ground motions, or other reasons.

Because of the cultural significance of the Cupola there is a great interest in qualitatively determining the likelihood of collapse of the dome due to earthquakes or other natural phenomena. This paper presents some considerations for those desiring to perform such an assessment.

\section{Structural Reliability}

Ang (Ang and Tang, 1984) define reliability as the "probabilistic measure or assurance of performance." That is the assurance of performance can only be measured with knowledge of the underlying uncertainties of the capacity versus demand problem. It is not sufficient to measure reliability only in terms of a factor of safety. Analysts and engineers will frequently mention a central "factor of safety" which is defined as the Capacity (C) divided by the Demand (D):

$$
F S=\frac{\text { Capacity }}{\text { Demand }}=\frac{C}{D} \quad 1
$$

We frequently conclude that if the factor of safety is greater than one, we are in a "Safe" state. If the factor of safety is less than one, then we are in an "Unsafe" state. In and of itself, however, this central factor of safety (FS) does little to provide confidence that the system will perform. In reality, both the Capacity (C) and the Demand (D) are random variables with uncertainties due to both inherent randomness and imperfect knowledge. If the uncertainties in both $\mathbf{C}$ and $\mathbf{D}$ are large, there could be a relatively large probability of failure (the case where the actual capacity is less than the demand), even for large factors of safety. This concept is illustrated in the preceding Figure 1 . In the figure, the capacity is represented by the probability density function $\mathrm{f}_{X}(\mathrm{x})$, and the demand is represented by the probability density function $f_{Y}(y)$. There is a small probability that the actual 
capacity $(\mathrm{X})$ is less than the demand (Y) This is shown in figure y assuming that the actual demand 7. The overall probability of failure is given as the convolution of $\mathrm{X}$ with respect to $\mathrm{Y}$ :

$$
P_{F}=\int_{0}^{\infty} F_{X}(y) f_{Y}(y) d y \quad 2
$$

Where $\mathrm{F}_{\mathrm{X}}(\mathrm{x})$ is the cumulative density function of capacity, $\mathrm{X}, F_{X}(x)=P(X \leq x)$. And $\mathrm{f}_{\mathrm{Y}}(\mathrm{y})$ is the probability density function for demand. It should be noted that $f_{Y}(y) d y=P(y<Y \leq y+d y)$ is not a probability; however, is the probability that values of $Y$ will be in the interval

$(y, y+d y)$.

The overlapping of the curves $\mathrm{f}_{\mathrm{X}}(\mathrm{x})$ and $\mathrm{f}_{\mathrm{Y}}(\mathrm{y})$ represent a qualitative measure of the failure probability PF. Thus to get a quantitative measure of the safety (or reliability) of the dome, both the uncertainty in the underlying strength (capacity) of the dome, and in the loading (demand) on the dome must be known or approximated.

\section{Seismic Fragilities and Probabilistic Risk Assessments}

Seismic risk is typically defined as the quantitative measure of the consequence of seismic induced failure. Risk, therefore, has two components. One is a consequence of damage. For an operating nuclear power plant, the consequence of concern is typically either core melt, or release of radioactive materials. For a typical manufacturing facility, the consequence of concern is loss of production capacity. The other component is the likelihood of damage producing earthquakes. High seismic risk can be very high consequence in areas with moderate seismic hazard, or moderate consequence in areas with high seismic hazard. Quantifying the seismic risk for a facility or process then involves defining the seismic hazard, and the probability of loss given seismic ground shaking.

Seismic probabilistic risk assessments combine logic trees and fault trees in order to produce a plant level damage state. Seismic probabilistic risk assessments used in the nuclear power industry assess the sequence of events whose failure could lead to a damage state such as core melt, or release.

Seismic fragilities are defined as the cumulative conditional distribution function that describes the probability of failure of a structure, system, or component subjected to earthquake ground motion. Figure 2 shows a typical seismic fragility curve. One can see from Figure 2 that at low levels of ground motion (peak ground acceleration in this case), the probability of failure is very low. At high levels of ground motion, the probability of failure approaches unity.

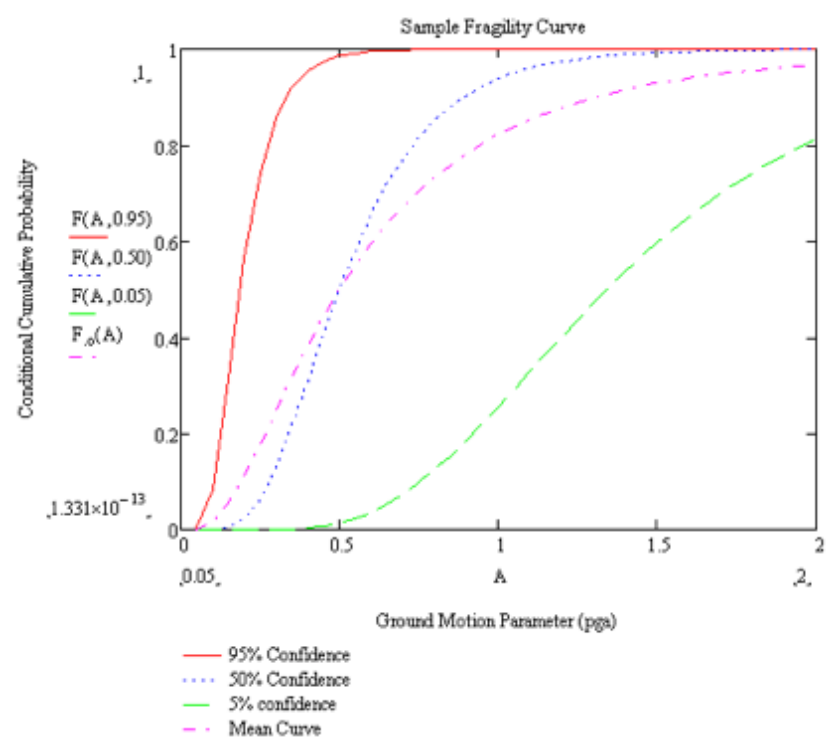

Figure 2. Typical Seismic Fragility 
The annual seismic induced frequency of failure is obtained by convolving the seismic fragility with the seismic hazard curve:

$$
P_{F}=-\int_{0}^{\infty}\left(\frac{d H(a)}{d a}\right) F^{\prime}(a) d a
$$

Where $\mathrm{H}(\mathrm{a})$ is the seismic hazard, and F'(a) is the seismic fragility. Equation 3 is very similar to the convolution integral given as equation 2. The result of the convolution, such as equation 3 is the annual frequency of seismic induced failure. Convolving the mean hazard with the mean fragility provides a single best estimate of the annual frequency of failure of systems, structures or components. Once this value is obtained, then risk-informed upgrade decisions can be made regarding the safety of the object.

In the United States, acceptable annual frequencies of failure vary widely. The U.S. Nuclear Regulatory Commission (US NRC) has stated its target performance goals of less than about $1 \times 10^{-5}$ for core damage and less than about $1 \times 10^{-6}$ for release (ASME, 2012). Similar performance objectives need to be set for the Cupola Di Santa Maria Del Fiore. Only when acceptable performance goals have been set, and the quantitative measure of seismic performance has been estimated, can one logically begin discussing the necessity and objectives of seismic strengthening.

\section{Conclusions and Recommendations}

The Cupola Di Santa Maria Del Fiore is a world heritage structure. Finished in 1434 it has experienced several large damaging earthquakes in its lifetime. The Cupola has visible cracks in several of its webs that form the periphery along its octagonal dome. The seismic risk of collapse of the structure in its current condition is not known. However, practitioners would like to estimate this risk in order to better decide if strengthening the Cupola is warranted.

In order to predict the seismic risk to the Cupola we need good estimates of the seismic hazard, and estimates of the uncertainties associated with this hazard. In addition to knowledge of the seismic hazard, risk analysts will need a good model of the structure subjected to ground motion. This model will need to use mean estimates of strength (material properties, weights, concurrent dead loads) and failure models (finite element based methods, discrete element based methods) to predict a damage state as a function of ground motion. Uncertainties and distributions of the state variables (strength, geometry, etc.) are also needed to predict the fragility.

The seismic fragility of the Cupola can be estimated using simulations, first-order second-moment methods, fast running surrogate models of the underlying physical process, or some combination of those. In order to derive the seismic fragilities of the Cupola we will need to identify those parameters that have a significant contribution to its stability. Parameters we judge to be important include crack size and orientation, material properties, mortar properties, bedding plane geometries, and dead load. Other parameters that we will need to investigate include foundation properties and subsurface material properties.

Working with other agencies such as the Parma University and the University of Florence we recommend undertaking the following tasks:

1. Identify "unacceptable" performance. Is this collapse? Is it extensive cracking?

2. Identify "acceptable" target performance goals in terms of an annual frequency if seismic induced failure (e.g., collapse frequency $<1$ x10-5/year)

3. Identify models (discrete element models, finite element models. Soil-structure interaction models) that could be used to predict response for a given set of state variables 
4. Estimate uncertainties for important state variables

5. Perform sensitivity studies to identify major contributors from step 4

6. Perform simulation to predict seismic fragility. Since the seismic fragility would be highly nonlinear depending on the damage state, the probability of collapse would have to be predicted at various ground motion values

7. Convolve the resulting mean fragility with the mean hazard to come up with a single best estimate of the annual frequency of failure

Once the model described above has been matured, the resulting decrease in the annual frequency of collapse could be investigated with alternate strengthening schemes to identify the best strengthening concept in terms of cost/benefit. Benefit in this sense would be the risk reduction achieved by the strengthening scheme selected.

\section{References}

Salmon, M.W., “Probabilistic Framework for Computational Modeling,” LA-UR-13-20896, unpublished presentation presented at the Workshop on Structural Cracking of the Cupola Di Santa Maria Del Fiore, Los Alamos National Laboratory, February 13-15, 2013

Gianni Bartoli, Michele Betti, and Claudio Borri, "The Dome of Santa Maria del Fiore in Florence: Monitoring and Structural Analysis," Unpublished, date unknown, See The Department of Civil and Environmental Engineering, University of Florence, Italy,

Carlo Blasi, Federica Ottoni, "60 Years of the Monitoring System on Santa Maria Del Fiore Dome in Florence," OPA Workshop, Monitoring of Great Historical Structures, Centro Arte e Cultura, Piazza San Giovanni 7 , Florence, Italy, January 19 - 20th, 2012.

Alfredo H-S, Ang, Wilson Tang, "Probability Concepts in Engineering Planning and Design, Volume II Decision, Risk, and Reliability,” John Wiley and Sons, New York, 1984.

ASME, "Forging a New Nuclear Safety Construct," The ASME Presidential Task Force on Response to Japan Nuclear Power Plant Events, The American Society of Mechanical Engineers, New York, June, 2012. 


\section{Workshop Agenda}

Day 1

Technical and historical aspects of the Cupola and the formation and evolution of major structural cracks.

Chair: Giulia De Lorenzi-Venneri

8:30-9:00 Introduction and opening remarks

(Carlo Blasi, Michele Fanelli e Giulia De Lorenzi-Venneri).

9:00-9:30 History and damages of Santa Maria del Fiore dome: historical and instrumental monitoring (Federica Ottoni, University of Parma). Brunelleschi's dome is affected by a widespread crack pattern which appeared soon after its construction. An historical outline of the crack width evolution is presented, critically examining the suggested hypothesis for the dome structural behavior. Moreover, the results of the statistical analysis carried out so far on the last monitoring systems installed on the dome can constitute a useful tool in clarifying the dome behavior and in assessing possible strengthening solutions.

9:30-10:00 The numerical analyses of Santa Maria del Fiore dome: state of the art (Gianni Bartoli, University of Florence). A brief discussion of all the numerical models (Finite Elements models) of the Dome of Santa Maria del Fiore developed during the last twenty years at the Department of Civil and Environmental Engineering (DICeA, Univ. of Florence) will be reported. The attention will be mainly focused on the different realized FE models aimed at reproducing the dome behavior under self-weight, temperature gradients, horizontal forces and on the influence of different modeling techniques (i.e. cracks modeling, influence of erection stages).

\section{0:00-10:15 Break}

\section{0:15-10:45 State of the art in numerical modeling of masonry structures}

(Michele Betti, University of Florence). Some experiences in numerical modeling of important historic masonry buildings in Tuscany are discussed, focusing on some issues as the F.E. modeling approach, the hybrid rigid block/multiscale continuum approach; the masonry nonlinear behavior modeling, the "loading" problem (static nonlinear pushover analysis versus dynamic nonlinear analysis) and the experimental in-situ survey, up to the Seismic Risk assessment. Moreover, some open issue in modeling and analysis of masonry structures are presented.

\section{0:45-11:15 The seismic response of historic masonry buildings: general issues}

(Eva Coïsson, University of Parma). To understand the seismic behavior of historic masonry buildings, the experience of real damage and collapse cases is fundamental, as these buildings react to earthquakes with typical, recurring mechanisms. Therefore, examples of the consequences of the recent Italian earthquakes on the built heritage are presented. In particular, the effects of near source ground motion and of high vertical accelerations are discussed. Also some significant cases of cumulative and delayed effects are presented.

11:15-11:45 Analyzing and modeling the response of historical monuments: open issues (Gianni Bartoli, University of Florence). In order to reach a reliable level in the understanding of the behavior of historical monuments, some open issues have to be solved: the modeling of temperature changes considering both spatial (thermal gradients through wall) and temporal fluctuations; the thermal "fatigue"; the dependence of natural frequencies from temperature and damage; the damage assessment by means of monitoring systems and the treatment of non-homogeneity in the mechanical characteristics of masonry structures. 
Day 2

LANL capabilities that may be relevant and complementary to Italian research.

\section{Chair: Chick Keller}

8:30-9:00 Introduction and opening remarks (Chick Keller).

9:00-9:30 Evolution of structural design and potential design changes (Kelsey Souza, ES-DE). Beginning with the initial propagation of cracks in the dome and throughout its 500+ life, engineers have proposed different types of rehabilitation of the cupola. Technology and structural engineering are continuously improving, and the options available today to rehabilitate the cupola are more advanced than any previous moment in history The vast resources at LANL will provide the team with access to these innovative technologies as well as access to LANL material testing facilities. With these resources, a structural reinforcement design can be developed to preserve the historical structure

9:30-10:00 Non-invasive Imaging of Very Thick Structures With Cosmic Ray Muons (Cas Milner, P-25). LANL developed a muon imaging system, to scan shipping containers for the presence of concealed nuclear material, and this technology is now being deployed in sea ports. This technique has been extended to the problem of imaging much thicker structures, and is being considered for measuring the location of fuel in the damaged nuclear power reactors at Fukushima Daiichi. The technology uses naturally occurring radiation, is non-invasive, and is the only practical non-destructive means of imaging the interior of large, delicate masses. This method could be applied to surveying the cupola of Santa Maria del Fiore and parts of the building foundation, in a search for undiscovered structural damage or unknown voids.

\section{0:00-10:15 Break}

10:15-10:45 Characterizing and forecasting seismic ground motion

(Richard Lee, AET-2). Identification of the seismic sources, ground motion prediction equations, local site response, and quantification of uncertainties in deriving the seismic hazard using a probabilistic seismic hazards assessment methodology will provide the basic seismic loading parameters needed for seismic vulnerability assessments of the cupola.

\section{0:45-11:15 Combined finite discrete-element method}

(Esteban Rougier, EES-17). Recently, the Combined Finite-Discrete Element Method (FDEM) was employed in ground-breaking manner by a Croatian research group to conduct an analysis on the Prothyron structure at the Peristyle in Split. However, these works were accomplished in a 2D and/or single processor realm. With the aim of enhancing modeling accuracy, the next generation of 3D FDEM capabilities has been developed at Los Alamos National Laboratory (LANL). These include state of the art contact detection, contact interaction, parallelization techniques and fracture. This talk discusses the advancements and possible applications to the Cupola problem.

\section{1:15-11:45 Discontinuum joint modeling}

(Esteban Rougier, EES-17). Building on the continuum-based predictions for damage, explicit and higher resolution fracture domains will be handled via the FDEM discontinuum modeling. However, for an extended analysis effort on brick and mortar structures using FDEM it is critical to understand the frictional/fracture characteristics of the mortar material and also the non-linear behavior of the bricks themselves. The FDEM framework has been designed in such a way that the joint and the material behaviors can be extended naturally into the model.

\section{1:45-13:30 Lunch}




\section{4:00-14:30 Continuum Fracture Modeling Approach}

(Aleksander Zubelewicz, T-1). The AZ_frac model is a mechanisms-based visco-plasticity fracture model where the key features are the ability to describe continuum fracture processes (crack opening and closure, energy dissipation, etc.) while also handling general anisotropic material characteristics. The model has built-in stochastic fracture. There is also the contribution of dynamic over-stress which is present when the rate of loading redistribution and release is slower than the rate of the energy delivered to the material. This phenomenon can be critical in the analysis of structural responses due to earthquakes where, in effect, it can trigger instabilities leading to structural collapse.

\section{4:30-15:00 Nonlocal constitutive models and second-gradient homogenization}

(D.J. Luscher, T-3). This subtopic within the continuum mechanics focus area of the proposed workshop will present a nonlocal continuum field theory and associated homogenization strategy with potential applicability to modeling a generally anisotropic heterogeneous composite stacking of bricks and mortar. For example, the framework may be suitable for combining with a discrete element method by capturing the long term evolution of damage prior to a simulated catastrophic event.

\section{5:00-15:30 Probabilistic framework for computational modeling.}

(Mike Salmon, AET-2). We will discuss the feasibility of tying the structural response method (see above FDEM, or deterministic) with the previously discussed probabilistic seismic hazard to develop a probabilistic loss model of the cupola. 
Cosalamos NNSA

Los Alamos National Laboratory, an affirmative action/equal opportunity employer, is operated by Los Alamos National Security, LLC, for the National Nuclear Security Administration of the U.S. Department of Energy under contract DE-AC52-06NA25396. A U.S. Department of Energy Laboratory

\section{LA-UR-14-27140}

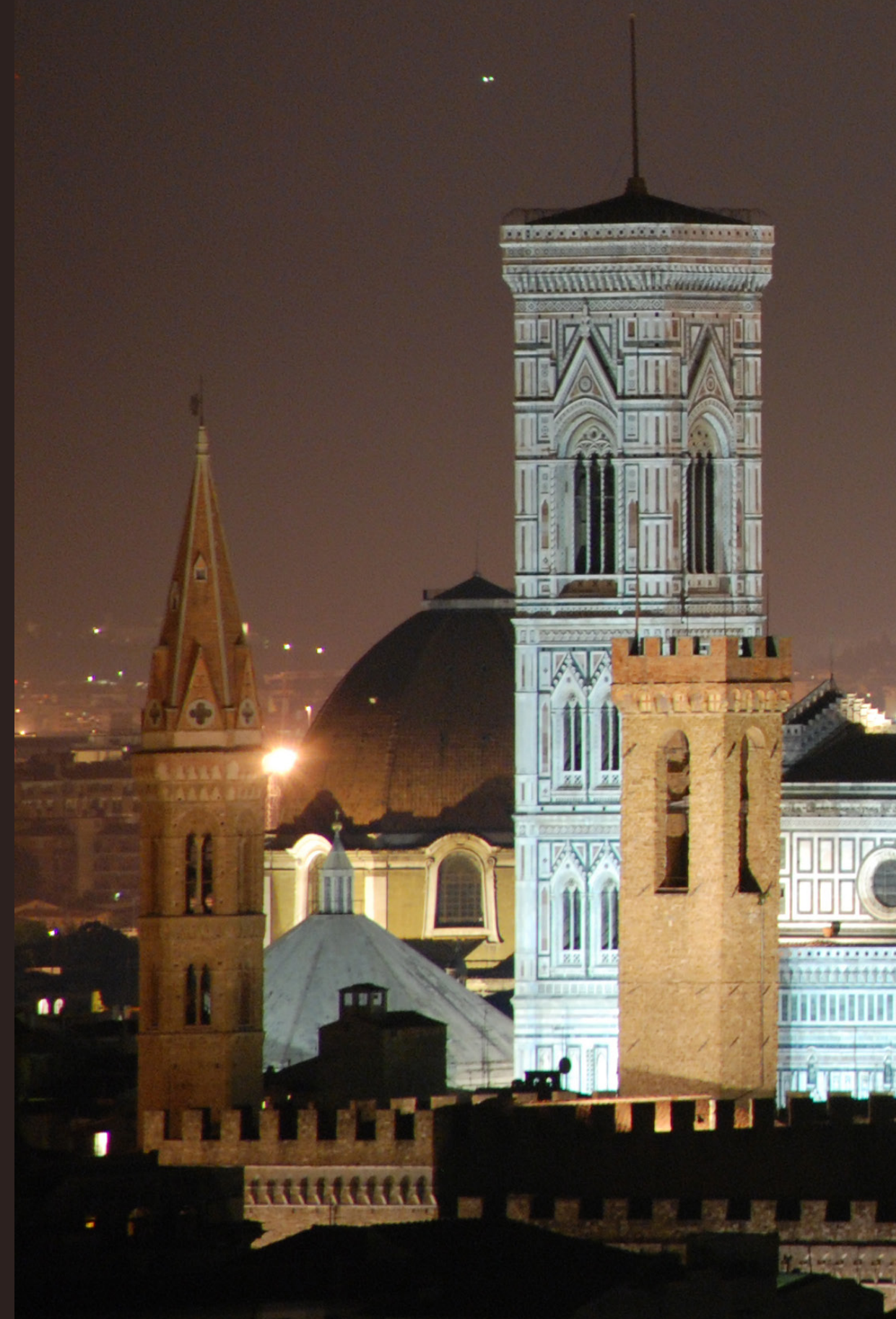

